\title{
ORNL Fusion Power Demonstration Study: Interim Report
}

Don Steiner

E. S. Bettis

T. J. Huxford

W. J. McAfee

H. E. McCoy

A. T. Mense

R. L. Reid

\author{
J. L. Scott \\ T. E. Shaninon \\ W. C. T. Stoddart \\ H. L. Watts \\ W. M. Wells \\ R. W. Werner \\ F. W. Wiffen
}




\section{DISCLAIMER}

This report was prepared as an account of work sponsored by an agency of the United States Government. Neither the United States Government nor any agency Thereof, nor any of their employees, makes any warranty, express or implied, or assumes any legal liability or responsibility for the accuracy, completeness, or usefulness of any information, apparatus, product, or process disclosed, or represents that its use would not infringe privately owned rights. Reference herein to any specific commercial product, process, or service by trade name, trademark, manufacturer, or otherwise does not necessarily constitute or imply its endorsement, recommendation, or favoring by the United States Government or any agency thereof. The views and opinions of authors expressed herein do not necessarily state or reflect those of the United States Government or any agency thereof. 


\section{DISCLAIMER}

Portions of this document may be illegible in electronic image products. Images are produced from the best available original document. 
Printed in the United States of America. Available from National Technical Information Service

U.S. Department of Commerce

5285 Port Royal Road, Springfield, Virginia 22161

Price: Printed Copy $\$ 5.50$; Microfiche $\$ 3.00$

This report was prepared as an account of work sponsored by the United States Government. Neither the United States nor the Energy Research and Development Administration/United States Nuclear Regulatory Commission, nor any of their employees, nor any of their contractors, subcontractors, or their employees, makes any warranty, express or implied, or assumes any legal liability or responsibility for the accuracy, completeness or usefulness of any information, apparatus, product or process disclosed, or represents that its use would not infringe privately owned rights. 
Contract No. W-7405-eng-26

FUSION ENERGY DIVISION

ORNL' FUSION POWER DEMONSTRATION STUDY:

INTERIM REPORT
Don Steiner *
J. L. Scott
E. S. Bettis
T. E. Shannon
T. J. Huxford
W. C. T. Stoddart
W. J. McAfee
H. L. Watts
H. E. McCoy
W. M. Wells
A. T. Mense
R. W. Werner ${ }^{\dagger}$
R. L. Reid
F. W. Wiffen

DATE PUBLISHED - MARCH 1977

Prejared by lise OAK RIDGE NATIONAL LABORATORY

Oak Ridge, Tennessee 37830 operated by

UNION CARBIDE CORPORATION for the

ENERGY RESEARCH AND DEVELOPMENT ADMINISTRATION

* Study director

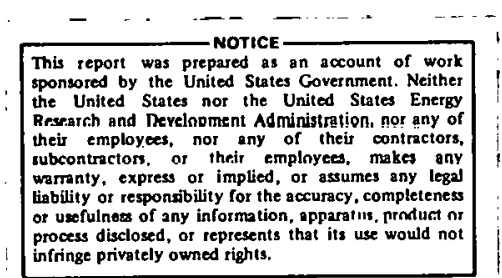

${ }^{\dagger}$ Visiting scientist, Lawrence Livermore Laboratory, Livermore, California 


\section{THIS PAGE}

\section{WAS INTENTIONALLY}

LEFT BLANK 
ABSTRACT . . . . . . . . . . . . . . . . . . . . . . . . . . . . .

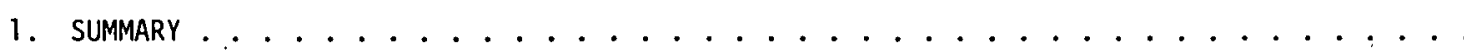

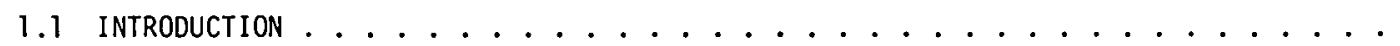

1.2 ECONOMICS CONSIDERATIONS AND PLASMA IMPLICATIONS . . . . . . . . . . . . . . . . 1

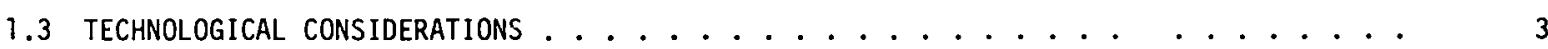

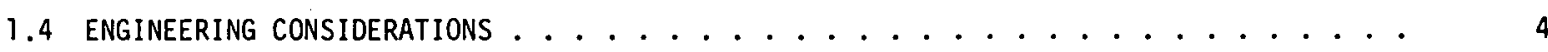

1.5 A PLAN FOR DEMONSTRATING COMMERCIAL FEASIBILITY . . . . . . . . . . . . . . . . . 5

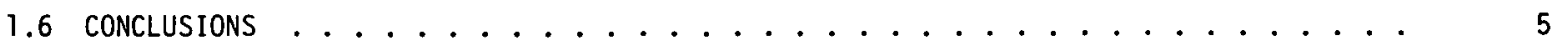

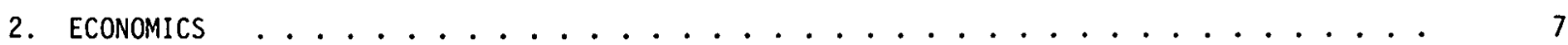

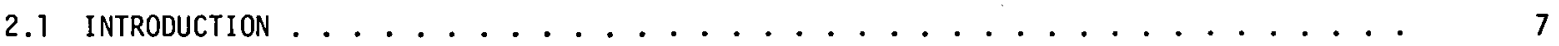

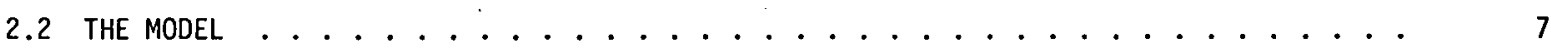

2.2.1 Component Cost Scaling . . . . . . . . . . . . . . . . . . . . . . 7

2.2.2 Plasma Parameter Scaling . . . . . . . . . . . . . . . . . . . 10

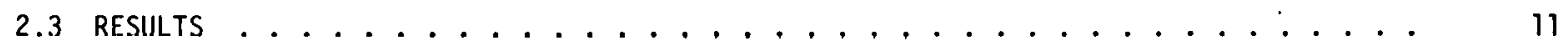

2.3.1 Cost Comparison with Published Cost Estimates . . . . . . . . . . . . 11

2.3.2 Parametric Results ........................... 11

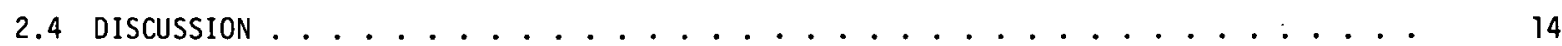

2.4.1 Implications of Results . . . . . . . . . . . . . . . . . . . 14

2.4.2 Representative Parameters for a Power Reactor . . . . . . . . . . . . 20

2.4.3 Shared Facilities and Multiple Units . . . . . . . . . . . . . . . 21

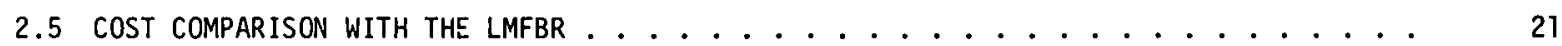

2.6 A ROUTE TO DEMONSTRATING COMMERCIAL FEASIBILITY . . . . . . . . . . . . . . . . . 23

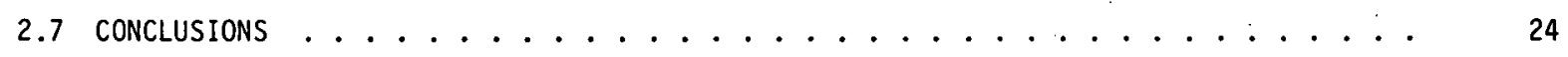

3. Plasma CONSIDERATIONS . . . . . . . . . . . . . . . . . . . . . . . . . . 27

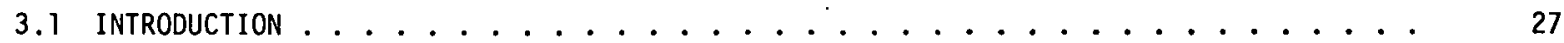

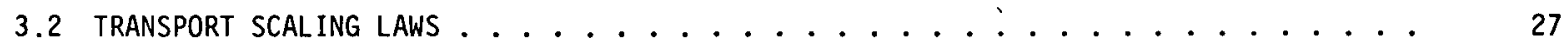

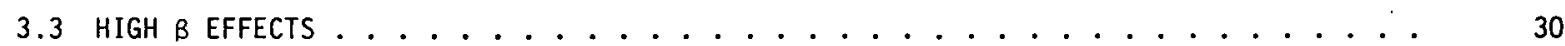

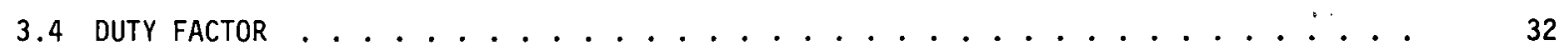

3.5 IMPURITY CONTROL . . . . . . . . . . . . . . . . . . . . . . . . 33

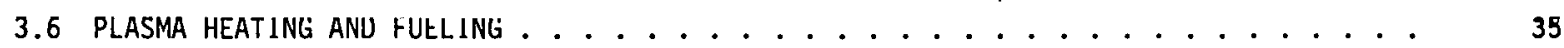

3.6.1 Heating .............................. . . . . . . . . . . . . . . . . . . . . . . . .

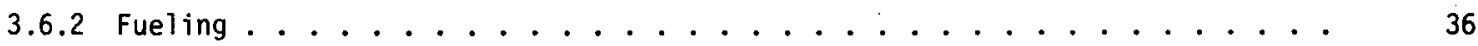

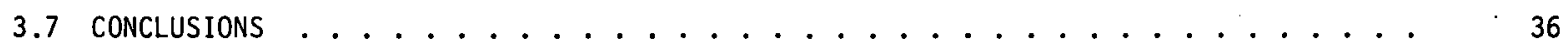

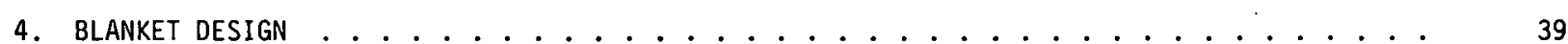

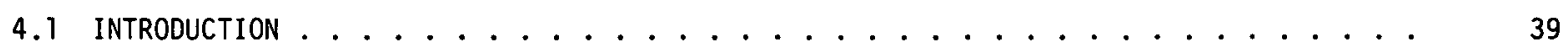

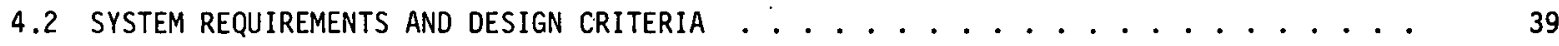

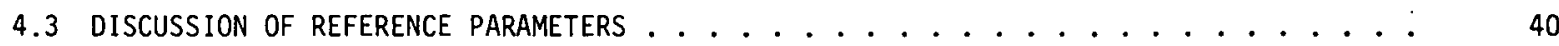

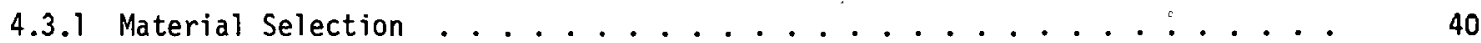

4.3.2 The Breeding Material ...................... . . . . 41

4.3.3 Coolant Selection .......................... . . . . . . 4 41

4.3 .4 Design Life . . . . . . . . . . . . . . . . . . . . . . . 42 42

4.3 .5 First Wall Loading . . . . . . . . . . . . . . . . . . . 42

4.3.6 Allowable Design Stress . . . . . . . . . . . . . . . . . . . . 42 


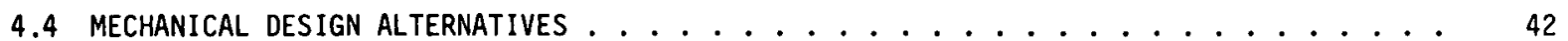

4.4.1 The Contour Blanket Concept . . . . . . . . . . . . . . . . . . . . . 42

4.4.2 The Cassette Blanket Concept ....................... 43

4.5 DESIGN STRESS ANALYSIS . . . . . . . . . . . . . . . . . . . . . . . 43

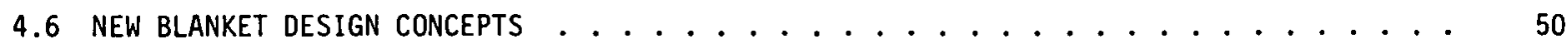

4.6.1 The FBZ Approach . . . . . . . . . . . . . . . . . . . . 50

4.6.2 The Balanced Energy Input . . . . . . . . . . . . . . . . . . 53

4.6.3 Modified Tube Wall Concepts . . . . . . . . . . . . . . . . . 53

4.6.4 Internal Tritium Recovery . . . . . . . . . . . . . . . . . . . 53

4.7 UNRESOLVED PROBLEM AREAS . . . . . . . . . . . . . . . . . . . . . . . 53

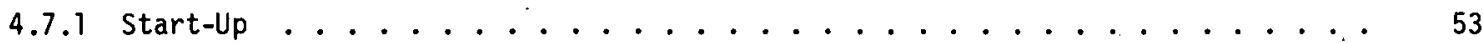

4.7.2 First Wall Structural Design . . . . . . . . . . . . . . . . . 55

4,7,3 Remnte Mnintennnr.e : . . . . . . . . . . . . . . . . . . 5 5

4.7.4 Internal PF Coils . . . . . . . . . . . . . . . . . . . . 55

4.7 .5 Tritium Removal .......................... . . . . 55

4.8 CONCLUSIONS . . . . . . . . . . . . . . . . . . . . . . . . . . 55

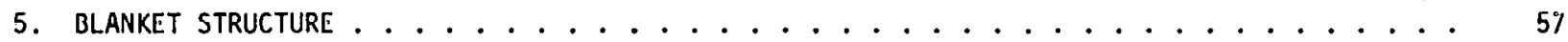

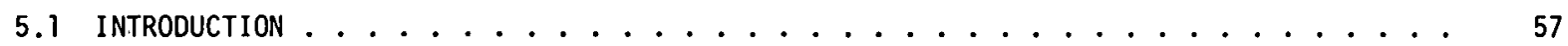

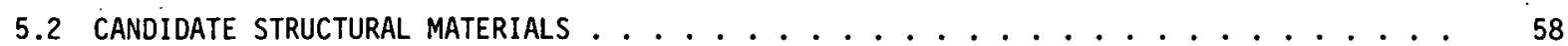

5.2.1 Austentitic staintess steels...................... b8

5.2 .2 Nickel-Base Alloys .......................... . . . . 60

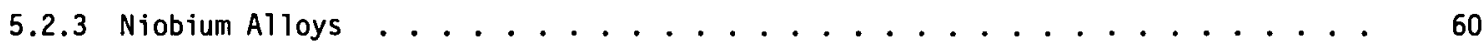

5.2 .4 Vanadium Alloys ........................... 61

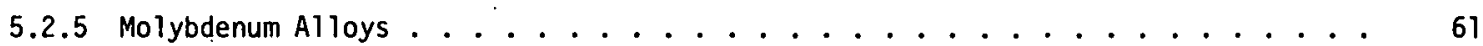

5.2.6 Aluminuñ Alloys . . . . . . . . . . . . . . . . . . . . 61

5.2.7 Summary of Candidate Alloy Comparisons . . . . . . . . . . ....... . 62

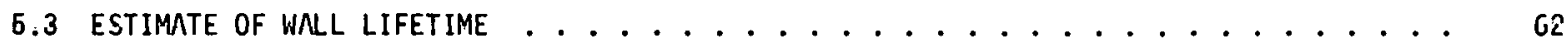

5.4 QUALIFICATION OF AUSTENITIC STAINLESS STEELS FOR COMMERCIAL FUSION POWER . . . . . . 66

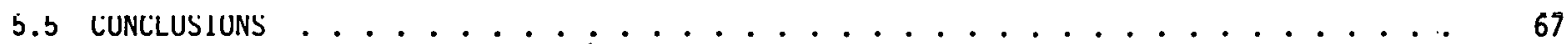

6. BLANKET COOLANT . . . . . . . . . . . . . . . . . . . . . . . . . 69

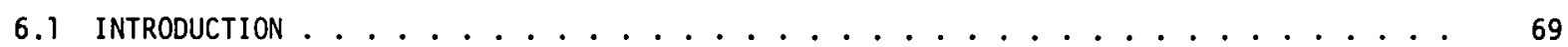

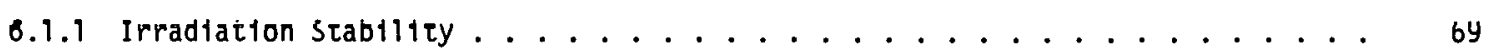

6.1.2 Coolant/Structural Material Compatibility ................. 69

6.1 .3 Heat Transfer Properties . . . . . . . . . . . . . . . . . . . 69

6.1 .4 Operation at Low Pressure . . . . . . . . . . . . . . . . . . . 70

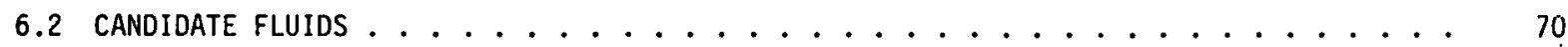

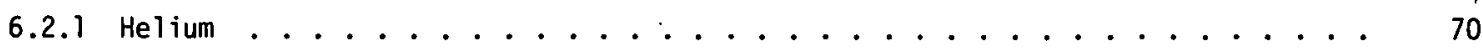

6.2.2 Water.............................. . . . 71

6.2 .3 Liquid Metals ... . . . . . . . . . . . . . . . . . 71

6.2 .4 Lithium and Beryllium Fluoride Salts . . . . . . . . . . . . . . . 72

6.2.5 Sodium-Potassium-Nitrate-Nitrite Mixtures . . . . . . . . . . . . . . . 73

6.2.6 Lithium-Sodium-Potassium Hydroxides . . . . . . . . . . . . . . . . . . 74

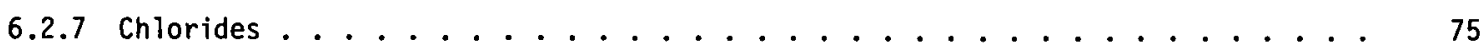

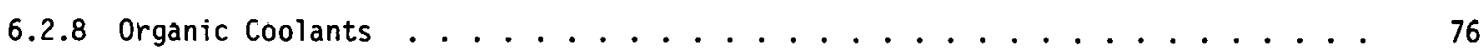

6.2 .9 Lithium-Sodium-Potassium Carbonates . . . . . . . . . . . . . . . . 77

6.3 DISCUSSION . . . . . . . . . . . . . . . . . . . . . . . . 77

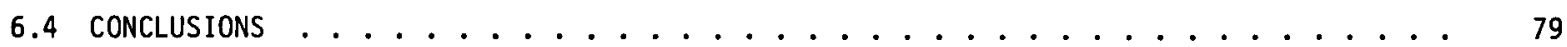




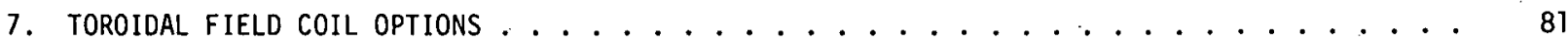

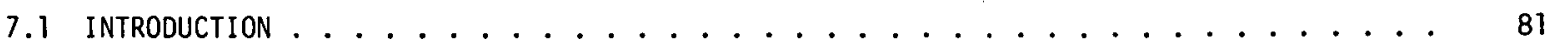

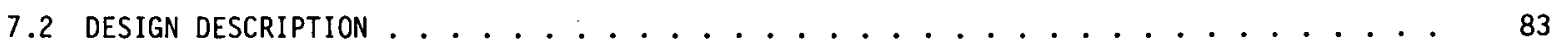

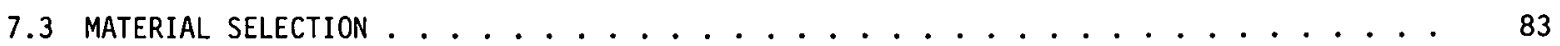

7.4 STRUCTURAL DESIGN AND FABRICATION . . . . . . . . . . . . . . . . . . . . 84

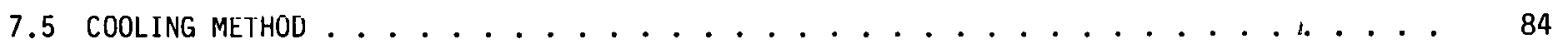

$7.6 \cos$. . . . . . . . . . . . . . . . . . . . . . . 85

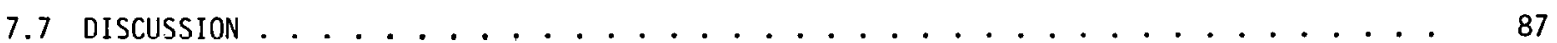

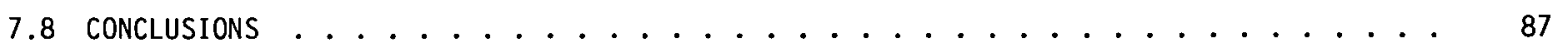

8. THE VACUUM TOPOLOGY . . . . . . . . . . . . . . . . . . . . . . . . . 89

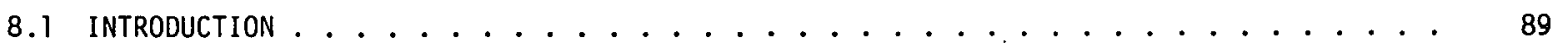

8.2 THE TECHNICAL AdVANTAGES . . . . . . . . . . . . . . . . . . . . 89

8.2.1 Elimination of All Remote Field Welding in the Reactor Region . . . . . . 89

8.2.2 "Hands-On" and Remote Handling Compatibility . . . . . . . . . . . . . . 89

8.2.3 Replacement Ease - Blanket Module . . . . . . . . . . . . . . . . . 90

8.2.4 Remote Handling .. . . . . . . . . . . . . . . . . . . . . . 90

8.2.5 Reduction of Physical Size . . . . . . . . . . . . . . . . . 90

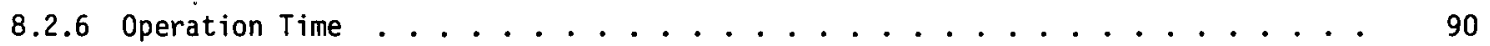

8.2.7 Tritium Control and Accidental Release . . . . . . . . . . . . . . . . 90

8.2.8 Relaxation of Pressure Loads . . . . . . . . . . . . . . . . . . 9 90

8.2.9 More Effective Control of Heat Transfer . . . . . . . . . . . . . . . . 91

8.2.10 Environmental Protection for Refractories . . . . . . . . . . . . . . 91

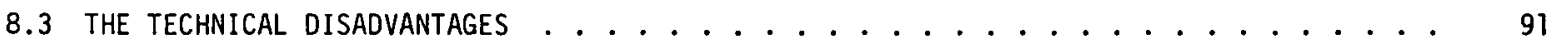

8.3.1 Large Surface Areas and Cont1nuous Outyassiriý . . . . . . . . . . . . . . 91

8.3.2 Components that "Abhor" Vacuum ...................... . 91

8.3.3 Vacuum Welding In Situ ...................... . . . 91

8.3.4 The Vacuum Building Itself ........................ . . . 91

8.3.5 Construction Beyond Current Technology . . . . . . . . . . . . . . . . 91

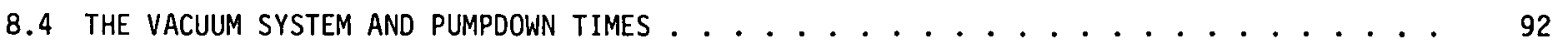

8.4.1 Vacuum System of Plum Brook . . . . . . . . . . . . . . . . . . 92

8.4.2 Current Achievable Vacuum Level . . . . . . . . . . . . . . . . . . 92

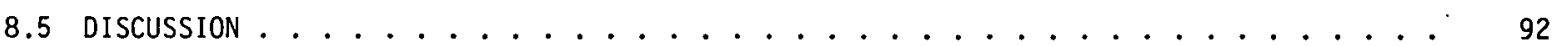

Э. POWER CONVERSION SYSTEM . . . . . . . . . . . . . . . . . . . . . 97

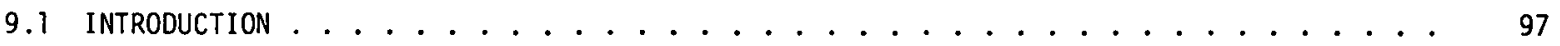

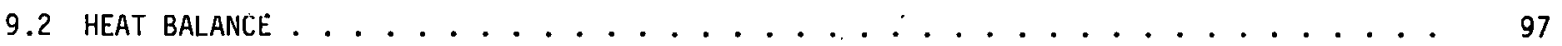

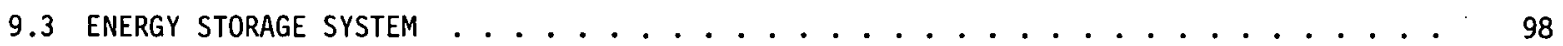

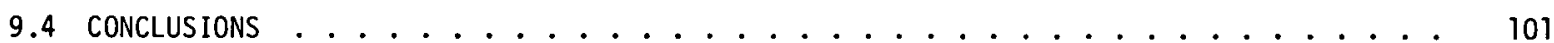

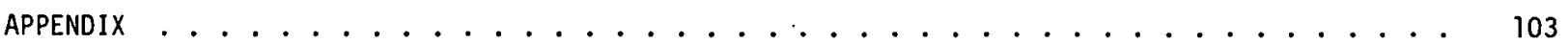

A.1 INPUT PARAMETERS . . . . . . . . . . . . . . . . . . . . . . . 103

A.2 PLASMA SIZE SCALING MODEL . . . . . . . . . . . . . . . . . . . . . 103

A.3 COMPONENT COST SCALING MODEL . . . . . . . . . . . . . . . . . . . . . 103

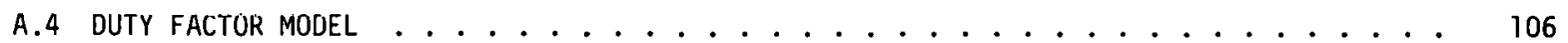




\section{THIS PAGE}

\section{WAS INTENTIONALLY LEFT BLANK}


The purpose of the ORNL Fusion Power Demonstration Study (Demo study) is to develop a plan for demonstrating, in this century, the commercial feasibility of fusion power based on the tokamak concept. The two-year study was initiated in FY 1976, and this interim report summarizes the results for FY 1976. Major results include:

1) the outline of a three-phase plan for demonstrating the commercial feasibility of tokamak fusion power in this century;

2) a parametric analysis of tokamak costs which provides the economic basis for the demonstration plan; and

3) a critical evaluation of the technological directions, design approaches, and plasma characteristics which serve as the technical basis for the demonstration plan. 
1. SUMMARY

Don Steiner

\subsection{INTRODUCTION}

The purpose of the ORNL Fusion Power Demonstration Study is to develop a plan for demonstrating, in this century, the commercial feasibility of fusion power based on the tokamak concept. The Fusion Power Demonstration Study (Demo study) was initiated in FY 1976 as a two-year study. This interim report summarizes the results of the Demo study for FY 1976. A final report will be issued at the conclusion of FY 1977.

In order to demonstrate commercial feasibility, the technical and economic feasibility of the tokamak concept for power generation must be clearly established through successful operation of demonstration facilities under practical utility conditions. A plan for demonstrating commercial feasibility must be based on technological directions, design approaches, and plasma characteristics which insure the economic competitiveness of the tokamak concept as a power generation system. However, not only must tokamak fusion power be perceived as a desirable goal, but also the cost and risk of achieving that goal must be viewed as acceptable. Thus, the cost of the technology and the facilities required for demonstrating commercial feasibility must represent acceptable risks to public and private groups. If commercial feasibility is to be realized in this century, it is our judgment that the number of new technologies and the number of facilities required for demonstration must be minimized. In carrying out the Demo study, we are emphasizing the application of current and near-term technologies. It is our opinion that such an approach will enhance the acceptability of the plan for demonstrating commercial feasibility without compromising the economic potential of fusion power systems.
As a final point, it must be emphasized that there is no unique set of technological directions, engineering designs, or plasma parameters which offers promise for the demonstration of commercial feasibility. Several such sets, no doubt, do exist. In this study we seek to define one promising set of techriologies, design approaches, and plasma characteristics. Thus, our objective is to develop a plan, not the plan, for demonstrating commercial feasibility.

\subsection{ECONOMICS CONSIDERATIONS AND PLASMA IMPL ICATIONS}

In order to establish the economic potential of tokamak power plants, we are focusing on both the plant costs and the operation and maintenance costs. The plant costs are being studied using a systems costing model. With this model we are examining the impact of technology, engineering design, and plasma operating characteristics on tokamak plant costs. In the area of operation and maintenance costs, our approach is to define and pursue those engineering design options which will maximize the reliability of key components and facilitate the maintenance of the tokamak system.

On the basis of our plant cost studies, it appears that the tokamak concept car achieve capital costs which are in the range of those predicted for the Liquid-Metal Fast Breeder Reactor (LMFBR). Moreover, uncertainties with regard to the economic potential of tokamak power plants are associated primarily with uncertainties in the expected plasma physics performance and not with foreseeable limitations in the areas of technology and engineering. The tokamak can achieve economic competitiveness with the LMFBR if the following set of plasma physics criteria is satisfied; again it is emphasized that the following set of criteria represents a promising set but not a unique one. 
1. Size scaling. The tokamak plasma should be capable of achieving ignition with plasma radi $i$ in the range $1-2 \mathrm{~m}$ and for associated toroidal fields on axis in the range 4.5-3.0 T. This range of sizes and fields requires a size scaling performance about an order of magnitude better than that predicted by full trapped particle scaling and is consistent with ignition requirements predicted by empirical scaling relationships.

2. Beta. Under operating conditions. point model calculations indicate that the plasma average beta would have to be about 10-15\%. The point model calculations do not account for density and temperature profile effects. When such effects are included, the required value of average beta may be significantly less than $210-15 \%$, perhaps $25-10 \%$. Such values of beta are still high compared to values obtained in current experiments but are compatible with recent calculations of high beta tokamak operation.

In addition to size scaling and beta, successful solutions in the areas of impurity control, plasma heating, and piasma fueling are critical to the economic competitiveness of tokamak power systems. In the Demo studies, we have assumed that successful solutions to these problems can be achieved. However, we are considering the impact of divertors on the overall engineering design and the economics of the tokamak power plant.

Assuming that the preceding plasma physics characteristics can be achieved, then a commercial tokamak fusion power plant would consist of multiple (2-5) tokamak reactor units sharing a number of common elements. Two key elements shared by these multiple units would be the pulsed power supplies for driving the plasma current and the pulsed power supplies which provide the plasma supplemental heating. Each reactor unit might produce about $2000 \mathrm{MW}$ of thermal output power; the precise value of the thermal output of each unit would be determined both by plasma physics considerations and by cost optimization considerations. The following points are noted with regard to the commercial tokamak fusion power plant.

1. The capital cost trends for tokamak power systems indicate that, at a fixed value of beta, unit capital costs decrease with decreasing plant size. This trend is contrary to the cost trends of fission reactors for which unit capital costs favor increased plant size.

2. The plasma characteristics required for the rommercial units are essentially the same as those required for an ignition demonstration device. Thus, many of the components developed for ignition demonstration will be prototypical of the components required for commercial power. This is an important observation and, as will be noted later, contributes to the possibility of minimizing the number of facilities required for demonstrating commercial feasibility.

3. The motivation for pursuing a power plant consisting of multiple reactor units tied into a common pulsed electrical system is based on our cost studies which show that the pulsed electrical system of the tokamak represents about 25\% of the total plant cost. This contrasts with fission power plants in which the electrical plant system cost represents only about $5 \%$ of the total plant cost. The pulsed electrical equipment is required to initiate the plasma current and achieve plasma heating and operates for only a fraction of each cycle. For example, with a 20-min burn time and a 1-min downtime, the pulsed equipment would be operaliny for only about $1 \%$ of the cycle. It. appears that this pulsed equipment could be economically and conveniently shared among several units.

4. The plant cost studies indicate that neutron wall loadings in the vicinity of 2-4 MW/ $\mathrm{m}^{2}$ will result in near-optimum plant costs. Such wall loadings must also lead to acceptable plant availability and costs of operation and maintenance. In our studies, we have reached the pre1 iminary conclusion that wall lifetimes of $\geqslant 5$ years will not significantly impact the plant availability. Therefore, it appears that integral wall loadings of about $10-20 \mathrm{MW}-y \mathrm{r} / \mathrm{m}^{2}$ should 
be acceptable for the structural material performance.

\subsection{TECHNOLOGICAL CONSIDERATIONS}

On the basis of our studies, it appears that the technological requirements for commercial tokamak fusion power can be satisfied with the following technology base.

1. The blanket structural material. It is our judgment that some type of austenitic stainless steel will be capable of achieving the desired 10-20 MW-yr/m² integral wall loading. Moreover, the unique helium production reactions associated with nickel-bearing alloys in thermal neutron fluxes allow an excellent simulation of fusion reactor neutron radiation effects in existing fission reactors. Although much additional work will be required to qualify an austenitic stainless steel for use in commercial fusion power plants, we are very enthusiastic about the prospects for such an alloy. At the same time we recommend continued work on refractory metals, especially niobium- and vanadium-base alloys.

2. The blanket coolant. In pursuing the choice of coolant, major emphas is was placed on the coolant circuit being capable of operating at low pressure. On this basis, it appears that sodium-potassium salts (of which nitrate-nitrites, hydroxides, and chlorides are candidates) offer the most promise. The nitrate-nitrite salt mixtures have been used most extensively in industrial applications, and therefore they have been recommended for primary consideration. These salt mixtures exhibit relatively low melting points $\left(\sim 150^{\circ} \mathrm{C}\right.$ ) and aiso they are relatively inexpensive $(\sim \$ 1 / \mathrm{kg})$. The salt thermal stability and compatibility with iron-base alloys seem acceptable to temperatures of $\sim 500^{\circ} \mathrm{C}$. A devel. opment program will be required to determine the ultimate acceptability of these salts in a fusion reactor environment. We recommend that helium and liquid lithium be pursued concurrently as potential blanket coolants.
3. The breeding material. It appears that liquid lithium offers the greatest potential for the breeding material. Lithium yields the highest flexibility with regard to tritium breeding. It has good thermal properties and acceptable chemical compatibility. Much further work is still required in the areas of tritium recovery and MHD effects.

4. The power conversion system. The recommended power conversion system would consist of a primary and intermediate salt loop coupled to a conventional steam cycle. The primary purpose of the intermediate heat transport loop is to prevent pressurization of the low pressure. blanket by high pressure steam should there be a tube leak in the steam generator. Assuming a primary loop salt exit temperature of about $450^{\circ} \mathrm{C}$, a steam cycle thermodynamic efficiency of $\sim 35 \%$ can be achieved with this power conversion system. The tokamak operates in a cyclic mode (e.g., a 20-min burn time followed by a 1-min downtime, yielding a duty cycle factor of $95 \%$ ). Salt storage tanks coupled to the intermediate heat transport loop would provide the necessary thermal storage to insure continuous power to the line during the entire tokamak operating cycle.

5. The coil system. It appears that superconducting coil requirements for the tokamak power plant can be satisfied with NbTi as the superconducting material. Moreover, it appears that normal conducting coils may also be feasible and desirable under certain conditions. For example, the application of normal conducting coils is not feasible for the toroidal field system of tokamak reactors which operate at low power density ( $\sim \mathrm{MW} / \mathrm{m}^{3}$ in the plasma) because, at low power density, the fusion power output would be comparable to the ohmic power losses in the coil system. In order to get an acceptable power balance, the thermal fusion power release should be at least an order of magnitude greater than the ohmic heating losses in the coil system. If tokamaks can operate at high power density $\left(\sim 5-10 \mathrm{MW} / \mathrm{m}^{3}\right.$ in the plasma) and if the required field on axis is in the range $23.0-4.5 \mathrm{~T}$, then it 
appears that normal conducting toroidal coils may be practical in some applications for reactor systems. Thus, it is our conclusion that the major thrust of a superconducting magnet development program should be directed to NbTi and that serious consideration should be given to the application and development of normal conducting coils for use in tokamak reactor systems. Work should, of course, continue on advanced superconducting materials.

6. The pulsed electrical system. It appears that the primary energy storage requirements of the poloidal field driving systein and the plasma heating system can be satisfied with motor-generator flywheel sets which are similar to those being proposed for the Tokamak Fusion Test Reactor (TFTR). Advanced energy storage concepts, such as homopolar generators and superconducting energy storage devices, have been proposed for the energy storage needs of tokamak fusion reactors. However, our studies indicate that the more conventional and currently available technology of motor-generator flywheel sets will be acceptable both on the basis of engineering and economics considerations. The advanced energy storage concepts should be pursued, but they do not appear to be necessary for commercial feasibility.

\subsection{ENGINEERING CONSIDERATIONS}

In order to maximize the reliability of key reactor components and to facilitate the maintenance of the tokamak power reactor, we are pursuing the following engineering design options.

1. Blankot first wall design. A major issue associated with the question of fusion power plant availability arises from a consideration of the reliability of the blanket first wall. The integrity of the first wall will be determined by structural design criteria which will account for probable failure modes caused by hydraulic and thermally induced stress. To provide a system with high reliability, the design margin (the difference between actual stress and allowable stress) should be maximized. Moreover, since the effects of radiation damage (such as loss of ductility) are quite sensitive to the operating temperature, it appears that the first wall reliability may be significantly improved by operation at somewhat lower temperatures $\left(\mathrm{e} . \mathrm{g} ., \sim 400^{\circ} \mathrm{C}\right.$ ) than the bulk of the blanket $\left(\mathrm{e} . \mathrm{g} ., \sim 500^{\circ} \mathrm{C}\right)$. The design approach pursued in the Demo study with regard to the blanket first wall therefore has been to minimize thermal and hydraulic stresses in the first wall and to operate the first wall at such a temperature that ductility loss will not be a serious limitation, while at the same time achieving acceptable thermodynamic efficiency.

2. Blanket modular approach. In order to minimize downtime and facilitate ma intenance, the blanket design philosophy has been to seek a modular approach which eases the problems of remote ma1ntenance. Thus, renule Illd Inlendrice has been identified as a major objective and design consideration in the development of the engineering design for the blanket configuration. In this context, we are stressing small, easily replaced individual blanket modules.

3. The vacuum topology. In tokamak reactor designs, it is commonly assumed that the first wall alsu serves as llie iliajur vacuum boundary between the plasma and atmospheric pressure. This usually requires that the first wall contain hundreds to thousands of 1 ineal meters of welds. Should a pinhole leak develop in a radioactive first wall, it is dnuhtful that. it. ran he repaired without unreasonable difficulty. Therefore, we are proposing that the tokamak reactor system be enclosed in a vacuum building. This completely changes the character of the first wall surface from one requiring absolute vacuum integrity and an extremely long life expectancy to one that need have only high pumping impedance (it can be slightly leaky because the pressures on either side are about the same) and a shorter life requirement because it comes apart. It is our opinion that such an approach has significant assembly, disassembly, and repaip advantages over the vacuum first wall approach. 
4. The application of normal conducting coils. As already discussed, it may be possible that normal conducting coils can be applied in tokamak systems without significant economic penalty due to power balance considerations. Assuming that the plant costs associated with normal coils are acceptable, it appears that normal coils may offer certain engineering advantages relative to superconducting coils, especially with regard to system maintenance and repair. For example, normal coils might be placed around the neutral beam injector ports. This would greatly ease shielding problems at these positions relative to the situation with superconducting coils. Moreover, the normal coils could be built in segments which could be disassembled rather simply. This type of procedure would allow relatively rapid access into the interior of the tokamak system. In such a scheme, the majority of the toroidal field coils would be superconducting, and only a fraction of the total coil set would be normal. We suggest that the application of normal conducting coils in tokamak reactors may, in certain situations, offer significant engineering advantages relative to superconducting coils, and therefore such applications should be pursued further.

\subsection{A PLAN FOR DEMONSTRATING COMMERCIAL FEASIBILITY}

On the basis of our studies, we recommend the following plan for demonstrating, in this century, the commercial feasibility of fusion power based on the tokamak concept. Commercial feasibility demonstration would involve three phases beyond the TFTR: (1) an ignition demonstration phase, (2) a power technology demonstration phase, and (3) a commercial prototype demonstration phase. The primary theme of the recommended plan is that a given site and facility should be developed to demonstrate sequentially the ignition, power technology, and commercial prototype phases. Initially the program would be directed to the construction of an electromagnetic facility (coils, power supplies, etc.) which would serve al1 phases of the demonstration program. The purpose of the first phase would be to examine ignition operation. Thus, this phase would not be concerned with power conversion and tritium breeding and recovery. In the second phase of the program, power technology demonstration is the main goal; this goal is similar to that of the Clinch River Breeder Reactor Project. Tritium breeding and power conversion components would be added to the basic facility. Following successful operation of this phase, additional tokamak power units would be added at the same site and tied into the single electrical plant. During this phase, the facility would be demonstrating commercial prototype operation.

We feel that such a program is rational because the plasma requirements for ignition are essentialiy the same as those associated with commercial plant operation. That is, plasma physics does not indicate that successively larger devices must be constructed proceeding from ignition to power demonstration and then to prototype commercial demonstration. Based on our cost estimates, it appears that such a program could be implemented in this century with a total facility cost of approximately $\$ 2-3$ billion (in FY 1976 dollars). This does not include engineering and contingency costs, nor does it include development costs.

\subsection{CONCLUSIONS}

The ORNL Fusion Power Demonstration Study has thus yielded two important conclusions.

1) Given successful resolution of several plasma physics problems, the tokamak concept can lead to a power plant with economic potential comparable to that of the LMFBR.

2) The program required for demonstrating commercial feasibility can be achieved in this century and seems to be acceptable in terms of risk and cost when viewed relative to other programs for alternate, long-term energy sources. 
THIS PAGE

WAS INTENTIONALLY

LEFT BLANK 


\section{ECONOMICS}

R. L. Reid

\subsection{INTRODUCTION}

The economic potential of tokamak power systems depends on technology, engineering, and plasma operating characteristics. In Sects. 4 through 9 of this report, we identify technological directions and engineering approaches which enhance the economic potential and the near-term feasibility of the tokamak concept. On the basis of these technological directions and engineering approaches, we have formulated a model to investigate the capital cost trends of tokamak power systems as a function of plasma operating characteristics. In this section we discuss the cost model, its results, and the conclusions drawn from these results.

\subsection{THE MODEL}

The model formulated to investigate the capital cost trends of tokamak power systems is composed of two parts, a component cost scaling portion and a plasma parameter scaling portion. The essential features of the model are described below.

\subsubsection{Component Cost Scaling}

This portion of the model determines cost as a function of system geometry and plasma characteristics. Existing cost estimates were used to determine normalizing factors for the various components of the tokamak power system. In particular, extensive use was made of the recent cost estimate by Westinghouse Fusion Power Systems Division for the TNS (The Next Step) reactor. This estimate was heavily relied upun because (1) it is tied to a hear= term device (scheduled for the 1980's), (2) it draws upon the Tokamak Fusion Test Reactor (TFTR) cost estimate in many cases, (3) it is a detailed estimate, and (4) it is a welldocumented estimate. For some components it was judged that cost estimates for other fusion systems were more representative of power systems than the TNS estimates. Estimates for conventional power system components were based on pressurized water reactor (PWR) cost estimates. The assumptions adopted with regard to component technology and engineering, scaling, and cost normalization are summarized below; the cost equations are presented in the appendix.

\subsubsection{Toroidal field (TF) coils}

The toroidal field coils are assumed to be superconducting, layer wound coils cooled by forced-flow supercritical helium. Depending on the maximum field required, the conductor might be a composite of multifilamentary NbTi superconductor in a $\mathrm{Cu}$ matrix or $\mathrm{Nb}_{3} \mathrm{Sn}$ superconductor in a CuSn matrix. The winding would be supported by interlayer stainless steel structure plus an outer case. For the model, the cross-section area of the winding was determined based on an average current density of $1800 \mathrm{~A} / \mathrm{cm}^{2}$. The case thickness was conservatively sized to carry all the hoop stress developed in the winding. The cost of the coil system was scaled as the eighttenths power of the stored magnetic energy and makes no distinction between alternate conductors. The eight-tenths power relationship was suggested in Ref. 2. Cost estimates taken from studies of large TF coils by General Electric ${ }^{3}$ and Westinghouse ${ }^{4}$ tend to verify this scaling parameter. The TF coil cost was normalized to the TNS cost estimate, ${ }^{5}$ which assumes $\mathrm{NbTi}$ as the superconductor.

1. Note that normal conducting TF coils are also béing cunsideried (sêt seul. 7).

2. M. S. Lubell et al., The Ecanomics of Large Superconducting Toroidal Magnets for Fusion Reactors, ORNL/TM-3927, Oak Ridge Nationa 1 Laboratory, Oak Ridge, Tennessee (August 1972). 
3. Conceptual Studies of Toroidal Field Magnets for the Tokamak (Fusion) Experimental Power Reactor, Final Report, Contract Number E(40-1)-5154, General Electric Co., Energy System Programs Department, Schenectady, New York (November 1976).

4. Conceptual Studies of Toroidal Field Magnets for the Tokamak Experimental Power Reactor, Final Report, Contract Number $E$ (40-1)-5153, Westinghouse Electric Corp., Large Rotating Apparatus Division, East Pittsburgh, Pennsylvania (October 1976).

5. W. B, Wond (IICC-ND Engineering Staff, Oak Ridge, Tennessee), "TNS Cost Estimate," private communication, September 16, 1976.

\subsubsection{Poloidal field (PF) coils}

The ohmic heating $(\mathrm{OH})$ coils were assumed to be superconducting ( $\mathrm{NbTi}$ ). The equilibrium field coils and divertor coils were assumed to be water-cooled copper coils. Cost was scaled as a function of coil volume, which for a constant current density varies as the product of the major radius and the plasma current. The PF coil cost was normalized to the TNS cost estimate. ${ }^{6}$

\subsubsection{Poloidal field driving system}

Motor-generator flywheel sets were assumed as the driving system for the PF coils. Cost was scaled as plasma volt seconds and was normalized to the TNS cost est1mate. ${ }^{5}$

\subsubsection{Blanket}

The blanket structure was assumed to be an austenitic stainless steel. Liquid lithium was taken as the tritium breeding medium, and a molten salt was taken as the coolant. Cost was scaled as a function of blanket volume. Blanket cost was normalized to an ORNL estimate for the blanket designs discussed in Sect. 4 (sei Ref. 6).
6. E. S. Bettis (Oak Ridge National Laboratory, Oak Ridge, Tennessee), "Demo Blanket and Heat Transfer Systems Cost," private communication, December 8, 1976.

\subsubsection{Shield}

The shield, located between the blanket and the TF coils, was assumed to be water-cooled and composed of stainless steel, lead, and borated water. Cost was scaled as shield volume and was normalized to the Argonne National Laboratory (ANL) Experimental Power Reactor (EPR) estimated shield cost. 7

7. Weston M. Stacey, Ir., et al., Tokamak Experimental Power Reactur Cunceptual Design, ANL/CTR-76-3, Argonne National Laboratory, Argonne, Illinois (August 1976).

\subsubsection{Neutral beams}

The ncutral beame are of the positive or negative ion type at energy levels in the range of $100-200 \mathrm{keV}$. The beams are used only to heat the plasma to the ignition temperature. Pulsed power is supjilied to the beam injector once each cycle by the motor-generator flywheel sets. Beam cost was scaled as the thermonuclear power of the plasma (the power associated with the 14.1-MeV neutrons and 3.5-MeV alpha particles) and normalized to the TNS cost estimate.

\subsubsection{Vacuum system}

The vacuum system was assumed to consist of primary pumps similar in design to existing commercially available cryosorption pumps (a)though much larger) and conventional roughing pumps. Cost was scaled as the torus surface area, as suggested in Ref. 8. The vacuum system cost was normalized to the ANL EPR cost estimate. $^{7}$ 
8. J. Sheffield and A. Gibson, Nucl. Fusion 15, 677 (1975).

\subsubsection{Tritium system}

The tritium system was assumed to consist of equipment (1) to purify and recycle tritium and deuterium for the plasma fuel cycle by the use of uraniuni beds and (2) to recover tritium from the lithium in a breeding blanket by the use of metal sorbents. Cost was assumed to scale as the torus surface area. The cost of the tritium system was normalized to the ANL EPR cost estimate. ${ }^{7}$

\subsubsection{Heat transport system}

The heat transport system consists of a steam generator; two molten salt loops (a primary loop to remove the heat from the blanket and an intermediate loop to isolate the low pressure blanket from the high pressure steam), and an energy storage system. The energy storage system, which consists of lanks to store hot and cold salt, allows a constant power input to the steam generator over the entire tokamak operating cycle (see Sect. 9). The cost of the heat transport system was scaled as a function of the thermal power output of the reactor. Thermal power consists of the thermonuclear power of the plasma (14.1MeV neutrons plus 3.5-MeV alpha particles) plus exothermic reactions in the blanket due to neutron capture ( $24.8 \mathrm{MeV}$ per fusion event). Cost was normalized to an ORNL estimate ${ }^{6}$ made for the heat transport system described in Sect. 9.

\subsubsection{Turbine}

The turbine-feedwater system is of conventional design. The system consists of a high and low tandem compound turbine section, feedwater heaters, a steam condenser, and a mechanical draft cooling tower. Turbine and steam system cost was scaled as the thermal power output of the reactor to the eighttenths power. ${ }^{9}$ The cost was normalized to the cost estimate for a 3285-MW(t) [1150-MW(e)] PWR. ${ }^{10}$ A thermal efficiency of approximately $35 \%$ was taken as typical of PWR's.

9. CONCEPT - A Computer Code for Conceptual Cost Estimates of Steam-Electric Power Plants, Phase IV User's Manual, ERDA-108 (June 1975).

10. Costs normalized using computer code described in Ref. 9.

\subsubsection{Conventional electric plant}

The conventional electrical plant is assumed to consist of equipment similar to that in a PWR power plant. This equipment includes switchgear, protective equipment, wiring containers, and power and control wiring. The cost of the conventional electrical plant was scaled as the thermal power output of the reactor to the sixtenths power. ${ }^{9}$ The cost was normalized to an estimate for a 3285-MW(t) [1150-MW(e)] PWR. 10

\subsubsection{Instrumentation and control (I\&C)}

Instrumentation and control cost was assumed to be composed of a fusion-related I\&C cost plus the I\&C cost associated with a conventional PWR power plant. For the cost model, the I\&C cost was held fixed (i.e., independent of power output) and taken to be equal to the sum of the I\&C cost for the TNS cost estimate ${ }^{5}$ and the cost estimate for a $3285-M W(t)[1150-M W(e)]$ PWR. ${ }^{10}$

\section{$2: 2.1 .13$ Auxiliary systems}

Auxiliary systems were assumed to be those associated with fusion power plus the conventional auxiliaries of a PWR plant. Fusionrelated auxiliaries include radioactive waste handling equipment, remote servicing systems, and ventilation systems. Conventional auxiliaries include air, water, and s'team service systems, coolant volume control systems, etc. The cost of the auxiliary system was held fixed and taken equal to the sum of the cost estimate for the TNS auxiliary system ${ }^{5}$ and the cost estimate for a 3285-MW(t) [1150-MW(e)] PWR. 


\subsubsection{Buildings}

Buildings were assumed to consist of an evacuated facility which would serve as the reactor containment building and other conventional buildings associated with a PWR power plant. The cost of the containment building was held fixed at $\$ 70$ million. This is the estimated current value of the Plum Brook Vacuum Facility in Sandusky, Ohio, which is a building of the approximate size necessary to house the tokamak systems under consideration. This current value is based on average escalation rate of $6.5 \%$ annually applied to the original 1962 cost of $2 \$ 30$ million. 11 The cost of the other buildings (i.e., turbine, administration, etc.), was scaled as the eight-tenths power of the thermal power output of the reactor 9 and normalized to the cost estimate of a 3285-MW(t) [1150-MW(e)] PWR.

In all cost normalizations, engineering and contingency costs were excluded. In some cases the cost normalizations represent costs for components constructed on a noncommercial basis (e.g., the magnet coils and the neutral beam injection systems); in other cases, the cost normalizations represent costs for components constructed on a commercial basis (e.g., the turbine-steam systems and the buildings). Thus, the capital costs generated by the model should be viewed as lying in the cost range spanned by systems constructed on a noncommercial basis and systems constructed on a commercial basis.

1T. R. W. Werner, ORNL Fusion Power Demonstration Study: Arguments for a Vacuum Building in which to Enclose a Fusion Reactor, ORNL/ 1M-392/, Oak Ridge National Laboratory, Oak Ridge, Tennessee (October 1976).

\subsubsection{Plasma Parameter Scaling}

In this portion of the model, a plasma physics model determines the plasma radius and field on axis required for ignition and operation, given specific values of neutron wall loading, beta, aspect ratio, plasma elongation, and $z_{\text {eff }}$. The model equations are presented in the appendix. For the purposes of this study, initial calculations were performed using the trapped particle plasma physics model described in Ref. 12. It is noted that this model is a zero-dimensional model and does not account correctly for density and temperature profile effects. This point is especially important when considering beta and its relationship to fusion power generation and is discussed in detail in Sect. 3. When profiles are accounted for, the value of the average beta required for a given fusion power output may be significantly less than that determined by a zero-dimensional model (see Refs. 13 and 14).

The plasma scaling relationships were normalized to TNS design values presented in Ref. 15. The major radius is determined from the calculated plasma radius and the specified aspect ratio. The TF coil radii are defined from the calculated plasma radius and specified values of (1) the distance from the plasma edge to the TF coil and (2) the TF coil elongation, which is the ratio of the vertical to the horizontal bore. Thermonuclear power during the burn (14.1-MeV neutrons plus 3.5-MeV alphạ particles) is determined from wall loading, plasma radius, major radius, and plasma elongation. Burn time is scaled as a function of plasma volt seconds, plasma resistance, plasma current, and the flux swing capabllity of the $\mathrm{OH}$ coil. The flux swing of the $\mathrm{OH}$ coil depends on the specified field in the coil (set at $7 \mathrm{~T}$ for this study) and the bore of the $\mathrm{OH}$ winding, which in turn depends on the major radius and TI enil radius. Cyclc averáge thermal power is computed from the burn time, the thermal power during the burn (thermonuclear power plus exothermic reactions in the blanket), and an assumed downtime of 1 min between cycles. See Sect. 3 for a more detailed discussion of the duty cycle assumptions. 
12. D. G. McATees et al., Plasma Engineering in a Deuterium-Tritium Fueled Tokamak, ORNL/TM-5573, Oak Ridge National Laboratory, Oak Ridge, Tennessee (October 1976).

13. J. Kesner and R. W. Conn, Space Dependent Effects on the Lawson Criteria, the Ignition Condition, and Thermal Equilibria in Tokamaks, UWFDM-155, Nuclear Engineering Department, University of Wisconsin; Madison, Wisconsin (December 1975).

14. Y-K. M. Peng and J. A. Holmes, Energy Balance Estimates for TNS, to be pub1 ished as an ORNL/TM.

15. TNS Engineering. Progress Report for the Month of August 1976, WFPS-TN-025, Westinghouse Electric Corp., Fusion Power Systems Division, Pittsburgh, Pennsylvania (September 1976).

\subsection{RESULTS}

\subsubsection{Cost Comparison with Published Cost Estimates}

The component cost scaling portion of the model was used to generate costs for the ANL and the General Atomic Co. (GA) EPR designs for which cost estimates are available (Refs. 7 and 16). These cost comparisons, listed in the subsystems format of the ANL and GA cost estimates, are shown in Table 2.1. Note that these cost estimates do nnt. include engineering and contingency costs.

As shown in Table 2.1, the costs predicted by the model are approximately $25 \%$ greater than the ANL estimate and approximate1y $45 \%$ greater than the GA estimate. The observed differences in total cost are due primarily to differences in the areas of magnet cost and electrical plant cost. The ORNL model predicts magnet costs greater than either the ANL or GA estimates by about a factor of two. At present, this difference is not understood because details are not available on the ANL and GA estimates. The model also predicts higher cost for the electrical plant; this variation is partially attributed to the technology assumed. The ORNL electrical plant cost is based on motor-generator flywheel sets for which a reasonably firm cost base exists, while the ANL and GA electrical plant cost estimates are based on the more advanced concept of homopolar generators, which are assumed to be less expensive than the motorgenerator flywheel sets. However, there is no established cost base for homopolar generators.

16. Experimental Fusion Power Reactor Conceptual Design Study, GA-A14000, General Atomic Co., San Diego, California (July 1976).

\subsubsection{Parametric Results}

Using the plasma scaling portion of the model to generate plasma radi $i$ and fields on axis, the model was exercised to examine the variation of plant cost as a function of tokamak design parameters for ignited plasmas. 17 The results are presented in Figs. 2.1 through 2.14. The following operating plasma parameters were held fixed throughout this study and are similar to T'NS design values: ${ }^{15}$

1) safety factor $q=3.0$,

2) electron temperature $T_{e}=14.6 \mathrm{keV}$,

3.) ion temperature $T_{i}=13.5 \mathrm{keV}$,

4) $\bar{z}_{\text {eff }}=1.1$.

In this phase of the Demo study we have focused on the variation of plant costs with neutron wall loading, beta, aspect ratio, and plasma elongation. In the next phase of this study, we will investigate the sensitivity of plant costs to other system parameters. Note that the cost estimates are presented on the basis of dollars per kilowatt thermal instead of dollars per kilowatt electric. Thermal power was adopted because the efficiency of the power conversion system (Sect. 9) has yet to be demonstrated. It is also noted that the efficiency of power conversion systems for alternative advanced power 
Table 2.1. Cost scaling comparison ${ }^{a}$

$\begin{array}{llll}\frac{\text { ANL EPR }}{\text { ORNL model }} & \text { ANL } & \underline{\text { GA EPR }} & \\ \text { prediction } & \text { estimate } & \text { ORNL model } & \text { GA } \\ \text { prediction } & \text { estimate }\end{array}$

\section{Subsystem}

Buildings

\begin{tabular}{rr}
78 & 72 \\
13 &. \\
31 & 27 \\
327 & 31 \\
18 & 106 \\
88 & 25 \\
29 & 88 \\
25 & 30 \\
54 & 27 \\
29 & 55 \\
176 & 33 \\
\hline
\end{tabular}

Blanket

72

27

31

106

Magnet. system

Neutral beams

Vacuum systeil and lritium

facilities

Heat transport system

I\&C

Auxiliary systems

Turbine plant

Electrical plant

IUTAL
768
609

\begin{tabular}{rr}
76 & 94 \\
7 & 26 \\
19 & 10 \\
208 & 95 \\
12 & 20 \\
75 & 42 \\
18 & 43 \\
25 & 5 \\
54 & 46 \\
20 & 26 \\
223 & 101 \\
\hline & \\
737 & 508
\end{tabular}

Figure 2.2 shows the effect of beta and neusystems, such as the LMFBR and solar systems, has yet to be demonstrated.

Figures 2.1 through 2.7 were generated with the following parameters held constant:

1) aspect ratio $A=4.0$ ( similar to TNS),

2) plasma elongation $\sigma_{p}=1.6$ (similar to TNS),

3) distance from the plasma edge to the TF coil $\Delta=2.0 \mathrm{~m}$ (consisting of a 10-cm plasma scrape-off space, a $75-\mathrm{cm}$ blanket, a $30-\mathrm{cm}$ space between the blanket and the shield, a $60-\mathrm{cm}$ shield, and a $25-\mathrm{cm}$ space between the shield and the TF coil),

4) TF coil elongation (vertical bore/ horizontal bore) $\sigma_{T F}=1.35$.

Figure 2.1 shows the effect of beta and neutron wall loading on plant capital cost per kilowatt of thermal output (i.e., unit capital cost) during the burn portion of the tokamak cycle.
Figure 2.2 shows the effect of beta and neu tron wall loading on unit capital cost averaged over the tokamak cycle.

Figure 2.3 shows duty factor (burn time/ cycle time) as a function of neutron wall loading and beta. This figure is based on the assumption lhal burn time is iimited only by the volt second capability of the $\mathrm{OH}$ coil.

Figure 2.4 shows required plasma radius as a function of beta and neutron wall loading.

Figure 2.5 shows reactor thermal power as a function of beta and neutron wall loading. Both the cycle average power (dashed line) and the power during the burn (solid line) are presented. Cycle average power is the product of the power during the burn and the duty factor of Fig. 2.3.

Figure 2.6 shows unit capital cost as a function of power level and beta.

Figure 2.7 shows required field on axis as a function of beta and neutron wall loading.

Figures 2.8 and 2.9 show the effect of 
ORNL-DWG 77-3707
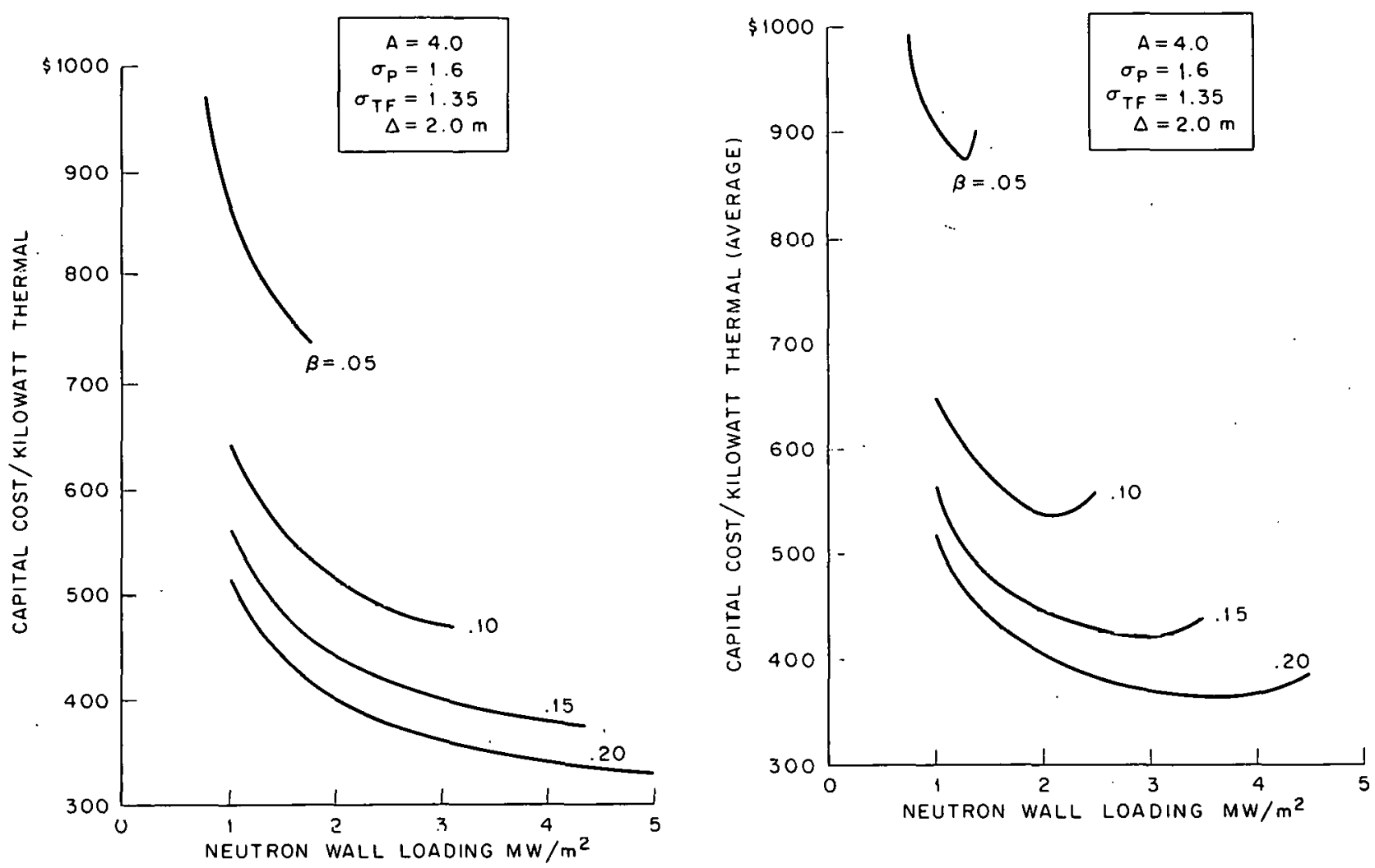

Fig. 2.1. Unit capital cost (based on thermal power during the burn) as a.function of neutron wall loading and beta.

aspect ratio and neutron wall loading on unit capital cost averaged over the cycle at constant values of beta of 0.15 and 0.05 , respectively $\left(\Delta, \sigma_{p}\right.$, and $\sigma_{1 f}$ are constant). The required plasma radius, $a$, and field on axis, $B_{T}$, are also included in Fig. 2.9 (beta $=0.05$ ) to show the effect of aspect ratio on these parameters.

Figures 2.10 and 2.11 present the relationship between plasma elongation, neutron wall loading, and unit capital cost (without and with duty factor effects, respectively) at a constant beta of 0.15 ( $\triangle$ and $A$ are constant).

Figures 2.12 and 2.13 show unit capital cost (without and with duty factor effects, respectively) as a function of plasma elonga-

Fig. 2.2. Unit capital cost (based on cycle average thermal power) as a function of neutron wall loading and beta.

tion and beta for a constant neutron wall loading of $2.0 \mathrm{MW} / \mathrm{m}^{2}$ ( $\Delta$ and $A$ are constant).

Figure 2.14 is a crossplot of Figs. 2.12 and 2.13 and shows the values of beta required to maintain a constant unit capital cost of $\$ 460 / \mathrm{kW}(t)$ and $\$ 560 / \mathrm{kW}(t)$, both on a burn and a cycle average basis, as a function of plasma elongation at a constant neutron wall loading of $2.0 \mathrm{MW} / \mathrm{m}^{2}$ ( $\Delta$ and $A$ are constant).

17. Note that these are operating points and not just ignited points. After ignition, the plasma will underyo a thermal excursion to a stable operating point (see Sect. 3 ). 


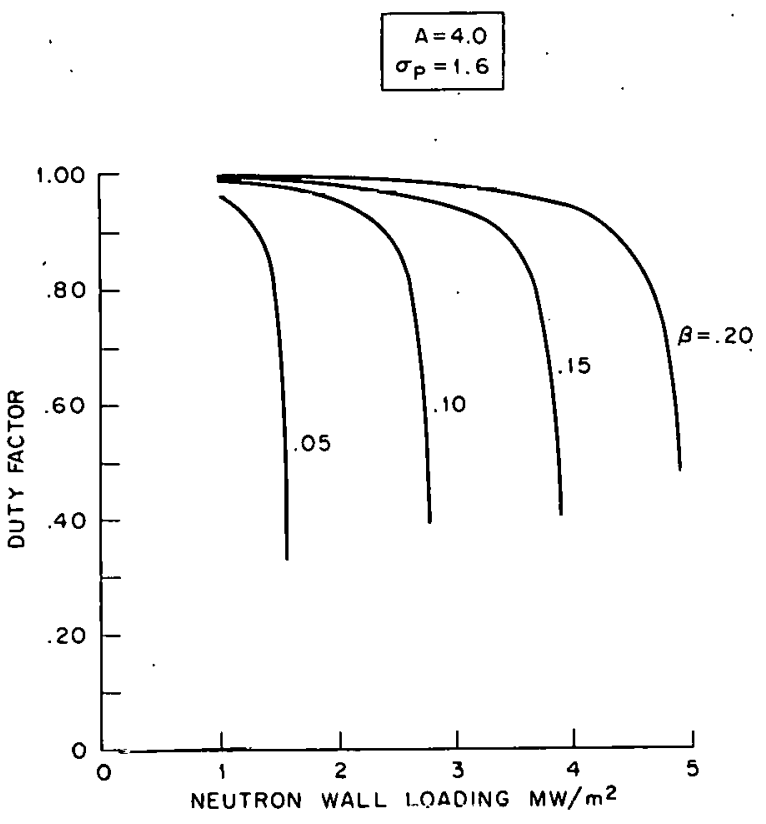

Fig. 2.3. Duty factor (burn time/cycle time) as a function of neutron wall loading and beta.

\subsection{DISCUSSION}

\subsubsection{Implications of Results}

\section{$2.4 .1_{i} 1$ Beta}

Beta has a major impact on unit capital cost, as evident from Figs. 2.1 and 2.2. For cxample, as bela decreases from $10 \%$ to $5 \%$, a factor of two decrease, unit capital cost increases by $\sim 35-40 \%$. As previously noted, the values $u \bar{f}$ beta presented in this study are consistent with a zero-dimensional trapped particle plasma physics model which does not account for density and temperature profiles. When profiles are acconuted for, the rcquired values of beta may be significantly less. For example, a recent calculation for $\mathrm{TNS}^{14}$ indicated that, when profiles are accounted for, the required beta (at the plasma operating condition) decreased from 0.14 to 0.085 , a $40 \%$ reduction. Also, in the UWMAK-III design, when profiles were accounted for, the required value of beta decreased from 0.083 to 0.058 , or approximately $30 \%$. 18

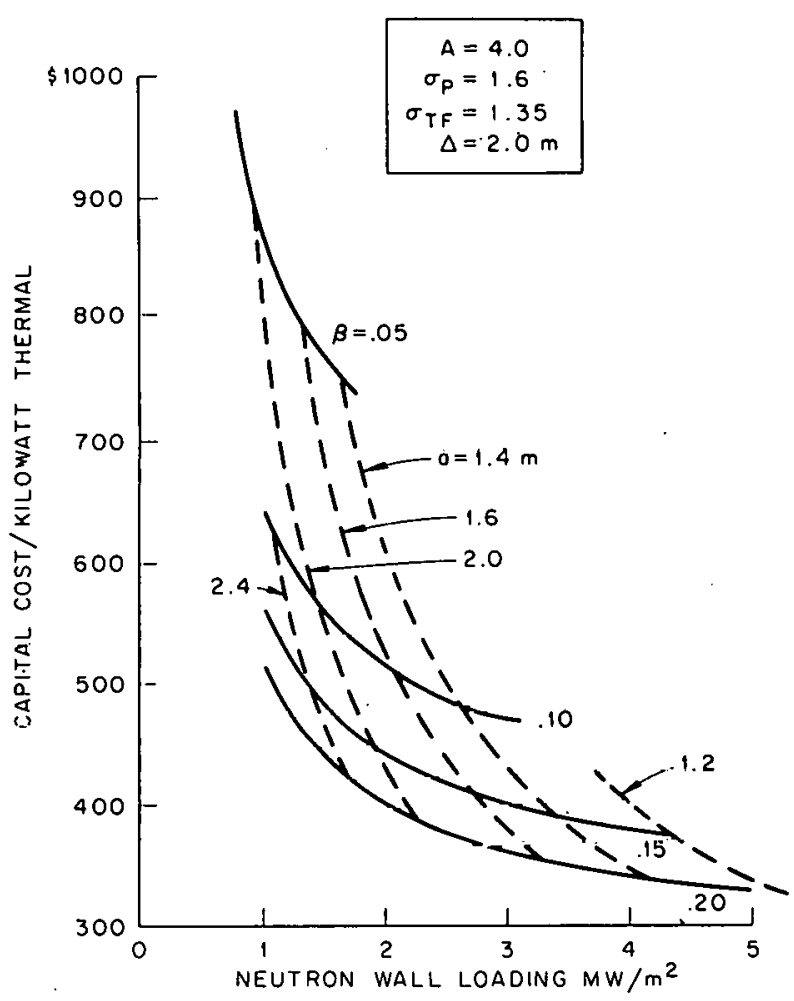

Fig. 2.4. Plasma radij associated with the cost curves of Fig. 2.1. These radif yield ignition on the basis of the trapped particle ecaling model adupted th this st.unly.

18. UWMAK-III, A Non-Cirrular Tokamak Power Reactor Design, UWFOM-150, Nuclear Engineering Department, University of Wisconsin, Madison, Wizconsin (July 1976).

\subsubsection{Neutron wall loading}

Neutron wall loading initialiy has a strong effect on capital cost al wall loädings of $1 \mathrm{MW} / \mathrm{m}^{2}$, but this effect diminishes with increasing wall loading. For example, Fig. 2.1 shows, at a constant beta of 0.15 , that increasing the wall loading by a factor of lwo from $1.0 \mathrm{MW} / \mathrm{m}^{2}$ to $2.0 \mathrm{Mw} / \mathrm{m}^{2}$ causes a decrease in unit capital cost from $\$ 560 / \mathrm{kW}(\mathrm{t})$ to $\$ 440 / \mathrm{kW}(\mathrm{t})$, a $21 \%$ reduction. An additional factor of two increase in neutron wall loading, from $2.0 \mathrm{MW} / \mathrm{m}^{2}$ to $4.0 \mathrm{MW} / \mathrm{m}^{2}$, reduces unit capital cost from 


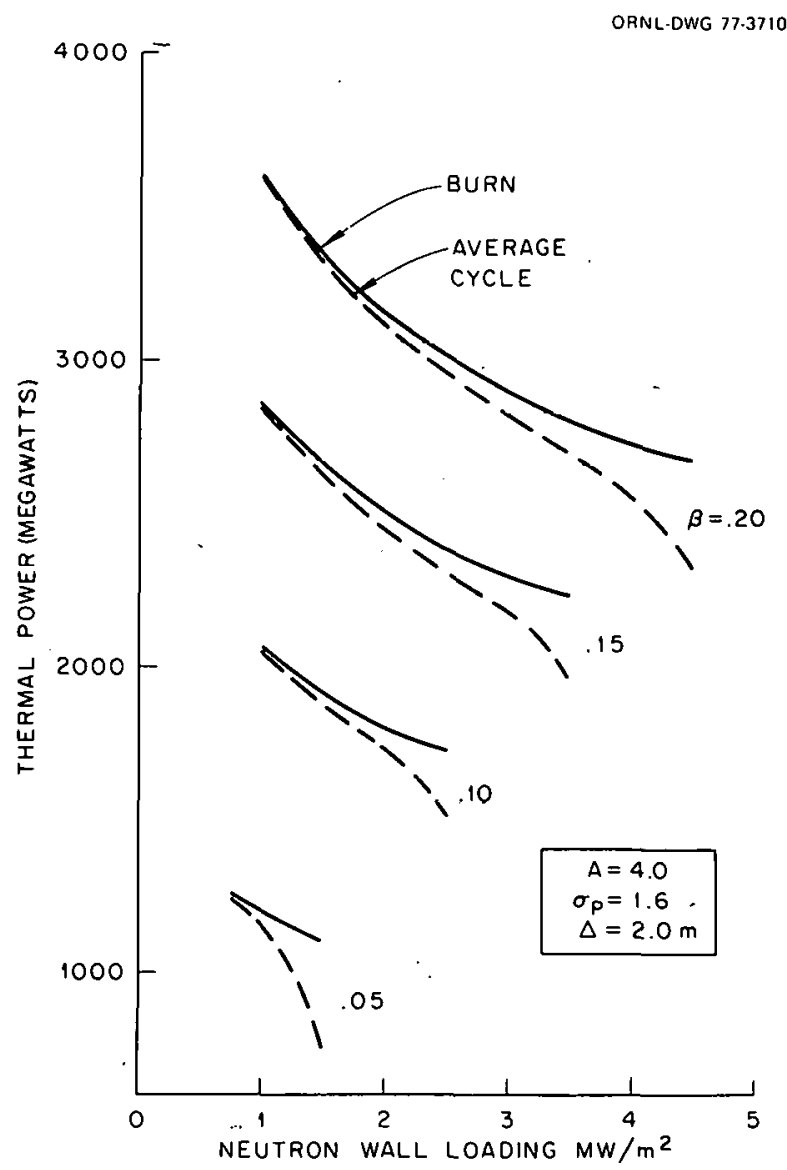

Fig. 2.5. Thermal power during the burn (solid line) and cycle average thermal power (dashed line) as a function of neutron wall loading and beta.

$\$ 440 / \mathrm{kW}(\mathrm{t})$ to $\$ 380 / \mathrm{kW}(\mathrm{t})$, a $14 \%$ reduction. It is noted from Fig. 2.1 that the capital cost of a tokamak power reactor favors high beta and wall loadings in the range of $2-4 \mathrm{MW} / \mathrm{m}^{2}$. Wall loadings beyond $4 \mathrm{MW} / \mathrm{m}^{2}$ reduce capital cost very little, yet decrease wall life and thus increase plant operating costs. It is suggested in Ref. 19 that wall lifetimes of approximately five years and more will not significantly reduce the plant capacity factor. Therefore, it appears that integral wall loadings of $10-20 \mathrm{MW}-\mathrm{yr} / \mathrm{m}^{2}$ would be adequate for the blanket structural material. It is noted that the curves of Fig. 2.1 were generated for wal1 loadings between $1.0 \mathrm{MW} / \mathrm{m}^{2}$ and either
ORNL. DWG 77.3711

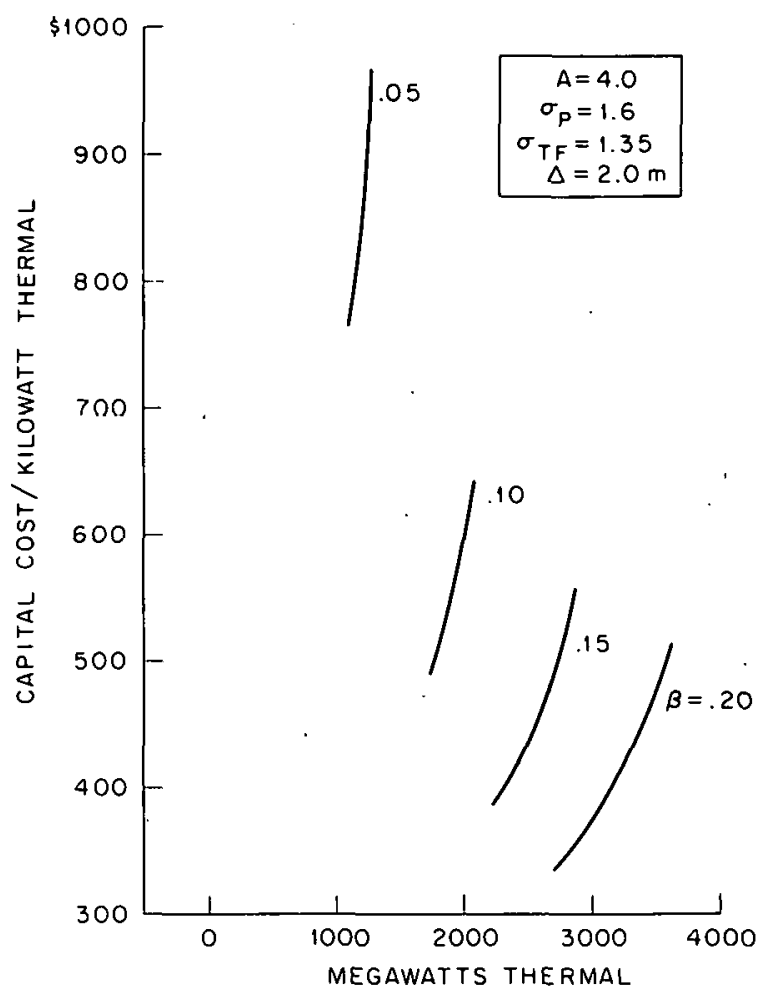

Fig. 2.6. Unit capital cost (based on thermal power during the burn) as a function of thermal power during the burn and beta.

$5.0 \mathrm{MW} / \mathrm{m}^{2}$ or that value of wall loading for which the center column radius of the torus goes to zero.

19. T. E. Shannon et al., Oak Ridge Tokamak Experimental Power Reactor Study - 1976: Part 5, Engineering, ORNL/TM-5576, Oak Ridge National Laboratory, Oak Ridge, Tennessee (February 1977).

\subsubsection{Volt second limitation}

The increase in unit capital cost observed by comparing Fig. 2.2 to Fig 2.1 results from the consideration of the volt second limitation of the $\mathrm{OH}$ coil on burn time and the corresponding influence on duty factor, which is . defined as the ratio of plasma burn time to the time required for a complete tokamak 
URNL UWG 773712

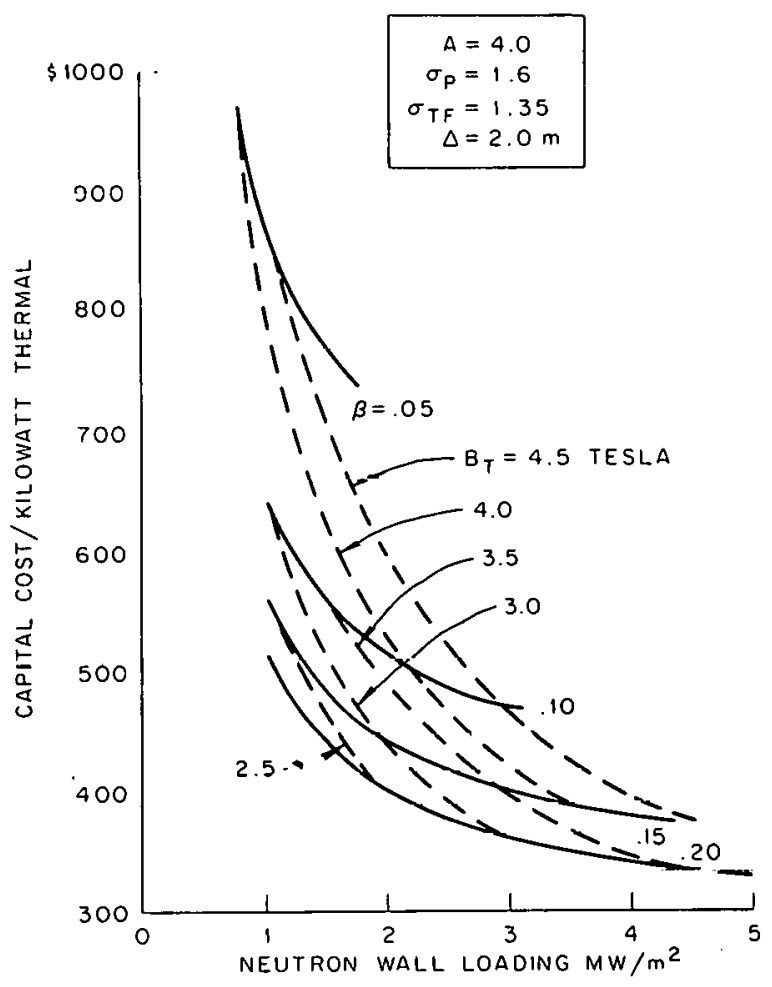

Fig. 2.7. Plasma fields on axis associated with the cost curves of Fig. 2.1. These tields on axis yield ignition on the basis of the trapped particle scaling model adopted in this study.

cycle. For this study, the cycle downtime was assumed to be $1 \mathrm{~min}$. The volt second capahility of the $\mathrm{OH}$ coil depends on the field in the coil, set at $7 \mathrm{r}$ for this study, and on the bore of the $\mathrm{OH}$ coil, which varies primarily as a function of the plasma radius and the aspect ratio. Duty factor as a function of beta and neutron wall loading (for constant aspect ratio and plasma elongation) is shown in Fig. 2.3.

The volt second capability of the $\mathrm{OH}$ coil may not be the limitation on duty factor because the burn time may be set by other considerations, such as impurity accumulation in the plasma. The intent of Fig. 2.2 is to show the potential impact of engineering and lecirrulogy on plant costs.

The unit capital cost of Fig. 2.1 is based

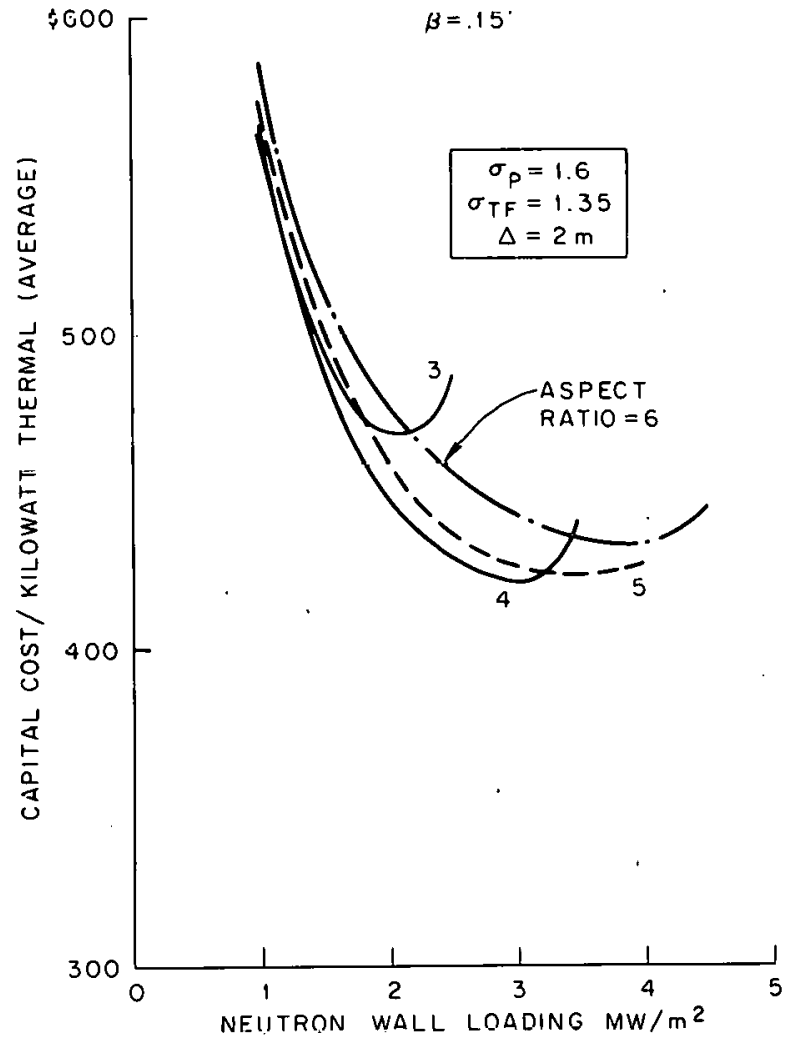

Fig. 2.8. Unit capital cost (based on cycie average thermal power) as a function of neutron wall lnading and aspect ratio at a constant beta of 0.15 .

on power output during the burn and is thus independent of duty factor. The unit capital cost of Fig. 2.2 is based on cycle average power (the unit capital cost of Fig. 2.1 divided by the duty factor) and is the more meaningful quantity to use when comparing tokamak cost with the cost of steady-state power plants.

\subsubsection{Plasma radius}

The required plasma radius for selfsustaining operation is shown in Fig. 2.4 as a function of beta and neutron wall roading for a constant plasma elongation of 1.6 and a constant aspect ratio of 4.0 . This figure indicates that a plasma radius in the range of $2-1 \mathrm{~m}$ is associated with wall loadings in the range of $2-4 \mathrm{MW} / \mathrm{m}^{2}$. This curve also indicates that for 


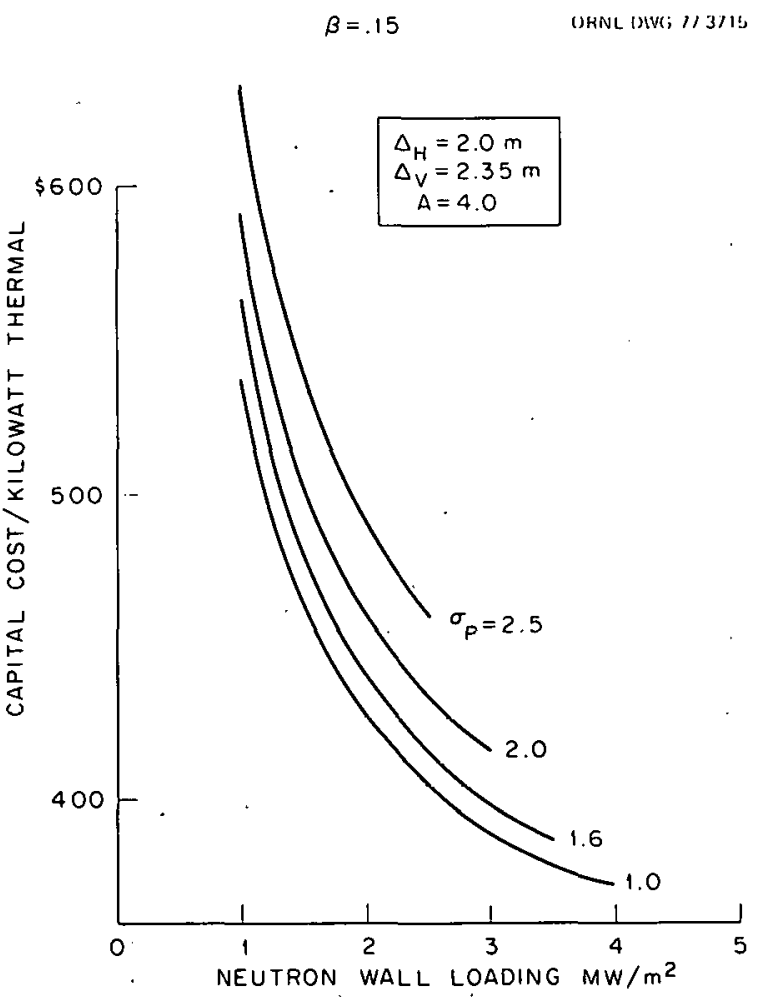

Fig. 2.10. Unit capital cost (based on thermal power during the burn) as a function of neutron wall loading and plasma elongation at a constant beta of 0.15 .

axis of 3.0-4.5 T are associated with wall loadings in the range of $2-4 \mathrm{MW} / \mathrm{m}^{2}$. These fields are low enough that $\mathrm{Nb}_{3} \mathrm{Sn}$ superconductor may not be required in the toroidal field winding; thus, Nbit superconductur may be adequate for commercial fusion power. However, an additional consideration for $\mathrm{Nb}_{3} \mathrm{Sn}$ is that it can be used at higher temperatures, thus providing greater stability and reduced refrigeration cost.

\subsubsection{Aspect ratio}

The optimum aspect ratio, for a beta of 0.15 , is approximately 4.0 , as shown in Fig. 2.8 (plasma elongation, TF coil elongation, and $\dot{\Delta}$ constant). This optimum aspect ratio occurs at a wall loading of approximately $3.0 \mathrm{MW} / \mathrm{m}^{2}$. Using a higher aspect ratio, say 6.0 , increases the unit capital cost slightly, but does allow 


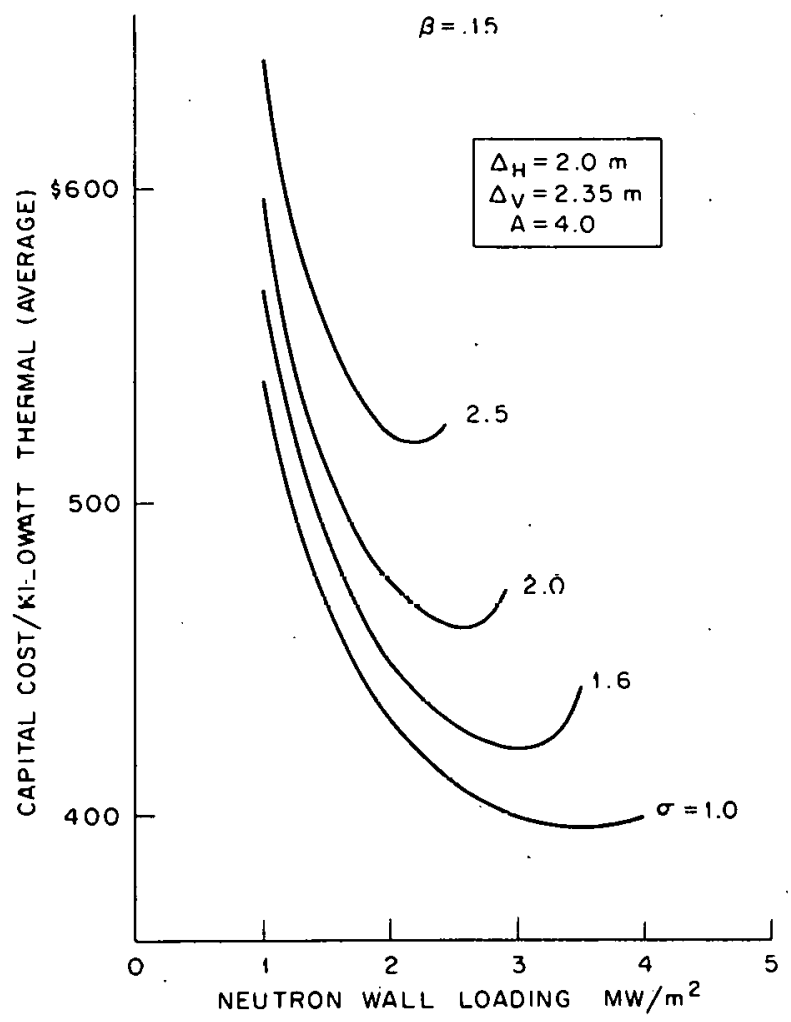

Fig. 2.11. Unit capital cost (based on average thermal power) as a function of neutron wall loading and plasma elongation at a constant beta of 0.15 .

operation at a higher wall loading $\left(4.0 \mathrm{MW} / \mathrm{m}^{2}\right)$ before the effect of duty factor causes the unit capital cost to start increasing with wall. loading. (Increasing the aspect ratio, at the same wall loading and beta, provides a larger center column radius and therefore a greater volt second capability for the $\mathrm{OH}$ coil.) Figure 2.9 is a plot similar to Fig. 2.8 except that it is for a constant beta of 0.05 . For this value of beta, the minimum unit capital cost occurs at an aspect ratio of approximately 6.0 and a neutron wall loading of $1.6 \mathrm{MW} / \mathrm{m}^{2}$. Note that the required plasma radius and the field on axis are also indicated on this plot to show the variation of these parameters with aspect ratio. In general, for about the same unit capital cost. one can choose to operate with a higher aspect ratio, higher field on axis, higher wall loading,

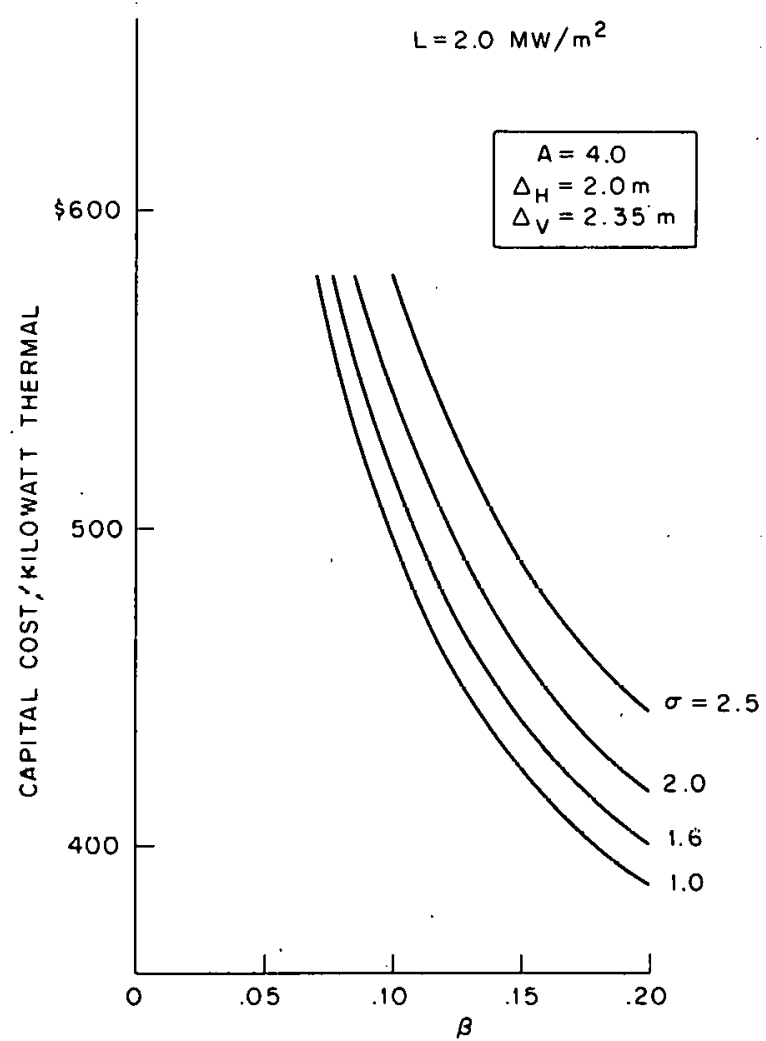

Fig. 2.12. Unit capital cost (based on thermal power during the burn) as a function of beta and plasma elongation at a constant ncutron wall luadiru of $2.0 \mathrm{MW} / \mathrm{m}^{2}$.

and smaller plasma radius, or with a lower aspect ratio, lower field on axis, lower wall loading, and larger jlasma ladius. The latter configuration wnuld operate with a longer wall life, more thermal power, and have a greater total capital cost.

\subsubsection{Plasma elongation}

Increasing the plasma elongation at constant beta and aspect ratio increases unit capital cost, as shown in Figs. 2.10 and 2.11. However, it is theorized 20,21 that an elongated plasma has the bcneficial effect of allowing a higher value of beta to be achieved. The difference between Fiys. 2.10 arid $2.11 \mathrm{ls}$ ayain the effect of duty factor. The unit capital cost of Fig. 2.10 is based on power output during the burn, while 


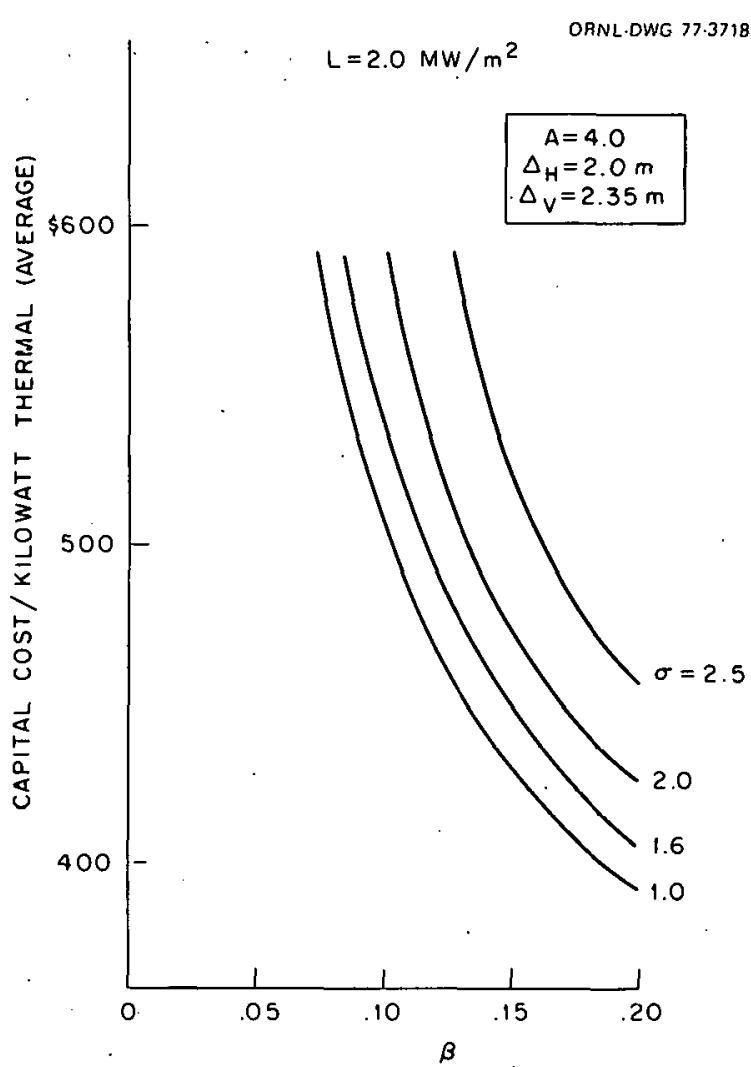

Fig. 2.13. Unit capital costs (based on cycle average thermal power) as a function of beta and plasma eiongation at a constant neutron wall loading of $2.0 \mathrm{MW} / \mathrm{m}^{2}$.

the unit capital cost of Fig. 2.11 is based on cycle average power (i.e., power during the burn times the duty factor). Note that for tliese figures the $T r$ coil clongation is not constant, but varies as a function of the plasma elongation through the relationship that $\Delta_{H}=2.0 \mathrm{~m}$ and $\Delta_{V}=2.35 \mathrm{~m}\left(\Delta_{H}\right.$ and $\Delta_{V}$ are the distances from the plasma edge to the TF coil in the horizontal and vertical directions, respectively).

The effect of plasma elongation and beta on unit capital cost at a constant neutron wall loading of $2.0 \mathrm{MW} / \mathrm{m}^{2}$ is shown in Figs. 2.12 through 2.14. The effect of duty factor is the difference in the unit capital cost of

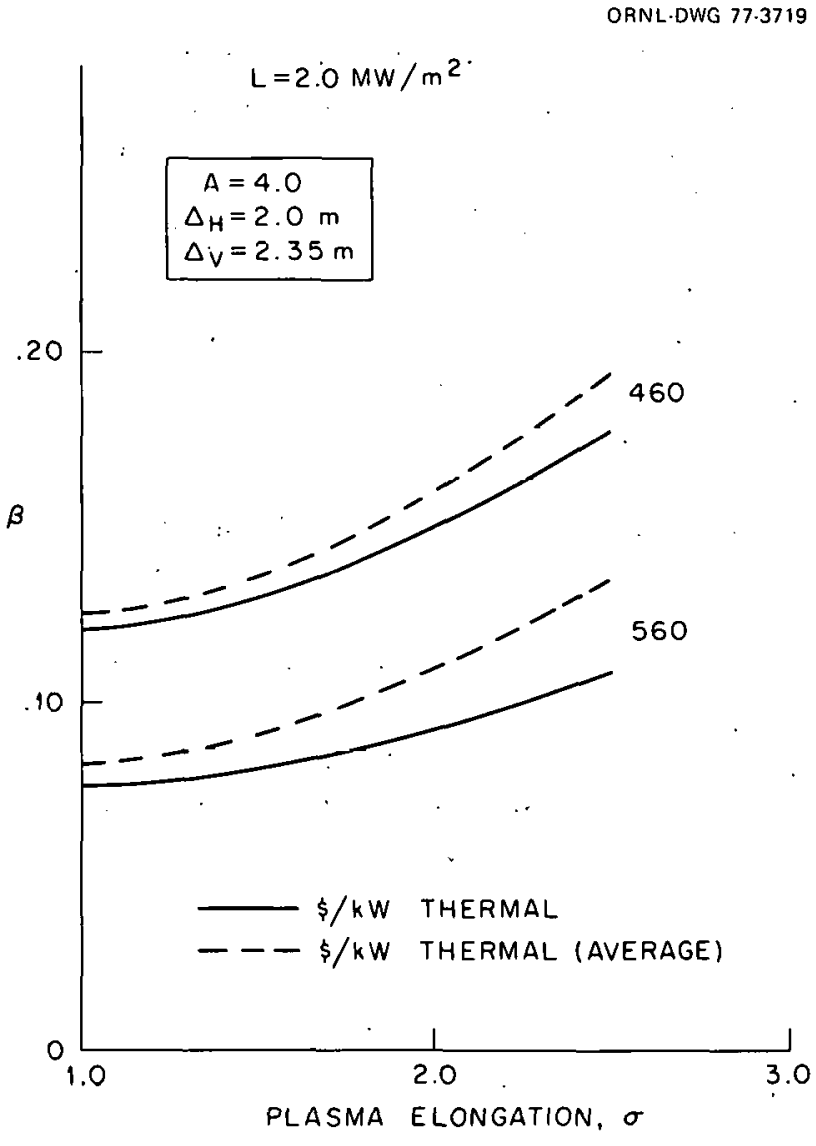

Fig. 2.14. Beta required to maintain a constant unit capital cost as a function of plasma elongation at a neutron wall loading of $2.0 \mathrm{MW} /$ $\mathrm{m}^{2}$. Lines of unit capital cost of $\$ 460 / \mathrm{kW}$ and $\$ 560 / \mathrm{kW}$ on the basis of both the thermal power during the burn (solid line) and cycle average thermal power (dashed line) as shown.

Figs. 2.12 and 2.13. Figure 2.14 is a crossplot of Figs. 2.12 and 2.13, and shows the beta required to maintain constant unit costs of $\$ 460$ and $\$ 560$ per kilowatt thermal with and without the effect of duty factor (solid lines are based on thermal power during the burn and dashed lines are based on cycle average power). For example, increasing plasma elongation from 1.0 to 2.0 requires an increase in beta from 0.12 to 0.16 ( $230 \%$ increase) to maintain a constant cycle average unit capital cost of $\$ 460 / \mathrm{kW}(\mathrm{t}$ ) (at a wall loading of $2.0 \mathrm{MW} / \mathrm{m}^{2}$ ). 
20. J. F. Clarke, High Beta Flux-Conserving Tokamaks, ORNL/TM-5429, Oak Ridge Nationa) Laboratory, Oak Ridge, Tennessee (June 1976).

21. S. 0. Dean et al., Status and Objectives of Tokamak Systems for Fusion Research, WASH-1295, United States Atomic Energy Commission, Washington, D.C. (1974).

\subsubsection{Representative Parameters for a Power Reactor}

For the purpose of subsequent discussions, a representative set of parameters was chosen for a power reactor: System parameters and costs are given in Tables 2.2 and 2.3. This is not an optimized reactor but one chosen from our studies for illustration.

Table 2.2. Design parameters for a tokamak power reactor

\begin{tabular}{|c|c|}
\hline Beta, B & 0.15 \\
\hline Neutron wall loading, L & $3.0 \mathrm{MW} / \mathrm{m}^{2}$ \\
\hline Safety factor, $q$ & 3.0 \\
\hline Aspect ratio, $A$ & 4.0 \\
\hline Delta, $\Delta$ & $2.0 \mathrm{~m}$ \\
\hline Plasma radius, a & $1.5 \mathrm{III}$ \\
\hline Plasma elongation, $\sigma$ & 1.6 \\
\hline Plasma volume, $\mathrm{V}$ & $426 \mathrm{~m}^{3}$ \\
\hline Wall area, $A_{W}$ & $474 m^{2}$ \\
\hline Field on axis, $B_{T}$ & $3.6 \mathrm{~T}$ \\
\hline TF coil elongation, $\sigma_{T F}$ & 1.35 \\
\hline TF coil horizontal bore & $7.0 \mathrm{~m}$ \\
\hline TF coil vertical bore & $9.4 \mathrm{~m}$ \\
\hline Burn time, $T_{B}$ & $20 \min$ \\
\hline Duty factor & 0.95 \\
\hline Thermal power (burn), $P_{B}$ & $2260 \mathrm{MW}(\mathrm{t})$ \\
\hline Thermal power (average), $\mathrm{P}_{\mathrm{A}}$ & $2150 \mathrm{MW}(\mathrm{t})$ \\
\hline Thermal efficiency, ${ }^{a} \eta_{T}$ & $\sim 0.35$ \\
\hline
\end{tabular}

See Sect. 9 .
Table 2.3. Capital cost (in 1976 dollars) for a representative tokamak power reactor [single unit plant producing $2150 \mathrm{MW}(\mathrm{t})]$

\begin{tabular}{|c|c|}
\hline Subsystem & (in millions) \\
\hline Reactor system & $\$ 265$ \\
\hline Heat transport system & 102 \\
\hline Turbine system & 80 \\
\hline Auxiliary system and maintenance & 99 \\
\hline Buildings & 90 \\
\hline Electrical plant & 242 \\
\hline I\&C & 25 \\
\hline TOTAL. & $\$ 903$ \\
\hline Cost/kW(t) (capital only) & $\$ 420$ \\
\hline
\end{tabular}

Once again it is emphasized that the costs shown in Table 2.3 do not include engineering costs, interest during construction, contingency, roturn on investment, or nther such indirect costs.

Several of the cost components discussed in Sect. 2.2 were grouped into systems for presentation in Table 2.3. These systems include the following components.

\section{1) Reactor system.}

The reactor system includes the TF colls, the PF coils, the divertor, the neutral beam injection system (excluding the electrical power supplies), the blanket, the shield, and the vacuum system.

\section{2) Electrical plant.}

The electrical plant includes pulsed power equipment for the PF coils and neutral beams plus the required conventinnal elertrical equipment.

\section{3) Auxiliary systems and maintenance.}

These areas include tritium processing equipment in addition to those items discussed in Sect. 2.2 for this cost category. 


\subsubsection{Shared Facilities and Multiple Units}

One of the major cost items for a tokamak reactor is the electrical plant, as indicated in Table 2.3. For the representative reactor design this item constitutes approximately $27 \%$ of the total capital cost. The majority of this cost, $24 \%$ of the total, is for the pulsed electrical equipment required to induce current in the plasma and to heat the plasma to the ignition lemperature. This is a cyclic operation and for the representative reactor, it occurs about once every $20 \mathrm{~min}$. The plasma current is induced by a current driven through the $\mathrm{OH}$ coil for a duration of approximately 2 sec. The plasma is heated by the injection of approximately $100 \mathrm{MW}$ (in the case of the representative reactor) of high energy neutral beams into the plasma for approximately 5-10 sec. Large pulsed power supplies are required to drive the plasma current and to provide the high energy beams.

The expensive pulsed electrical plant of a tokamak jower facility lies dormant during most of the cycle; therefore, the concept of multiple tokamak units tied into a common pulsed electrical plant appears attractive. As an example, two units of the representative reactor of 2150 $M W(t)[750 \mathrm{MW}(e)]$ at one site, each sharing one central pulsed electrical plant, would be a possible configuration. Such a configuration would reduce the total average capital cost for a single reactor unit from $\$ 903$ million to $\$ 795$ million and would reduce capital cost per thermal kilowatt from $\$ 420$ to $\$ 370$. Table 2.4 shows system capital costs for this multiunit configuration. (These systems contain the same cost elements as those defined for Table 2.3.) Table 2.4 also shows the effect of clustering three and five $2150-M W(t)$ units around a single pulsed electrical plant.

In addition to the pulsed electrical plants, other equipment could be shared if the single site, multiple unit concept is adopted. This might include:

- switchyard and transmission lines

- much of the large mainteriance equipment
- tritium processing plant

- helium refrigeration

- gas reprocessing plant (D-T recycle)

- feed pellet production facilities

- cooling towers for waste heat

- computer for instrumentation

- radioactive waste storage

- feedwater treating plant

- administrative overhead (security, office, etc.)

- railroad spur and handling facilities

- spare parts, coils, blanket modules, and strategic items

- machine shop

- maintenance crew

- building ventilation and control system

- standby emergency system.

The sharing of such equipment could lead to further reductions in unit capital costs.

\subsection{COST COMPARISON WITH THE LMFBR}

As indicated previously, the capital costs estimated by the model should be viewed as lying in the cost range spanned by systems constructed on a noncommercial basis and systems constructed on a commercial basis. In order to compare the estimated tokamak capital costs with cost estimates for the Liquid-Metal Fast Breeder Reactor (LMFBR), the arguments of Levenson et al. ${ }^{22}$ have been adopted to establish the cost range spanned by LMFBR systems constructed on a noncommercial basiss and LMFBR systems constructed on a commercial basis. This cost range was established as described below.

The capital cost for a noncommercially constructed LMFBR is represented by the cost estimate for the $975-\mathrm{MW}(\mathrm{t}) \mathrm{Cl}$ inch River Breeder Reactor Plant (CRBRP) which is $\$ 506$ million (in 1974 dollars). 22 This cost estimate does not include engineering and contingency costs. To escalate from mid-1974 dollars to mid-1976 dollars, a factor of 1.24 was used (based on the cost index data of the 
Table 2.4. Capital cost for a multiunit power reactor ${ }^{a}$ (1976 millions of dollars)

$\begin{array}{lrrr}\text { Number of units } & 2 & 3 & 5 \\ \text { Thermal power (MW) } & 4300 & 6450 & 10750 \\ \text { Reactor system } & 530 & 795 & 1325 \\ \text { Heat transport system } & 204 & 306 & 510 \\ \text { Turbine system } & 160 & 240 & 400 \\ \text { Auxiliary and maintenance systems } & 198 & 297 & 495 \\ \text { Buildings } & 180 & 270 & 450 \\ \text { Electrical plant } & 271 & 300 & 358 \\ \text { I\&C TOTAL COST } & 50 & -35 & 125 \\ \quad \text { \$/KW(t) } & 1590 & 2283 & 365.3 \\ & 370 & 354 & 341\end{array}$

\footnotetext{
aulsed elertrical plant cost only is reduced due to clustering. No other shared cost is assumed.
}

July 1976 Handy Whitman Bulletin). The adjusted CRBRP capital cost, after adding escalation, is $\$ 627$ million (in 1976 dollars) which is equivalent to $n \$ 650 / \mathrm{kW}(t)$. This value is shown in column 1 of Table 2.5. Column 2 shows CRBRP cost scaled to power ratings of 2150 and 4300 $M W(t)$. These costs were scaled assuming the . capital costs vary as the 0.65 power of the thermal rating. ${ }^{22}$ Following the nhservations of Levenson, we assume there is a relative cost factor of $\sim 2.0$ when one compares the cost of fission reactors constructed on a noncommercial basis with the cost of fission reactors constructed on a commercial basis. The costs for the commercially constructed LMFBR, shown in column 3 of Table 2.5, were generated by applying a factor of 2.0 reduction to the power-scaled CRBRP. costs in column 2.

The estrmated capital costs of the represenlalive lukamak plants are given in column 4 for a single 2150-MW(t) system and in column 5 for a two-unit, 4300-MW(t) cluster with shared pulsed electrical equipment.

Based on the cost ectimates shown in Tablc 2.5, it appears that the estimated tokamak power systems lie in the range spanned by the noncommercially constructed and the commercially constructed LMFBR systems. For example, the capital cost per kilowatt thermal is $\$ 420$ for the tokamak which lies in the range $\$ 490-\$ 245$ spanned by the LMFBR at the 2150-MW(t) level. At the $4300-M W(t)$ level, the tokamak cost estimate is $\$ 370$ and the LMFBR range is $\$ 380$ $\$ 190$ per kilowatt thermal.

The following observations are made concerning the capital cost comparisun of tokamaks wilh lhe LMFBR.

1) Tokamak capital cost.estimates are more uncertain than LMFBR capital cost estimates

2) The tokamak capital costs given in Table 2.5 should be viewed as rcpresentative and rarlinily nut as optimized with respect to costs or unit size.

3) The factor of improvement which might he gained in progressing from prototype to commercial units is not known for either the LMFBR or the tokamak.

4) Multiple unit operation favors tokamaks with regard to capital costs.

22. M. Levenson et. al., Nuc). News ( $\Lambda$ pril 1976). 
Table 2.5. Capital cost comparison between LMFBR and representative tokamak plants (in 1976 dollars per kilowatt thermal)

$\begin{array}{ll}\frac{\text { CRBRP }}{650} \quad \frac{\begin{array}{c}\text { Noncommercially } \\ \text { constructed } \\ \text { LMFBR }\end{array}}{490[\text { at } 2150 \mathrm{MW}(t)]} \\ & 380[\text { at } 4300 \mathrm{MW}(t)]\end{array}$

oncommercially

\section{Commercially constructed} LMFBR

245

190
Tokamak (single unit), $2150 \mathrm{MW}(\mathrm{t})$

420
Tokamak

(2-unit cluster), $4300 \mathrm{MW}(\mathrm{t})$

\subsection{A ROUTE TO DEMONSTRATING COMMERCIAL} FEASIBIL ITY

Based on our studies, it is recommended that a single site, multiple unit concept be adopted to demonstrate commercial fusion power. This plan has three phases: (1) an ignition demonstration phase, (2) a power technology demonstration phase, and (3) a commercial prototype demonstration phase.

During the ignition demonstration phase, a central pulsed electrical plant would be built to provide pulsed power for all the urits. Concurrently, a single tokamak would be built and connected to the central pulsed electrical plant. The single tokamak would be an ignition device and would consist primarily of a torus, a shield, TF coils, PF coils, neutral beam injectors, and a divertor system. The TF coils would be sized to accommodate a blanket in the next phase.

During the power technology demonstration pliase, a blanket, a heat transnort. system. a turbine system, and a tritium breeding system would be added to the ignition demonstration tokamak. Electrical power produced during this phase could be fed into a commercial grid.

During the commercial prototype demonstration phase, additional identical units would be added and tied into the central pulsed electrical plant. A single site might be producing 1500-3000 MW(e), and commercial prototype operation would be demonstrated. The number of units and the power level would be determined by both plasma physics considerations and system optimization considerations.

The above sequence has several major advantages.

1) The plasma physics requirements are the same for the ignition device and the commercial prototype. A series of successively larger devices does not have to be scaled up and demonstrated. This in itself reduces the time required to proceed from ignition demonstration to commercial operation.

2) Capital equipment is conserved during all phases leading to commercial demonstration.

3) Power is supplied to a commercial power grid early as each unit is added at an individual site.

The estimated facility cost of the first two phases of the program to demonstrate commercial fusion power (the ignition demonstration phase and power technology demonstration phase) can be determined trom Fig. 2.15. This figure shows that the estimated capital cost for a single tokamak unit is in the vicinity of $\$ 1$ billion for tokamaks designed for wall loadings of 2-4 MW/ $\mathrm{m}^{2}$ with values of beta greater than 0.10 . For the representative tokamak described in Tables 2.2 and 2.3 , this cost through power demonstration is approximately $\$ 900$ million. For the lynltion demonstration phase only, the cost of the heat transport system, the blanket, the turbine, and the tritium system can be deleted. 
ORNL.OWG 773720

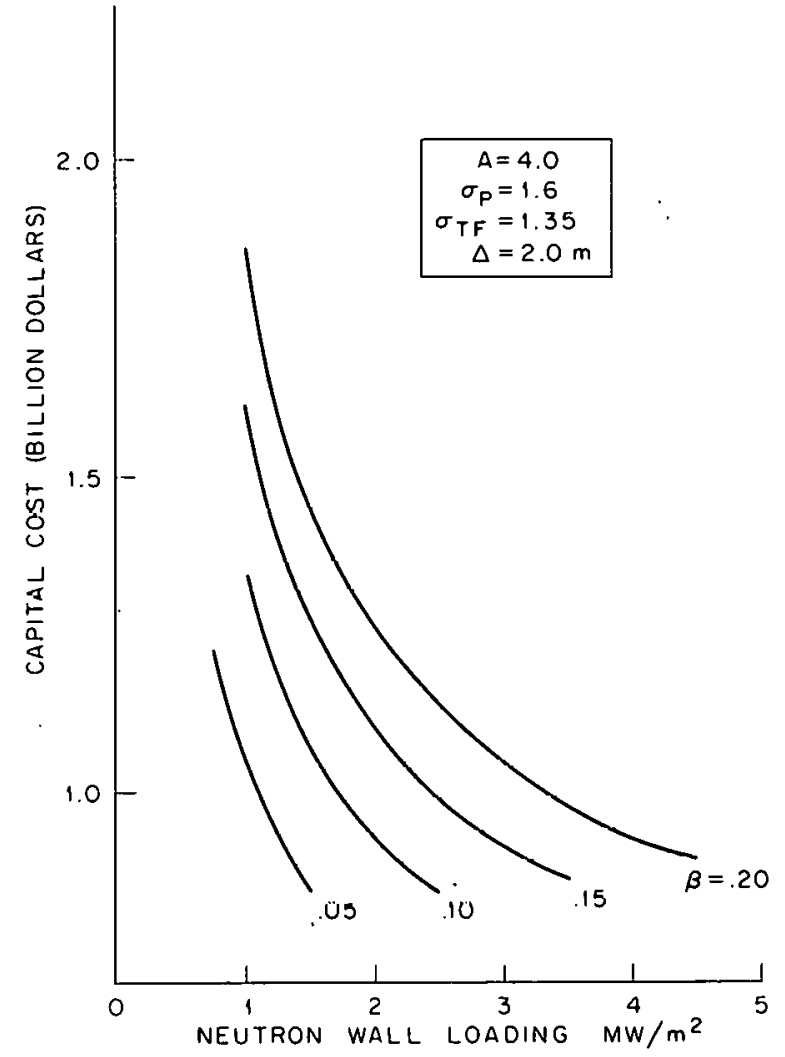

Fig. 2.1b. Total capital cost (for a single tokamak unit) as a function of neutron wall loading and beta.

This results in a cost for the ignition demonstration phase of approximately $\$ 650 \mathrm{mil}-$ lion. The third phase (commercial prototype demonstration) would increase the cost of the program to $\$ 1.6$ billion for a two-unit system delivering $\sim 1500 \mathrm{MW}(\mathrm{e})$ and $\$ 2.3$ bilition for a three-unit cluster delivering $22250 \mathrm{MW}(\mathrm{e})$, as shown in Table 2.4 (a thermal efficiency of $35 \%$ was used lu cunvert to electrical megawatts for the purpose of discussing program cost). These costs are representative of construction costs lying between commercial and noncommercial values and are summarized in Table 2.G.

\subsection{CONCLUSIONS}

On the basis of our plant cost studies, it appears that the tokamak concept can achieve capital costs which are in the range of those predicted for the LMFBR. Moreover, uncertainties with regard to the economic potential of tokamak power plants are associated primarily with uncertainties in the expected plasma physics performance and not with foreseeable limitations in the areas of technology and engineering. The tokamak can achieve ecumullic competticivenéss with the I MFRR, if the following sct of plasma physics criteria is satisfied; again, it is emphasized that the following set of criteria represents a promising set but not a unique one.

1. Size scaling. The tokamak plasma should be capable of achieving ignition with plasma radi $i$ in the range $1-2 \mathrm{~m}$ and for associated toroidal fields on axis in the range 4.5-3.0 T. This range of sizes and fields requires a size scaling performance about an order of magnitude better than that predicted by full trapped particle scaling and is consistent with ignition requirements predicted hy empiricial scaling relationships.

2. Beta. Under operating conditions, point-mndel calculations indicate that the plasma average beta would have to be about $10-15 \%$. The point-model calculations do not account for density and temperature profile effects. When such effects are included, the required value of average beta may be significantly less than $210-15 \%$, perhaps $25-$ 10\%. Such values of heta are still high sompared to values obtained in current experiments but are compatible with rerent. ralcullations of high beta tokamak operation.

In addition to size scaling and beta, successful solutions in the areas of impurity control, plasma heating, and plasma fueling are critical to the economic competitiveness of tokamak power systems. In the Demo 
Table 2.6. Capital cost of demonstration program

\begin{tabular}{|c|c|c|c|}
\hline Phase & $\begin{array}{c}\text { Phase cost } \\
\text { (billions of dollars) }\end{array}$ & $\begin{array}{l}\text { Power } \\
{[M W(e)]}\end{array}$ & $\begin{array}{l}\text { Total program cost - } \\
\text { sum of all three phases } \\
\text { (billions of dollars) }\end{array}$ \\
\hline Ignition demonstration & 0.65 & & ' \\
\hline $\begin{array}{l}\text { Power technology } \\
\text { demonstration }\end{array}$ & 0.25 & 750 & \\
\hline $\begin{array}{l}\text { Commercial prototype } \\
\text { demonstration }\end{array}$ & & & \\
\hline 2-unit cluster & 0.70 & 1500 & 1.6 \\
\hline 3-unit cluster & 1.40 & 2250 & 2.3 \\
\hline
\end{tabular}

studies, we have assumed that successful solutions to these problems can be achieved. However, we are considering the impact of divertors on the overall engineering design and the economics of the tokamak power plant.

Assuming that the preceding plasma physics characteristics can be achieved, then a commercial tokamak fusion power plant would consist of multiple (2-5) tokamak reactor units sharing a number of common elements. Two key elements shared by these multiple units would be the pulsed power supplies for driving the plasma current and the pulsed power supplies which provide the plasma supplemental heating. Each reactor unit might produce about 2000 MW of thermal output power; the precise value of the thermal output of each unit would be determined both by plasma physics considerations and hy cost. optimization considerations. The following points are noted with regard to the commercial tokamak fusion power plant.

1. The capital cost trends for tokamak power systems indicate that, at a fixed value of beta, unit capital costs decrease with decreasing plant size. This trend is contrary to the cost trends of fission reactors, for' which unit capital costs favor increased plant size.

2. The plasma characteristics required for the commercial units are essentially the same as those required for an ignition demonstration device. Thus, many of the components developed for ignition demonstration $w+11$ be prolulypical of the components required for commercial power. This is an important observation and contributes to the possibility of minimizing the number of facilities required for demonstrating commercial feasibility.

3. The motivation for pursuing a power plant consisting of multiple reactor units tied into a common pulsed electrical system is based on our cost studies which show that the pulsed electrical system of the tokamak represents about $25 \%$ of the total plant cost. This contrasts with fission power plants in which the electrical plant system cost represents only about $5 \%$ of the total plant cost. The puised electrical equipment is required to initiate the plasma current and achieve plasma heating and operates for only a fraction of each cycle. For example, with a 20-min burn time and a 1 -min downtime, the pulsed equipment would be operating for only about $1 \%$ of the cycle. It appears that this pulsed equipment could be economically and conveniently shared among several units.

4. The plant cost studies indicate that neutron wall loadings in the vicinity of 2-4 $\mathrm{MW} / \mathrm{m}^{2}$ will result in near-optimum plant costs. Such wall loadings must also lead to acceptable plant availability and costs of operation and maintenance. In our studies, we have reached the preliminary conclusion that wall lifetimes of $\geqslant 5$ years will not significantly impact the plant availability. Therefore, it appears that integral wall loadings of about $10-20 \mathrm{MW}-y \mathrm{r} / \mathrm{m}^{2}$ should be acceptable for the slruclurd malerial performance. 
A three-phase program, built around a single site-multiple unit concept, offers a viable plan for demonstrating commercial feasibility of tokamak fusion power. The three-phase program consists of (1) ignition demonstration (central pulsed electrical plant plus a single ignition device), (2) power technology demonstration (blanket and power conversion system added), and (3) commercial prototype demonstration (additional tokamak units added and tied to central pulsed electrical plant). Based on our cost estimates, such a program could be implemented in this century with a total facility cost of around \$2-3 billion (in FY 1976 dollars). This does not include engineering and contingency costs, nor dues it include development costs. 


\section{PLASMA CONSIDERATIONS}

A. T. Mense

\section{$3.1 \cdot$ INTRODUCTION}

The analysis in the previous section indicated that an economically attractive tokamak power reactor was produced when operated within the following range of parameters.

\begin{tabular}{|c|c|}
\hline $\begin{array}{l}\text { Plasma minor } \\
\text { radius }(\mathrm{m})\end{array}$ & $1 \leqslant a \leqslant 2$ \\
\hline $\begin{array}{l}\text { Aspect ratio } \\
(R / a)\end{array}$ & $4 \leqslant R / a \leqslant 5$ \\
\hline $\begin{array}{l}\text { Plasma elongation } \\
(b / a)\end{array}$ & $1.0 \leqslant b / a \leqslant 3$ \\
\hline $\begin{array}{l}\text { Toroidal field on } \\
\quad \text { axis (T) }\end{array}$ & $3.0 \leqslant B_{T} \leqslant 4.5$ \\
\hline Safety factor & $2.5<q<4$ \\
\hline $\begin{array}{l}\text { Plasma current } \\
\text { (Amperes) }\end{array}$ & $2.0 \times 10^{6} \leqslant I_{p} \leqslant 4 \times$ \\
\hline Effective $Z$ & $1 \leqslant z_{\text {eff }}<2$ \\
\hline $\begin{array}{l}\text { Average beta } \\
{\left[\bar{B} \equiv \bar{p} 2 \mu_{0} / B_{T}^{2}(R) ;\right.} \\
\text { see Sect. } 3.3 \text { for } \\
\text { further detail.] }\end{array}$ & $0.10 \leqslant \bar{\beta} \leqslant 0.20$ \\
\hline $\begin{array}{l}\text { The above parameters } \\
\text { plasma densities and } \\
\text { ranges listed. }\end{array}$ & $\begin{array}{l}\text { could be produced with } \\
\text { temperatures in the }\end{array}$ \\
\hline $\begin{array}{l}\text { Average plasma } \\
\text { density }\left(\# / \mathrm{m}^{3}\right)\end{array}$ & $\bar{n}>1.0 \times 10^{20}$ \\
\hline $\begin{array}{l}\text { Average electron } \\
\text { temperature (kev) }\end{array}$ & $\overline{\mathrm{T}}_{\mathrm{e}}>10$ \\
\hline $\begin{array}{l}\text { Average ion } \\
\text { temperature }(\mathrm{keV})\end{array}$ & $\overline{\mathrm{T}}_{i}>10$ \\
\hline
\end{tabular}

The purpose of this section is to consider the likelihood that tokamaks can operate in this desired part of parameter space.

At the outset it should be emphasized that one cannot prescribe in detail the "doses" of plasma physics required to achieve these desired plasma parameters. We have used the best analytic and numerical tools available to perform the plasma analyses in this study, but the results are no better than the assumptions involved. Simply stated, the experimental evidence at hand is not adequate to provide definitive procedures on how to achieve ignition in a tokamak device.
This is not surprising since the tokamak program is still relatively young (working on its second generation of devices) and much has yet to be learned. Nevertheless, we have attempted to explain the anticipated plasma behavior in an ignition-grade device based upon assumed transport scaling models. It is our view that one should approach the following discussion of plasma physics with the understanding that a commercial demonstration plant would be pursued only after an ignition test reactor (e.g., TNS) has been successfully operated. In the ignition tests, the detailed plasma behavior will be determined. It can be argued that the results of these ignition experiments could drastically alter the plasma details which we propose in this report. This will, be true if it is found that the transport scalings and heating techniques are markedly different from those we adopt here. This is the chance one takes in a study of this kind, and no further caveat is necessary.

This section is organized as follows. First the scaling laws adopted in this study will be described. Following this is a brief review of the advantages of high $B$ operation. Methods currently being considered as the best avenues to the achievement of high $\beta$ will then be detailed. The plasma operating cycle and effective duty factor will be discussed, followed by considerations of impurity control, plasma heating, and fueling. Finally, the salient implications of the plasma analysis will be summarized.

\subsection{TRANSPORT SCALING LAWS}

As was indicated in the economics section, there is some interest attached to constructing net power-producing tokamaks having a physical size smaller than that proposed as EPR's. 1-3 When energy and particle confinement times scale roughly as the plasma minor radtus squared $\left(a^{2}\right)$, 
one is compelled to investigate plasma parameter regimes which reduce the magnitude of the thermal and particle loss processes. One such regime is that of high density operation. Recent gas puffing experiments on both ALCATOR $^{4}$ and ORMAK ${ }^{5}$ tend to indicate that high density plasma operation is achievable. The experimental team working on ALCATOR drew the inference that particle diffusion and electron thermal conduction times scale directly with the plasma density. In addition, ALCATOR and ORMAK experimental parameter scans also tend to indicate that $z_{\text {eff }}$, which is a measure of some (but not all) of the impurity effects in a plasma, scales inversely with the density. These observations lead us to believe that high density operation may be possible and in fact very desirable. The fusion reaction rate is proportional to $n^{2}\langle\sigma v\rangle$ where the $\longrightarrow$ indicates an average over the plasma volume and $\langle\sigma v\rangle$ equals the fusion reaction parameter $\left(\mathrm{cm}^{3} / \mathrm{sec}\right)$. The $n^{2}$ dependence helps to produce large power densities, which are always economically attractive. We have considered the so-called "empirical" scaling 1 aw $^{4}$ suggested by the ALCATOR data. However, we have used in addition the other "extreme" on plasma scaling behavior (i.e., the trapped particle modes).

It has been proposed on theoretical grounds that magnetically trapped particles in a tokamak which operates at very high temperatures (or low density) may be responsible for supporting some microscopic electric field fluctuations which are referred to in very broad terms as microinstability turbulence. This turbulence can have the consequence of transpoorting energy and particles out of the hot plasma core and thus preventing ignition. In a very hot, high density tokamak such as the one we propose to look at here, the mode which theoretically would dominate the transport over most of the plasma cross section is the (dissipative) trapped ion mode. ${ }^{6}$ However, neither this mode nor its lower temperature counterparts (trapped electron modes and collisional draft waves) have been conclusively identified as being responsible for energy/particle loss in tokamak experiments. This may be due to the lack of adequate diagnostic techniques. However, for this study we have considered both the empirical and trapped particle mode scaling laws. Using the dimensionless parameters

$$
\begin{aligned}
& N \equiv \bar{n}_{e} / 10^{14} \# / \mathrm{cm}^{3}, \\
& a_{0} \equiv a / 100 \mathrm{~cm}, \\
& T \equiv T_{e}\left(=T_{i}\right) / 10 \mathrm{keV}, \\
& I \equiv \bar{n}_{e^{\tau}{ }_{\text {Energy }} / 10^{14} \mathrm{~cm}^{-3}-\mathrm{S},}
\end{aligned}
$$

and

the scaling law for empirical scaling (where $\tau_{\text {Energy }}=3.2 \times 10^{-19}$ Ne q $1 / 2 \mathrm{a}^{2}$ ) is given by.
$\mathrm{I}_{\text {emp }} \propto \mathrm{N}^{2} \mathrm{a}_{0}^{2}$,

and the trapped ion (TI) mude (assuming $D$ and $x$ published in WASH-1295) is given by

$$
I_{T I M} \propto \frac{N^{2} a_{0}^{4}}{T^{7 / 2}} \text {. }
$$

In comparing Eqs. (1) and (2) we note that $\tau \propto N$, but only the TI mode has a temperature dependence. The inverse temperature dependence causes the confinement time to decrease as the plasma heats up and adversely affects the achievement of ignition, although it has a positive effect on the reactor temperature control once ignition is achieved. (Ignition is defined as the point in parameter space at which the alpha power deposited in the plasma equals the energy loss from the plasma.) Both scaling laws have been found to yield ignition criteria in the same regime (i.e., $a \simeq 1-2 \mathrm{~m}, \bar{n}=10^{20} \# / \mathrm{m}^{3}$, etc.). Once ignited, however, the plasma temperature runs away if empirical scaling is used. (The temperature rises up to $60-80 \mathrm{keV}$, where the synchrotron radiation catches hold and causes the loss rate curve to exceed the power production.) Thus for the quantitative studies done on Demo, we have used only the trapped particle modes. By scaling, we mean the way in which the diffusion coefficient $D$ and thermal diffusivities $x_{i}$ and $x_{e}$ depend functionally on $T_{e}, T_{i}, N$, etc. The other important concern is how large a factor multiplies these functional forms; i.e., the. 
diffusion coefficient has the form

$$
D=C * f\left(T_{e}, T_{i}, M, B\right) \text {. }
$$

We need to know how large $C$ is before we can determine the ignition and operation characteristics. Unfortunately the theoretical analysis procedures used to date on the trapped particle modes do not produce a seifconsistent value for this multiplying factor

c. The empirical scaling laws also have this difficulty, but one can definitely determine $C$ by requiring a fit to experimental data. In using the trapped particle modes, we evaluate both the TI scaling and the empirical scaling (where $C$ is determined from ALCATOR data) for $T=10, N \simeq 1-2$, and $a_{0}=1$; then they agree in magnitude, provided we multiply the confinement times (as given in WASH-1295) by a factor $\simeq 10$. Thus the use of transport coefficients $\left(0, x_{e}\right.$, and $\left.x_{i}\right)$, which scale as the trapped particle modes but whose magnitude is $1 / 10$ of that shown in WASH-1295, gives agreement with the empirical scaling law at ignition temperatures and indeed allows ignition criteria to be fulfilled.

If for some reason the transport coefficients are larger than 1/10 trapped particle values, then the scaling laws tell us that we must either go to higher densities or a larger plasma minor radius. The high densities $\left(\bar{n}>2 \times 10^{14} \# / \mathrm{cm}^{3}\right)$ required for plasma ignition with a minor radius of $150 \mathrm{~cm}$ may be difflcult tu achieve already, so the logical alternative would be to go to a larger plasma minor radius. This would tend to increase the cost of the reactor. We have taken the multiplier of $1 / 10$ for the Demo study presented here.

A time-dependent, spatially-independent computer code (sometimes call a $0-D$ code due to the absence of any spatial dependence) was used to evaluate the plasma operation. This code was developed at ORNL as part of the FBX, EPR, and TNS studies. ${ }^{7}$ The code weighs in the following transport scaling laws.

Electron thermal conductivity: pseudoclassical, 1/10 trapped electron modes, $1 / 10$ trapped ion mode.
Ion thermal conductivity: neoclassical, $1 / 10$ trapped ion modc.

Particle diffusion coefficient: pseudoclassical, 1/10 trapped electron modes, $1 / 10$ trapped ion modes.

The code uses the combination of the above scaling laws, which weighs the largest coefficient the most. Our numerical modeling of a representative tokamak reactor using these scalings (as described in Table 2.2, Sect. 2.4.2) has indicated that most of the contributions to the energy and particle confinement times come from the trapped ion mode, at least over most of the reactor operating cycle. One-dimensional, spacetime codes tend to validate this conclusion as long as the plasma impurity content over most of the plasma remains low. This time-dependent code has produced the set of operating parameters shown in Table 3.1, and a further elaboration of their importance will be made in the discussion of high $B$ effects.

1. D. G. McAlees et a1., Oak Ridge Tokamak Experimental Power Reactor Study, ORNL/TM5572-5577, Oak Ridge National Laboratory, Oak Ridge, Tennessee (October 1976).

2. W. Stacey et al., ANL/CTR-76-3, Argonne National Laboratory, Argonne, Illinois (1976).

3. General Atomic Fusion Study Group, GA-A14000, General Atomic Co., San Diego, California (1976).

4. D. R. Cohn, D. L. Jassby, and R. R. Parker, Prospects for Thermonuclear Ignition in a "Collisional" Tokamak, MATT-1170, Princeton Plasma Physics Laboratory, Princeton, New Jersey (October 1975).

5. L. A. Berry et al., "Confinement and Neutral Beam Injection Studies on ORMAK," paper $\mathrm{CN}$ 35/A4-1, presented at the 6 th Conference on Plasma Physics and Controlled Nuclear Fusion Research, Berchtesgaden, West Germany (October 1976). See also Fusion Energy Division 1976 Annual Report (to be published).

6. S. 0. Dean et a I., Status and objectives for Tokumak Systems for Fusion Rescarch, WASH. 1295, USAEC (1974). 
Table 3.1. Tokamak reactor parameters

\section{Machine parameters}

\begin{tabular}{|c|c|}
\hline Major radius, $R_{0}(m)$ & 6.0 \\
\hline Plasma radius, $a(m)$ & 1.5 \\
\hline Field strength on axis, $B_{T}(T)$ & 3.6 \\
\hline Fleld strength at winding, $B_{T}^{\max }(T)$ & 7.1 \\
\hline Wall area, $A_{\text {wall }}\left(\mathrm{m}^{2}\right)$ & 474. \\
\hline Plasma volume, $V\left(m^{3}\right)$ & 426. \\
\hline Hlasma elongation, $a$ & 1.6 \\
\hline \multicolumn{2}{|l|}{ Plasma parameters } \\
\hline Safety factor, $q$ & 3.0 \\
\hline Plasma current, $I_{p}(M A)$ & 4.0 \\
\hline Beam power, $P_{b}(M W)$ & $\geqslant 100$ \\
\hline Average electron density, $n_{e}\left(m^{-3}\right)$ & $1.7 \times 10^{20}$ \\
\hline Average electron temperature, $\mathrm{T}_{\mathbf{e}}(\mathrm{keV})$ & 14.1 \\
\hline Average ion temperature, $T_{j}(\mathrm{keV})$ & 13.1 \\
\hline Global energy confinement time $\tau_{E}(s)$ & 1.5 \\
\hline Toroidal (total)-beta, $B$ & 0.15 \\
\hline Thermal power, $P_{t h}(M W)$ & 1700 \\
\hline 14-Mèv nèutron wâll loading, $\mu_{n} / s\left(M W / m^{2}\right)$ & 3.0 \\
\hline Impurity level, $Z_{\text {eff }}$ & 1.07 \\
\hline \multicolumn{2}{|l|}{ Power balance } \\
\hline Alpha power, $P_{a}(M W)$ & 283. \\
\hline Conduction and convection loss, $\mathrm{P}_{\mathrm{t.r}}(\mathrm{MW})$ & 247. \\
\hline
\end{tabular}

7. D. G. McAlees et al., Oak Ridge Tokamak Experimental Power Reactor Study, ORNL/ TM-5572-5577, Oak Ridge National Laboratory, Oak Ridge, Tennessee (October 1976).

\subsection{HIGH $\beta$ EFFECTS}

The economic potential of fusion power is enhanced if the plasma can operate with a high ratio of plasma pressure to magnetic field confining pressure. This ratio is usually measured by a parameter called $\bar{\beta}$ :

$$
\bar{B} \equiv \frac{\text { average plasma pressure }}{\left[B_{T}\left(R_{n}\right)\right]^{2} / 2 \mu_{0}},
$$

where the average plasma pressure is a volume average of all the partial pressures in the plasma (ions, electrons, alphas, and impurities). The use of the vacuum toroidal field at the magnetic axis, $B_{T}\left(R_{0}\right)$, in the evaluation of $B$ is mostiy a matter of convention. It was made 
clear in the economics section that a good share of the fusion reactor cost is in the magnetic field system $\left[\$ \sim\left(B^{2} \text { volume }\right)^{0.8}\right]$. Knowing this, we wish to make the most efficient use possible of the magnetic field. This is done by enclosing the highest plasma pressure (energy density) compatible with magnetohydrodynamic (MHD) stability constraints.

There are two methods being investigated at the present time for achieving high $B$ operation in tokamaks. The first method is to deform the plasma cross section from its usual circular shape. This elongation (as being pursued in Doublet, ISX, and PDX) may allow higher $\beta$ operation, and it also allows the best usage by the plasma of the available magnetic field for a given plasma volume. The second approach, which is in fact not mutually exclusive of the technique noted above, is the very rapid heating of the plasma (using intense neutral beams and/or rf waves). If the heating can be accomplished on a time scale which is short compared to the time it takes the'magnetic field to diffuse resistively, then the magnetic flux (both toroidal and poloidal) must be conserved. This flux conserving tokamak (FCT) operation implies that $q(\Psi)$, which measures the ratio of toroidal flux to poloidal flux, must remain the same function of $\Psi$ during the heating: for a cylinder, $q(\Psi) \rightarrow q(r)=$ safety factor $=(r / R)\left[B_{T} / B_{p}(r)\right]=\#$ times a magnetic field line circles the device the "long-way" in moving once around the plasma the "shortway"; and $\Psi$ is defined as the poloidal magnetic flux. Once a low temperature equilibrium with a favorable $q(\Psi)$ profile in the plasma is established, it is hoped that rapid heating and thus preservation of $q(\Psi)$ will produce a high temperature, stable plasma. This is feasible based on the results of the neutrat beam injection program at ORNL, which have demonstrated that significant beam power can be deposited in the plasma with no catastrophic consequences. Assuming that this experimental line of inquiry continues, one can foresee a very natural route to attaining high $B$ operation. The MHD stability analys is of high $\beta$ tokamak reactors is just beginning. The Mercier modes (both ideal and resistive) are usually stable at high $\beta$ equilibria. The questions remaining are those of the ballooning modes and the resistive kink tearing modes. Bateman ${ }^{8}$ has prel iminary computer results derived from his $3-D$ initial value codes which show $\bar{B} \approx 5 \%$ as stable, but his work only analyzed one particular set of FCT equilibria. His opinion is that higher $\bar{\beta}^{\prime}$ 's are possible.

There may not be a need, however, for $\bar{B} \approx$ $10-20 \%$ in order to be economically attractive and also use FCT equilibria. This statement has to do with profile effects which can only be analyzed using (at least) a 1-D transport code preferably coupled to a 2-D MHD code and properly arranged beam penetration and deposition code. The point was initially noted at the University of Wisconsin and pointed out by Conn and Kesner. 9 The generation of very centrally $(r=0)$ peaked temperature and density profiles, which would imply a large ratio of peak to average $B$, is beneficial. The point can be seen simply by noting that the fusion reaction rate is

$$
\overline{\left.n^{2}<\sigma V\right\rangle_{D T} V / 4}
$$

where the bar ( ) indicates an average over the plasma volume. The spatially-independent codes in use represent this term as

$$
(\bar{n})^{2}\langle\sigma V\rangle_{D T} V / 4 \text {, }
$$

where $\langle\sigma V\rangle_{D T}$ is evaluated at the average ion temperature. One can easily see that Eq. (5) can be many times smaller than Eq. (4) for the same value of $\bar{B} \propto \bar{n} \bar{T}$. Thus it is not surprising to find, as in TNS, that one can achieve the same fusion power levels with a lower value of average $\beta, \bar{\beta}$, if one can achieve and $1 i$ ve with peaked pressure profiles. 10 In particular we have found from some $1-D$ work that if the trapped particle modes are operative in a fusion grade 
tokamak plasma, particularly with a divertor holding the separatrix density low, peaked pressure profiles seem to be a natural consequence. 11

In summary then we note that the consequences of high $\beta$ operation (providing it can be stably achieved and maintained) are beneficial and, once profile effects are weighed in, may allow reasonable reactor operation for $\bar{B} \simeq 5-10 \%$.

\section{1}

8. R. G. Bateman (Oak Ridge National Laboratory, Oak Ridge, Tennessee), private communication, December 1976.

9. J. Kesner and R. W. Conn, Space Dependent Effects on the Lawson Criterion, the Ignition Condition, and Thermal Equilibrium in Tokamaks, UWFDM-155, University of Wisconsin, Madiṣnn, Wisrnnsin (December 1975).

10. TNS Design Team (Oak Ridge National Laboratory, Oak Ridge, Tennessee), private communication, December 1976.

11. A. T. Mensc, A Transpont Model fan a Tokamak with a. Poloidal Divertor. Ph.D. Thesis, University of Wisconsin, Madison, Wisconsin, $197 \%$.

\subsection{DUTY FACTÓR}

Preliminary consideration of plant availability suggests ${ }^{12}$ that an economically attractive tokamak power reactor must operate with a duty factor $20 \%$. Duty factor is defined in this context as the ratio of burn time to total cycle time (burn time + downtime). The estimated time required to bring the plasma to full current and the fusion power to its full value will take on the order of 10 sec. This is based on the usage of our 0-D code and assumes the input of $100 \mathrm{MW}$ of 200 $\mathrm{keV}$ deuteron beams. The shutdown problem for fusion reactors has not yet been seriously addressed in any fusion study, but we estimated that one could ramp the current down on a time scale of $20 \mathrm{sec}$ without a great deal of difficulty. Giving ourselves $30 \mathrm{sec}$ (which is probably longer than needed) to recock the transformer, pump out any residual gas, and refill the chamber, we arrive at a total downtime of roughly $60 \mathrm{sec}$.

The question of how long a burn time one could have has been addressed in this study strictly from the point of view of available volt seconds in the ohmic heating $(\mathrm{OH})$ transformer. This presupposes a very effective impurity control system, to be discussed later in this section. Using the available space in the reactor center $(r \simeq: 1.8 \mathrm{~m})$, an analys is was performed as to what the maximum number of voltseconds for the $\mathrm{OH}$ transformer would be using NbTi superconductors arranged in a cylinder. The analysis indicated that $60 \mathrm{~V}-\mathrm{sec}$ was the maxilum value and was limited by $B_{\max } \simeq 7 \mathrm{~T}$ at the inside of the center transformer coil. For a plasma current of 4 megamps and a plasma inductance of roughly $11 \mu \mathrm{H}$, the volt-seconds requirement to bring the plasma current to its final operating value is $\left(11 \times 10^{-6}\right)\left(4 \times 10^{6}\right)=44 \mathrm{~V}$-sec. We have assurited fur lhis sludy lhat the equilibrium field coils will provide $75 \%$ of this volt-seconds requirement. Thus only 11 of the $60 \mathrm{~V}-\mathrm{sec}$ available are used during start-up. Taking spitzer resistivity for $2=1$

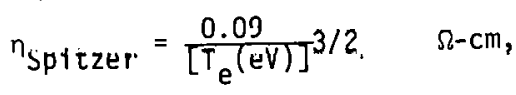

one finds the plasma resistance (ignoring trapped particle corrections) to be roughly

$$
R_{P} \simeq \frac{(2 \pi R)(0.0 y)}{\pi a b} \overline{\left(\frac{1}{T e^{3 / 2}}\right)} \quad \Omega
$$

For the representative reactor design we consider here, this turns out to be $1.8 \times 10^{-9} \Omega$. If we assume a resistance anomaly factor which could include trapped particle effects, profile effects, impurity effects, and turbulence effects of 5-6, then we arrive at a burn time of $\simeq 20 \mathrm{~min}$. [(60-11) $\mathrm{V}-\mathrm{sec} / \mathrm{R}_{\mathrm{p}} I$ volts]. We have essentially legislated for Demo that 20 min of burn would be adequate. This would give a duty factor of 20/21 $\simeq 95 \%$. 
Whether or not a burn of $20 \mathrm{~min}$ is really feasible is very much an open question. It would certainly be considered unrealistic if we cannot control the plasma impurity content with some measure of assurance. In a study of this kind, one must realize again that a fusion reactor (or any other device for that matter) cannot be a viable entity if one has no control over some of its operational parameters. Our belief is that if we cannot control the impurity behavior, we probably cannot control the reactor behavior. We are assuming good impurity control.

The question naturally arises as to why such a long burn time is needed. Couldn't one somehow shorten the downtime, have a shorter burn time, and still obtain the same duty factor? The answer is, of course, yes. In fact one can easily compute that if we only needed a 10-sec downtime, a 200-sec burn time would still give a duty factor of $\cong 95 \%$. The problem which deserves some consideration from the engineering design point of view is the fatigue introduced on the reactor structural material during these transients (start-up and shutdown). From a cyclic loading approach, we know that to lowest order components develop cracks based upon the total number of times the part is "flexed" or strained. This seems to be almost independent of the flexing rate (i.e., \# of flexes/unit time). Let us assume that a certain part will crack after it has been flexed two million times. If we cycled the part once every $200 \mathrm{sec}$, we note that it would reach the two million mark six times faster than if we flexed it once every $1200 \mathrm{sec}$. This translates into real dollars very quickly. At present, we have not done detailed enough analysis on the structural components being subjected to thermal stresses and torques due to transient magnetic fields to state what the minimum burn time should be for an "economically" acceptable fusion reactor, but it is safe to say that longer burn times appear very much more attractive.
12. D. Steiner, "The Technological Requirements for Power by Fusion," in. American Nuclear Saciety Critical Reviews \#2, reprinted from Nucl. Sci. Eng. 58, 107-165 (1975).

\subsection{IMPURITY CONTROL}

In order to achieve long burn times, the plasma must maintain its central core region $(r<0.4$ a) essentially free of high $Z$ impurities. Meade ${ }^{13}$ has calculated that if the high density central core regions of a plasma were to have as little as $0.2 \% \mathrm{w}$ (i.e., $n_{w} / n_{e} \simeq 0.002$ ), then ignition would be prevented. On the other hand, one could tolerate this kind of impurity concentration if the impurities remained essentially on the outside $(r>0.5 a)$ of the plasma where few fusion events are occurring. The requirement of exactly how far in towards the plasma core one can tolerate the impurities depends considerably on the thermal conductivity of the plasma. Keeping high $Z$ impurities from getting in the core is the biggest problem, and if once in, preventing them from reaching the central core region over the course of the desired burn time is also a problem.

Another impurity problem is that of alpha particles. ORNL EPR studies ${ }^{5}$ using a $0-0$ code have shown that if the reactor ran in a manner which did not allow the alphas to leave (and be collected), the reactor would "de-ignite" after 2100-200 sec. This calculation presupposed that the reactor must be fueled in such a manner that it never exceeds the designed operating $\bar{B}$, so as alphas built up and contributed to $\bar{\beta}$, the fueling rate was adjusted down. It is conceivable that one might run a tokamak reactor on a slowly increasing pressure scenario, provided one can accept the consequences of exceeding the $\bar{\beta}_{\text {crit }}$ for some instability. This is largely an unexplored concept. In addition, however, Kelley ${ }^{14}$ realistically states that one may never be able to keep the helium impurity content down because of the very high pumping speed requirements to malntatn $\mathrm{He} / \mathrm{ni}_{\mathrm{D}+\mathrm{T}}$ at its fractional burn-up value. 
However, if we can collect it and hold it up for only a few hundred seconds, we may be able to achieve long burn times. In the fusion program this whole area of particle collection schemes, preferential selection, and holdup of selected impurities has not been pursued in much depth. It clearly deserves much more attention.

In this particular study we have tried to assess the problems involved in using a bundle divertor as an aid to impurity and plasma "edge" controi. The most obvious positive comment on divertors is that they work! The C stellarator divertor worked; ${ }^{15}$ the DITE bundle divertor 16 lowered the high $Z$ impurity content significantly, which in turn lowered the electromagnetic radiation to the wall. The DIVA(JFT-2a) plasma ${ }^{17}$ behaves favorably, although its physical smaliness renders it vulnerable to many atomic processes normally shielded off in a larger device. The problem with other impurity control schemes is that they are untested. The exception is ALCATOR when it is run in its high density operating regime. As yet there is no clear (readily extrapolatable) explanation as to why, when operated in this manner, it is so impurity free. Thus it seemed difficult to claim that Demo operated using the same impurity control scheme as ALCATOR since the reasons for ALCATOR's cleanliness are not understood.

The bundle divertor was selected for study based upon two factors. First, the TNS study group at ORNL was looking at the poloidal divertor. Second, the bundle divertor seemed to have easier assembly, access, and shielding requirements. The problems with the bundle divertor are as follows.

1) It breaks the axisymmetry of the tokamak. This did not seem to affect DITE, al though it may affect future reactor grade plasmas.

2) It requires very large currents since it must null the toroidal field ( 2.9 T) using the quadruple field generated by two coils with oppositely directed currents.
3) The mechanical stress on the divertor coils is large.

4) The forces on surrounding coils are now asymmetric due to the presence of the divertor.

All of the above considerations led us to estimate that probably only one, or at the most three, bundle divertors could be engineered to fit onto our design.

Taking this to be the allowable limit, one then estimates whether or not the full. 283 MW of alpha-produced power can be handled safely inside the burial chambers of the divertor(s). The answer is probably not. Even if the walls were corrugated to increase the effective area over which the energy is deposited, one is hard pressed to handle these large heat loads. One possible answer to this problem is to decouple the alpha produced energy from the particle collection (i.e., bombardment) process in the divertor burial chamber. One way of doing this is to establish a plasma blanket in addition to having the divertor. This blanket, which is established in the "divertor zone," may help to conduct some of the energy to the walls. In addition it might also provide a reasonable particle bath in which to immerse impurities. They could then radiate the energy (which has been conducted and convected out of the plasma core) to the wall. The divertor may give one the means to directly control this impurity content. All of these hypotheses need to be investigated in more depth. However, one point is clear. The energy leaving the plasma must be decoupled from the energy carried (convectively) by the particles in the divertor scrape-off zone to the burial chambers. This must be experimentally investigated.

In light of these facts, we have required that the first wall heat transfer system be able to tolerate the whole alpha particle heat load. This amounts to an increase in the surface heat load by the amount of $0.6 \mathrm{MW} / \mathrm{m}^{2}$. The impurities produced due to charge exchange, plasma, and neutron bombardment of the first wall and the collection plates in the divertor were assumed collectible and controllable using a set of devices (as yet unknown) in the divertor chamber. 
13. D. Meade, Nucl. Fusion 14, 289 (1974).

14. G. G. Kelley (Oak Ridge National Laboratory, Oak Ridge, Tennessee), private communication, December 1976.

15. C. R. Burnett et al., Phys. Fluids I, 438 (1958).

16. J. W. M. Paul et al., "Divertor and Injection Experiments in DITE Tokamak," paper $\mathrm{CN}-35 / \mathrm{A}-17$, presented at the 6 th Conference on Plasma Physics and Controlled Nuclear Fusion Research, Berchtesgaden, West Germany, October 1976.

17. H. Meada et al., paper $\mathrm{CN}-35 / \mathrm{A}-18$, presented at the 6th Conference on Plasma Physics and Controlled Nuclear Fusion Research, Berchtesgaden, West Germany (October 1976).

\subsection{PLASMA HEATING AND FUELING}

\subsubsection{Heating}

It is generally acknowledged that ohmic heating - as long as turbulence does not significantly affect the momentum transfer process, i.e., produce an anomaly factor

$$
A_{R}=n / n_{\text {Spitzer }} \geqslant 100
$$

or so - by itself will not be sufficient to bring a tokamak plasma to an ignition temperature. Because of this limitation of ohmic heating, programs have been developed for supplemental heating schemes. The two most popular are neutral bcam injection aind If liealing.

Much work has been done both theoretically and experimentally on neutral beam injection heating. The most significant accomplishment in this area is that beam-slowingdown theory and experimental measurements show remarkable agreement. ${ }^{18}$ Also the success is best attributed to the fact that the beam slowing down has been solely classical in nature, 1.e., one has no need to call upon instabilities or turbulence to explain the energy degradation of the beam or the power transfer ratios to the plasma constituents (ions, electrons, and impurities). Using beam injection, both TFR and ORMAK have succeeded in achieving $\mathrm{T}_{\mathbf{i}}>\mathrm{T}_{\mathrm{e}}$ without deleterious consequences to the plasma equilibrium and stability. Beam injection is planned for all major tokamak experiments in the world, which speaks highly of the confidence in beam heating; therefore, we have included neutral beam heating in this study. The requirements to ignite a high density plasma such as the representative reactor plasma considered here are quite large. The analys is using our 0-D code indicates that $100 \mathrm{MW}$ of injection power could bring such a plasma to ignition in v10 sec. However, when one adds the additional requirement that the beam must be capable of penetrating into the magnetic axis, the required beam energy becomes very large ( 200 keV). This requires a beam development program.

The other scheme for plasma heating is to use rf power. The application of this scheme to tokamaks has been largely theoretical although some experimental work was performed on ST and ATC at the Princeton Plasma Physics Laboratory. 19,20 A recent EPRI-sponsored report ${ }^{21}$ reviews some of the possible methods and wavelengths. The essence of the problem seems to be that short wavelengths (electron cyclotron heating at $100 \mathrm{GHz}$ ) can penetrate into the center of the plasma, but high powers (100 MW) are either unavailable or very inefficiently $(<15 \%)$ produced. The lower frequencies (i.e., lower hybrid, Alfvén, and magnetosonic) are available at high powers, but there are still questions regarding plasma penetration and feasible launching structures. Some of these problems may be resolved if $r f$ heating is pursued in PLT. The potential advantages of $r f$ heating, relative to neutral beam heating follow.

1) Its penetration characteristics may be much less affected by $Z_{\text {eff }}$ than are neutral beams.

2) Efficiency in producing high powers may be higher than neutral beams.

3) One does not have to worry about sputtering due to charge-exchange beam and/ or plasma fast neutrals.

4) There need be no concern about having to pump additional (injected) particles. 
Fxperimental results should be available by 1980 or so on some of the problems outlined above. We have not considered rf heating in the Demo study because of resource limitations. We do advocate that it be pursued as a schene for heating a net power producing fusion reactor.

18. L. A. Berry et al., "Confinement and Neutral Beam Injection Studies on ORMAK," pdper $\mathrm{CN}-35 / \cap 4$ 1, presented at. the 6 th Conference on Plasma Physics and Controlled Nuclear Fusion Research, Berchtesgaden, West Germany, October 1976.

19. J. C. Hosea, Fast and Slow Ion Cyclotron wave Generation and Heating in the ST Tokamak, MATT-1129, Princeton Plasma Physics Laboratory, Princeton, New Jersey (May 1975).

20. A. C. England, High Power Electron $\mathrm{C} y$ clotron Heating in ISX and ORMAK Upgrade at ORNL, ORNL/TM-5425, Oak Ridge National Laboratory, Oak Ridge, Tennessee (May 1976).

21. R. W. Conn and G. L. Kulcinski, Study of Fast Magnetosonic Wave and Neutral Beam Heating of Large Tokamaks, EPRI-ER-268, Electric Power Research Institute (September 1976).

\subsubsection{Fueling}

Except for the pellet injection wurk (both theoretical and experimental) performed at ORNL by L. Stewart, C. Foster, and S. Milora, ${ }^{22}$ little attention has thus far been given to the fueling pronblem in tokamaks. The reason for this situation is that presentday devices make use of wall recycling of charge-exchange neutrals and plasma plus gas puffing to attain desired densities. The explanation for plasma buildup during puffing in high density devices such as ALCATOR is not rompletely understood. However, it seems reasonable to believe that "edge" fueling by gas puffing may result in relatively flat density profiles. This can have favorable consequences on transport but possibly unfavorable consequences on power production vs $\bar{B}$, as discussed previously. Further pellet injection and gas puffing experiments are to be performed on ISX and possibly PDX, if they are needed. Pellet technology is currently being investigated at ORNL. Numerical investigations at ORNL are just now under way to determine if "deep" pellet penetration is really needed to maintain a long burn lime plasma. These numerical results should be availahhle early in 1978.

22. C. A. Foster et a1., ORNL Neutral Gas Shielding Model for Pellet-Plasma Interactions, ORNL/TM-5776, Oak Ridge Nationạ 1 Laboratory, Oak Ridge, Tennessee (November 1976).

\subsection{CONCLUSIONS}

In summary, the following points are central to the plasma analysis performed for this study.

1) Both empirical and trapped particle mode scaling laws allow for ignition of a 1-2 m minor radius, $\left(n=2 \times 10^{14} \mathrm{~cm}^{-3}, T=10=15 \mathrm{keV}\right)$, high density plasma provided one can find a vlable scheme for reaching these high average densities withưut causing the plasma to gn disruptive. Pellet injection may be such a scheme.

2) From both $0-D$ and $1-U$ transport simulalions using the trapuid particle mode scaling laws, one finds that over most of the burn phase the energy transport is governed by the trapped ion mode. Thus, it appears justifiable to perform economic sensitivities using only the TI mode scaling law. The results should not differ significantly from those using a combination of modes.

3) A1l presently conceived transport scaling laws are speculative when extrapulaled to ignition grade plasmas. However, one should consider the use of the trapped particle modes as a pessimistic model with respect lo the effects of temperature on reaching ignition. 
4) An examination of the 1-D profile effects on TNS, ${ }^{10}$ which is similar in nature (but with a much shorter burn time) to commercial size plasmas, one finds that reasonable fusion power levels can be attained with high ratios of $\beta(r=0) / \bar{\beta}$. This indicates economically attractive operation at $\bar{B} \sim 10 \%$ based upon 1-D results. This appears consistent with operating the plasma in an FCT mode up through ignition.

5) The impurity content of the plasma $\left(z_{\text {eff }} \approx 1.06\right)$ is due only to fusion-produced alpha particles, and any wall - or divertororiginated impurities are assumed to be controlled. A bundle divertor is being examined for this purpose, but it cannot handle the 283 MW of alpha power. Thus much of this is assumed to be deposited on the first wall either by EM radiation near the plasma edge or by thermal conduction through a "warm" plasma blanket $(T \leqslant 100 \mathrm{eV})$.
6) With $100 \mathrm{MW}$ of 200-keV deuteron beams, ignition is reached in roughly $10 \mathrm{sec}$. If the empirical scaling is used, the plasma is thermally unstable past ignition, which means that $T \rightarrow 60-80 \mathrm{keV}$ where the synchrotron radiation loss rate catches the power production rate. Trapped particle scaling produces a thermally stable operation point at

$\overline{T_{e}} \simeq 14 \mathrm{keV}, \bar{T}_{j} \simeq 13 \mathrm{keV}, \overline{\mathrm{n}} \simeq 2 \times 10^{14} \mathrm{~cm}^{-3}$.

7) Fueling to replenish the $D$ and $T$ lost and fused is accomplished through a combination of "edge" recycling, divertor gas recycling, and pellet injection. Careful 1-D transport studies have not yet been performed, and the results quoted are based on a $0-D$ code.

8) Further experimental plasma physics work is needed in the areas of a) impurity control including divertors, b) negative ion neutral beam technology, c) rf heating, d) pellet injection, and e) understanding of ALCATOR operation and cleanliness. 
THIS PAGE

\section{WAS INTENTIONALLY LEFT BLANK}




\section{BLANKET DESIGN}

T. E. Shannon

\subsection{INTRODUCTION}

Design concepts for the reactor blanket system are proposed based on the application of current and near-term technologies wherever possible. Conservative limits on pressures and temperatures were selected to permit a reliable structural design approach within the high energy radiation environment.

The preliminary blanket designs focus generaliy on generic problems rather than on specific problems relating to hardware deve1opment and demonstration. The reactor system requirements and design parameters were selected to cover a range of values within those expected for the successful development of tokamak fusion power.

Two mechanical design approaches, which differ primarily in configuration and method of assembly, are presently under constderation. Both concepts comply with the fundamental objectives described.

\subsection{SYSTEM REQUIREMENTS AND DESIGN CRITERIA}

The reactor blanket system consists of the internal tokamak components from the edge of the plasma to the inside of the toroidal field (TF) coils. The major components (shown in Fig. 4.1) include:

1) a high vacuum toroidal region to provide a clean environment for the deuterium-tritium (D-T) plasma ( $A$ secondary vacuum is provided by the reactor containment building, which eliminates the $\Delta p$ on the toroidal vessel. See Sect. 8 for a description of the vacuum building.),

2) a neutron-absorbing, fertile material to capture the high energy neutrons for producing heat and breeding tritium,
3) a heat exchanger to transfer the absorbed heat energy to a power conversion system, and

4) a shield to reduce radiation and protect the TF coils from neutron heating.

Blanket design concepts were developed to satisfy overall reactor system requirements while providing practical engineering solutions for safety, reliability, fabricability, maintainability, and long life. The plasma is assumed to produce a power density resulting in a neutron wall loading in the range of $2-4 \mathrm{MW} / \mathrm{m}^{2}$. Sufficient blanket and shielding material is provided to accommodate superconducting IF coils, but the use of normal coils would significantly reduce this requirement (see Sect. 8). Finally, the reactor system requires a reasonably high thermodynamic cycle efficiency (>30\%) for economic electrical power conversion.

The design approach adopted in this study resulted in the following guidelines for the blanket system:

1) low coolant pressures,

2) structural material alloys based on current commercial materials,

3) provision for remote maintenance,

4) secondary vacuum system to reduce pressure on toroidal high vacuum region and

5) conservative limits on design stress, corrosion, and material and coolant temperatures.

Due to system design constraints and space limitations, a specific blanket design represents a compromise of alternatives. In the design of the superconducting TF coils, for example, minimizing refrigeration requirements caused by neutron heating tends to drive the blanket/shield thickness up, which in turn increases the size and cost of the coil. The optimum design must be based on a trade-off between refrigeration and coil costs. As another example; the 


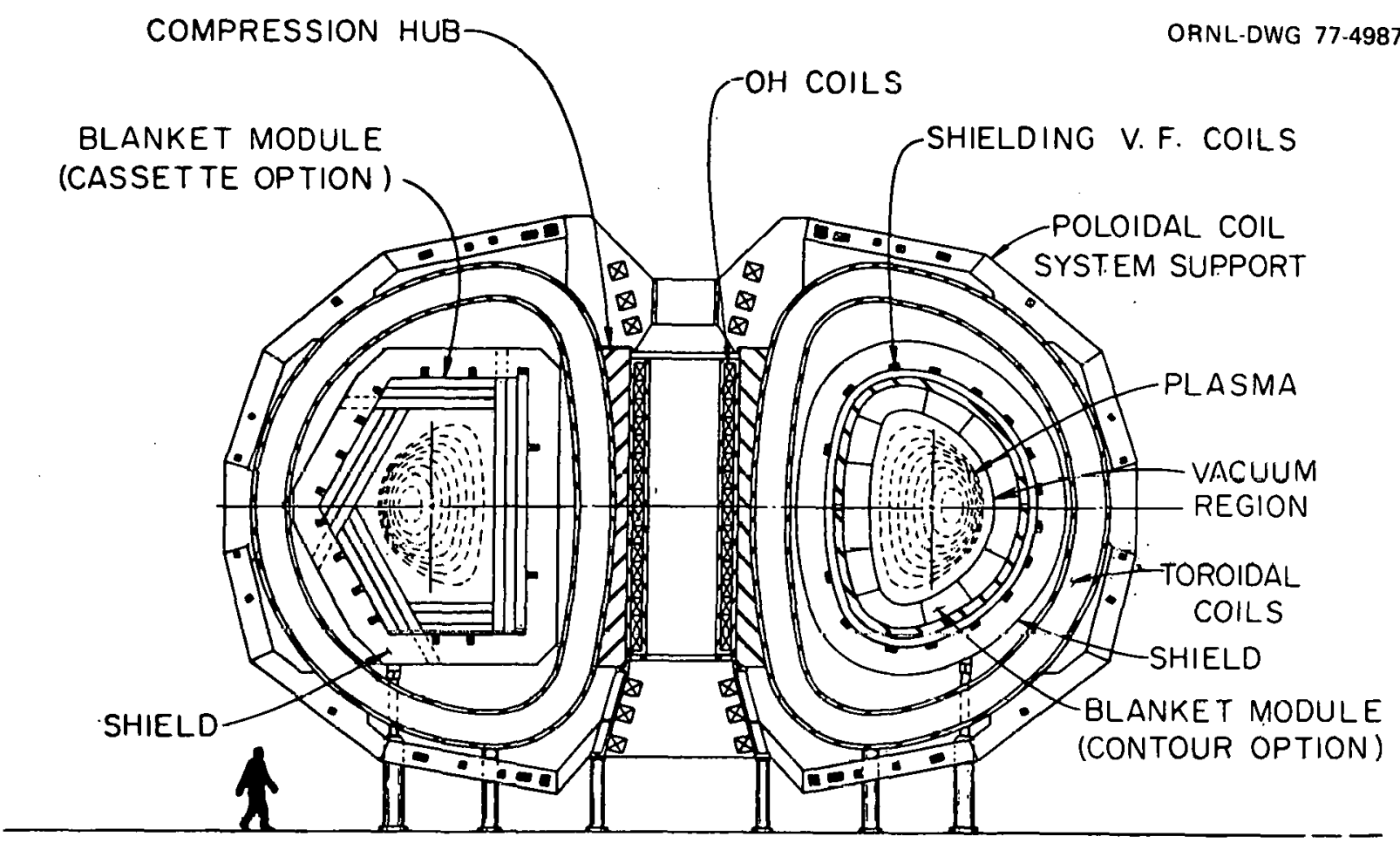

Fig. 4.1. Tokamak reactor cross section showing major blanket components.

efficiency of the power conversion system increases with increasing coolant temperature, while radiation damage and allowable structura) design stress favor operation at reduced temperature. Also, energy deposition at the first wall imposes thermal stress, which may be reduced by decreasing the wall thickness; pressure loading, however, favors increasing the wall thickness.

Obviously, the optimum selection of major components is a complex task requiring system modeling techniques. Current blanket designs retilect experience gained from previous ORNL studies and a nominal consideration of the design space. The parameters listed in Table 4.1 were selected as a basis for the blanket design studies and are not intended to represent a specific optimized reactor design.

\subsection{DISCUSSION OF REFERENCE PARAMETERS}

\section{3:1 Material Selection}

The first structural wall of the tokamak reactor vessel is exposed to the total neutron flux from tho fusion reaction. (This is un! ike fission reactor experience, where only consumable core components are exposed to significant irradiation.) In addition, Lhis wall ulus L Lais fei. by conduction some portion of the fusion alpha power. The material selection must be based on an overail consideration of the following criteria:

1) compatibility with plasma vacuum requirements,

2) proven fabrication techniques compatible with remote maintenance requirements,

3) reasonable life ( $\geqslant 5$ years) under radiation damage (see Sect. 2),

4) creep and stress rupture resistance to operating loads, and

5) resistance to fatigue under thermal and structural loading. 
Table 4.1. Blanket design parameters

\begin{tabular}{ll}
\hline & \multicolumn{1}{c}{$\quad$ Value } \\
Structural material & Austenitic stainless steel \\
Absorber/breeding material & Lithium \\
C.onlant & Molten salt (HITEC) \\
Design life & $3 \times 10^{5}$ pulses \\
Fusion burn time & $20 \mathrm{~min}$ \\
Duty cycle & $95 \%$ \\
Neutron wall loading & $2-4 \mathrm{MW} / \mathrm{m}^{2}$ \\
First wall design heat flux & $0.5-1 \mathrm{MW} / \mathrm{m}^{2}$ \\
Brceding ratio & $>1$ \\
Maximum allowable coolant temperature & $450-500^{\circ} \mathrm{C}$ \\
Maximum allowable structure temperature & \\
First wall & $2400^{\circ} \mathrm{C}$ \\
Other & $2500^{\circ} \mathrm{C}$ \\
\hline
\end{tabular}

We selected materials and a temperature range for the first wall which minimize radiation effects. The preliminary blanket design assumes an alloy similar to type 316 stainless steel. Temperatures were assumed to be $400^{\circ} \mathrm{C}$ or less in the region next to the first wall where the damage rate is highest. Progressively higher temperatures (up to $500^{\circ} \mathrm{C}$ ) were allowed elsewhere because damage decreases with radial distance into the blanket. This approach is described in more detail later in this section. Section 5 contains a complete summary of the structural materials evaluation.

\subsubsection{The Breeding Material}

It appears that liquid lithium offers the greatest potential for the breeding material. Lithium yields the highest flexibility with regard to tritium breeding, and it has good thermal properties and acceptable chemical compatibility. Much further work will he required in the areas of tritium recovery and magnetohydrodynamic (MHD) effects.

\subsubsection{Coolant Selection}

To provide a blanket design with high structural reliability, we investigated the use of a low pressure coolant. This low pressure requirement significantily restricts the available coulants. Helium and water were rejected because of the high pressures required for a satisfactory thermodynamic cycle. Lithium metal was also eliminated because of complications resulting from MHD considerations. The only remaining coolant seemed to be a molten salt. A commercial heat transfer salt, HITEC, was assumed for the preliminary design. It consists of $53 \%$ potassium nitrate, $40 \%$ sodium nitrite, and $7 \%$ sodium nitrate. The heat transfer properties (density, viscosity, vapor pressure melting point, and heat capacity) are adequate for reasonable component design. Section 6 includes a detailed description of the coolant selection. 


\subsubsection{Design Life}

The design life parameter of $3 \times 10^{5}$ pulses represents a reactor life of 10-15 years, assuming a 20-min burn time and 95\% duty cycle. A plant capacity factor has not been determined, but a target design value of $70-80 \%$ would be desirable. These factors were selected to evaluate the thermal fatigue life in the first wall.

\subsubsection{First Wall Luadiny}

The alpha power resulting from the D-T fusion represents approximately $20 \%$ of the fusion power. Some portion of this power will be deposited directly on the first wall as a heat flux. If a magnetic divertor is developed, some portion of this power may be deposited in the particle trap of the divertor. Considering the major uncertainty in divertor concepts at this time, we recommend that the first wall be designed to handle the most extreme case, the total alpha power.

\subsubsection{Allowable Design Stress}

The allowable design stresses for this preliminary design study were guided by the ASME Nuclear Vessel Uesign lode. It is recognized that significant new code development will be required in support of the unique structural problems in fusion reactor blankets. Ihe existing codes, however, provide à good " basis for preliminary design evaluation. A more detailed discussion of the stress analysis is included later in this section.

\subsection{MECHANICAL DESIGN ALTERNATIVES}

Two blanket mechanical design concepts are currently being evaluated as alternatesolutions to the problem of remote maintenance and repair. Both concepts will be reviewed in this report; however, we expect to select one of these for a more thorough design and analysis for the remainder of this year's study.

One design, called the contour blanket concept, is similar to the blanket design proposed in the ORNL Experimental Power Reactor (EPR) Design. 1 The individual blanket modules form a contoured envelope to conform to the plasma shape. The other design, called the cassette blanket concept, is a new design that provides flat blanket modules for ease of disassembly. Both concepts have been conceptually designed to satisfy the basic guidelines and design parameters.

1. C. A. Flanagan et al., Oak Ridge Tokamak Experimental Power Reactor Study - 1976, Part 4, Nuclear Engineering, ORNL/TM-5575, Oak Ridge National Laboratory, Oak Ridge, Tennessee (December 1976).

\subsubsection{The Contour Blanket Concept}

This design concept consists of a sircular array of small blanket modules which form segments of the torus and fits between TF coils. The number of wedge-shaped blanket segments is three times the number of TF coils. Bearings are mounted on the inside of the shield segments so that blanket segments, when inserted between the TF coils, can be rotated under the coils. Figure 4.2 is a schematic illustration of this concept and Fig. 4.3 is a plan view of the tokamak assembly. Each blanket segment is made up of 12 modules located poloidally around a structural trame. An elevation view of one complete blanket segment with framework, modules, and inner wall is shown in Fig. 4.4. The framework provides support for the modules and first wall and, in addition, provides the coolant inlet manifolds for the blanket.

The first wall is of tubular construction to provide a thin wall for thermal stress reduction. The blanket module consists of a double-walled vessel with coolant flowing between the walls. Inside the module there is metallic lithium, a graphite reflector, stainless steel gamma shield slabs, and coolant tubes. Details of the bianket cross section are shown in Figs. 4.5 and 4.6 . Around the top of the module on all four sides is 


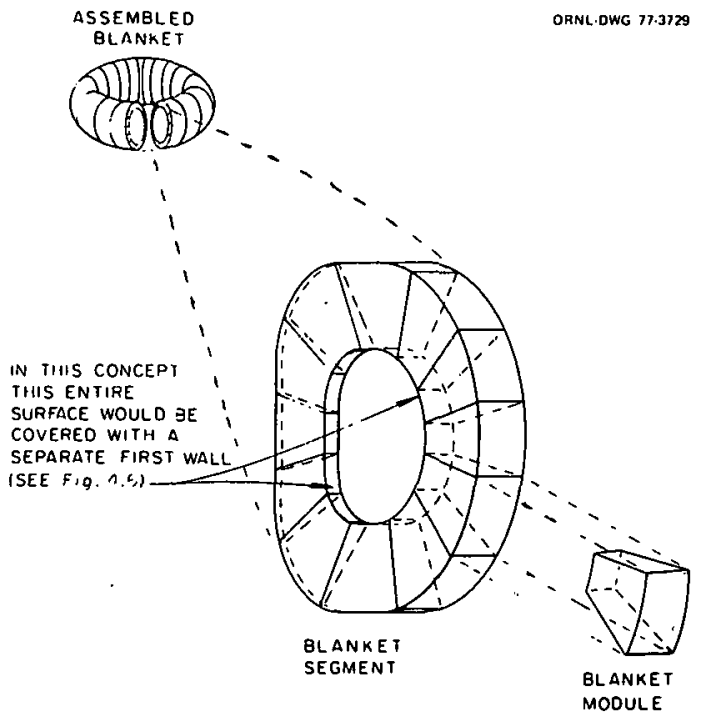

Fig. 4.2. Contour blanket concept

a coolant-collecting plenum from which coolant pipes run down at three points to deliver coolant to the first wall structure.

The three parts of the blanket - module walls, first wall, and bulk blanket - are cooled in series. The inlet manifold feeds and returns coolant from each of the 12 modules in a segment. Coolant enters the module in a center pipe, which discharges the coolant between the walls at the center bottom. Coolant flows between all walls, is collected in the plenum around the top, flows down through three feed pipes to the first wall, up through one outlet pipe, and down an annular center concentric pipe to the coolant tubes for the bulk blanket.

\subsubsection{The Cassette Blanket Concept}

Plasmas in tokamak systems were initially developed in toroidal shells with circular cross sections. As understanding of plasmas has increased, the effective shape of the plasma has become elliptical or elongated. The physical surrounding walls no longer dictate this shape - physics makes this specification. It should theretore follow that the. shape of the blanket be dictated by engineering requirements, i.e., the striving towards fabricability, ease of maintenance, economy, and dependability. The rectangular blanket design. using cassette modules is a step in this direction. The components comprising the blanket, the cassette modules, are designed as long, relatively thin box-like volumes. The walls of these volumes are a series of contiguous $U$ shaped tubes containing the coolant and completely enveloping the lithium-moderating fluid contained within. Removal and replacement of these cassette units by remote means are reduced to linear motions. Figure 4.7 illustrates schematically one subassembly of cassette modules occupying the space between adjacent TF coils. The number of subassemblies is equal to the number of TF coils, and each subassembly is divided radially into three slices. Cassette removal is effected through the middle slice in order to clear the Tf coils. Figure 4.8 shows a plan view of this concept. The individual cassettes slip out between vertical field coils so that they need not be disturbed.

Figure 4.9 is a cross section of a cassette showing one of the U-shaped coolant flow channels. These individual flow channels are joined one to the next to form the complete unit. The ends have a nested set of $\mathrm{U}$-tubes for closure and for cooling. Section A-A of Fig. 4.9 illustrates how the tubes are formed side by side while still preserving the individual tubes' circular shape.

\subsection{DESIGN STRESS ANALYSIS}

A preliminary elastic stress analysis was conducted to assess the feasibility of the structural aspects of the design concepts. For the lithium and salt fluids contained in the blanket region, pressure will be low, but there will be a system of relatively high cyclic thermal stresses induced by alpha power and nuclear heating (neutron-induced) deposited on the first wall. It was assumed that away from the first wal1, the large mass of lithium will keep the temperature reasonably constant during the off 


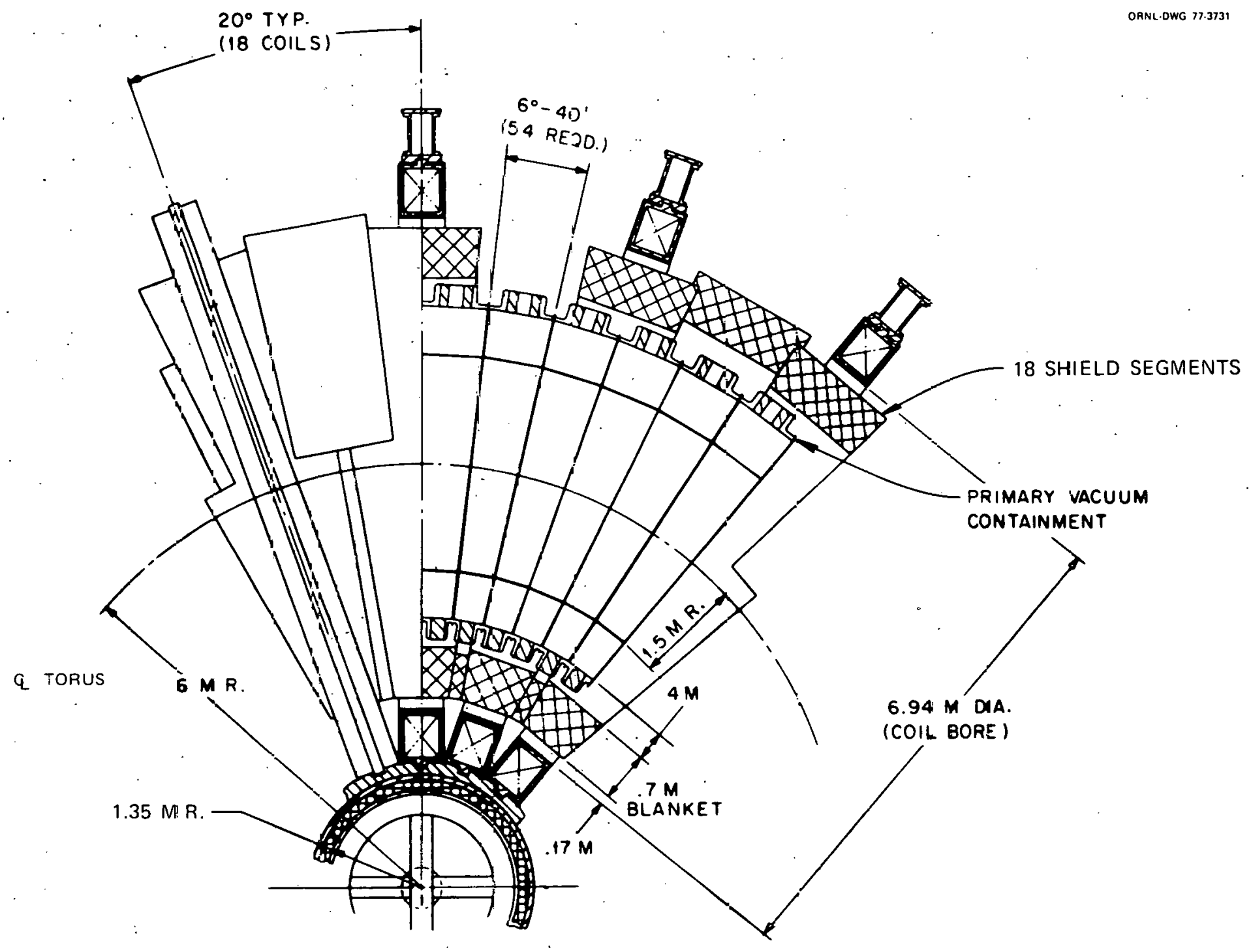

Fig. 4.3. Tokamak plan view contour blanket concept. 


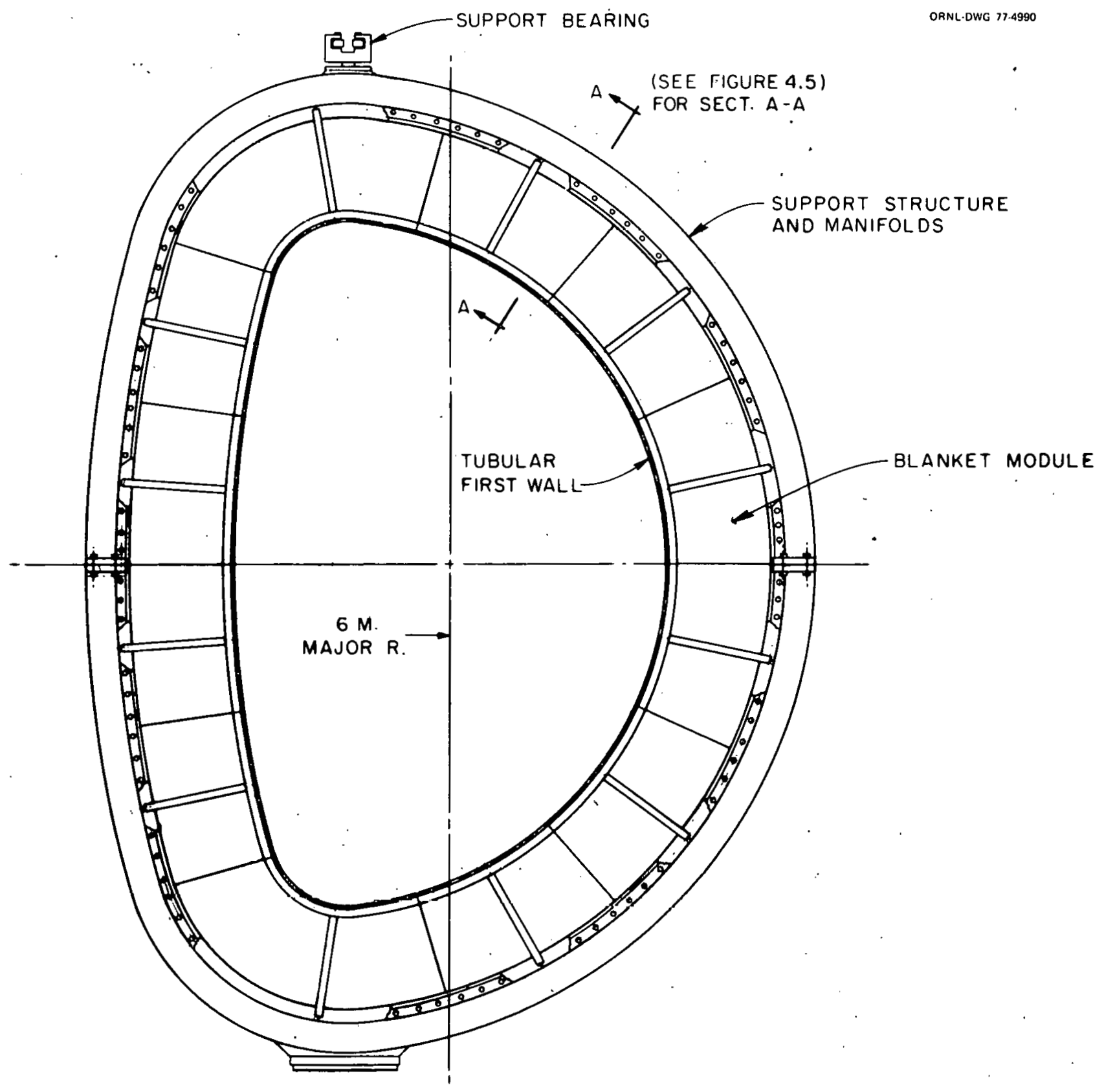

Fig. 4.4. Blanket module assembly-contour concepl. 


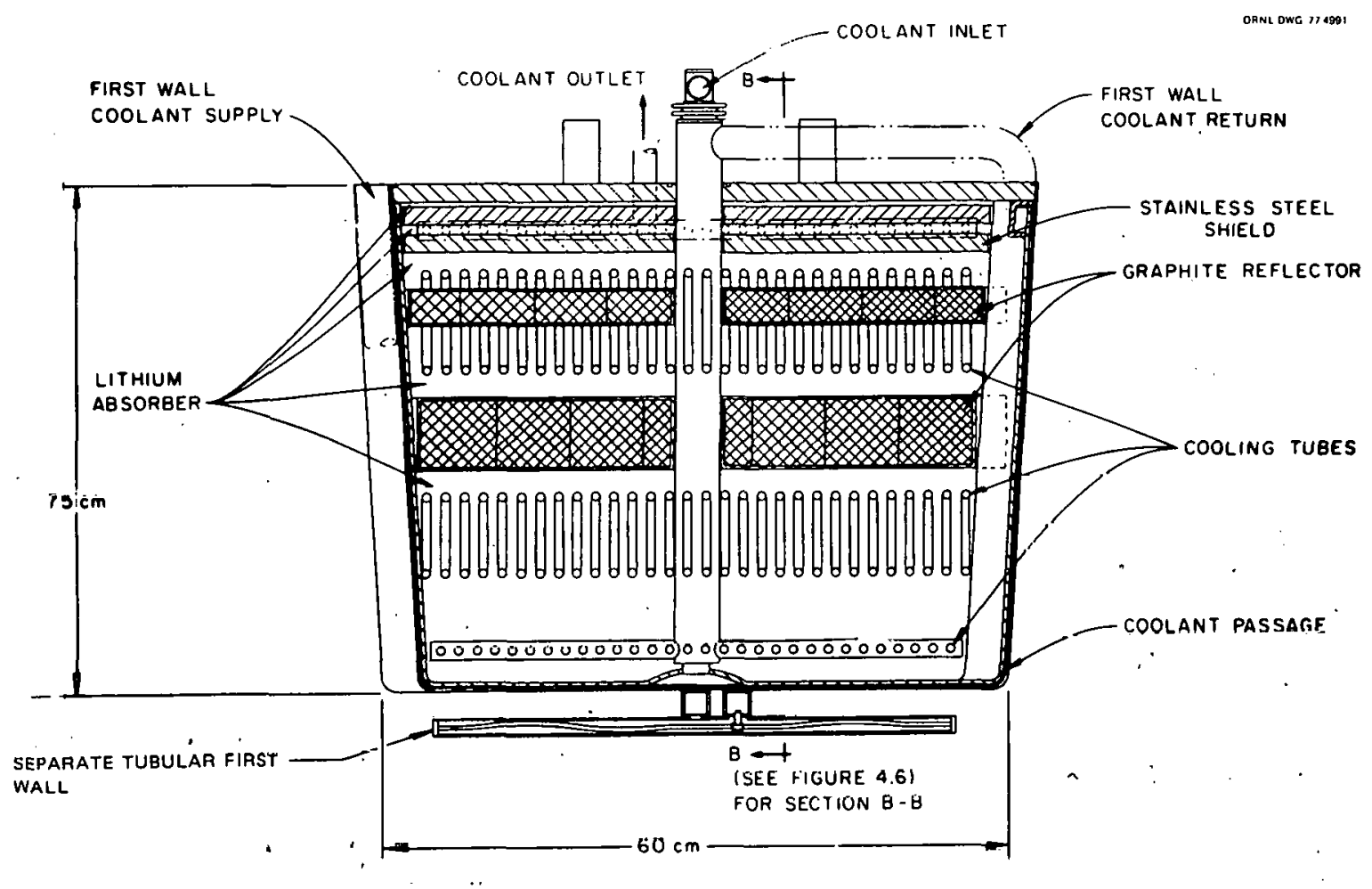

Fig. 4.5. Blanket module section $A-A$ contour concept.

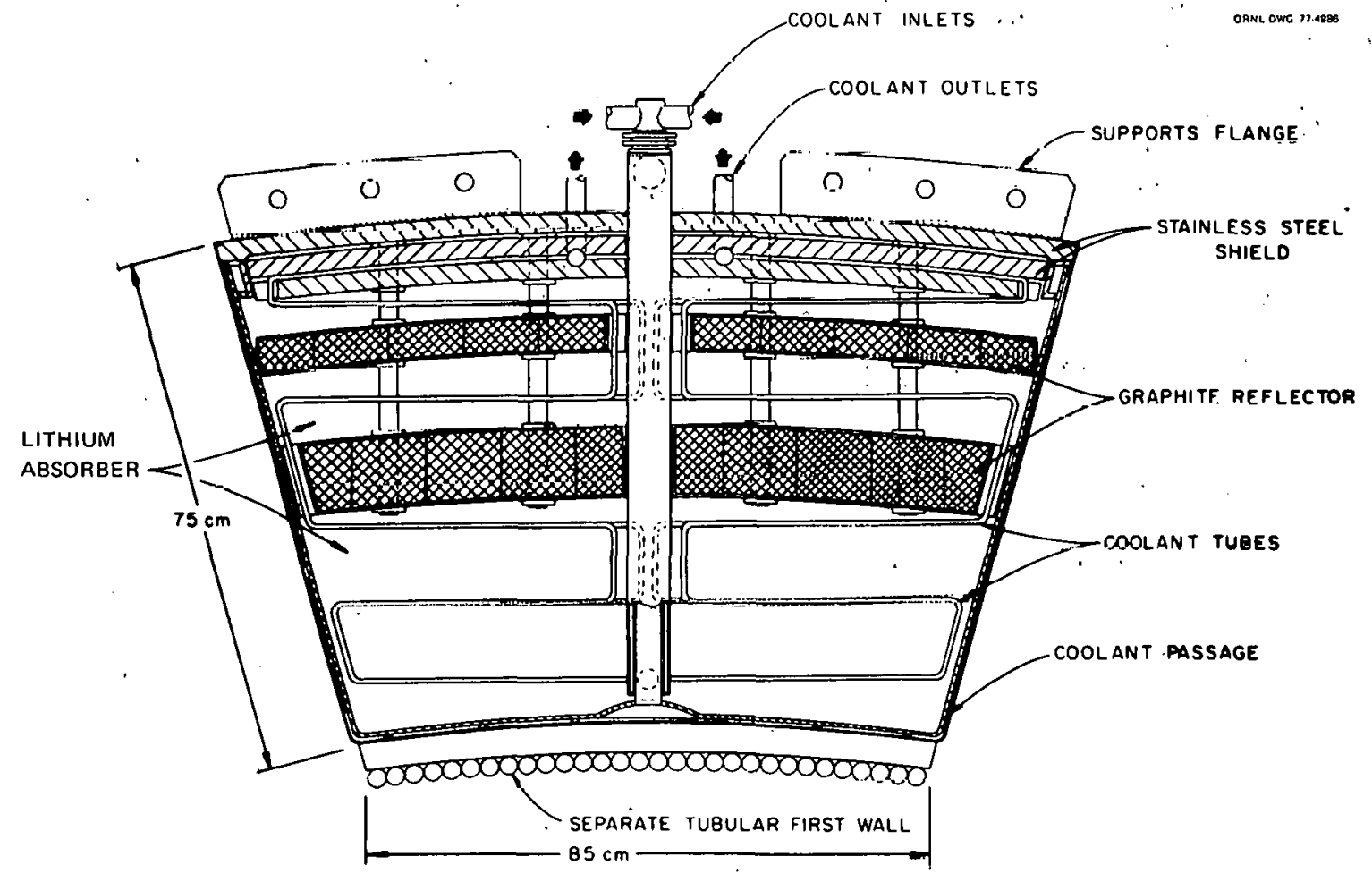

Fig. 4.6. Blanket module section B-B contour concept. 


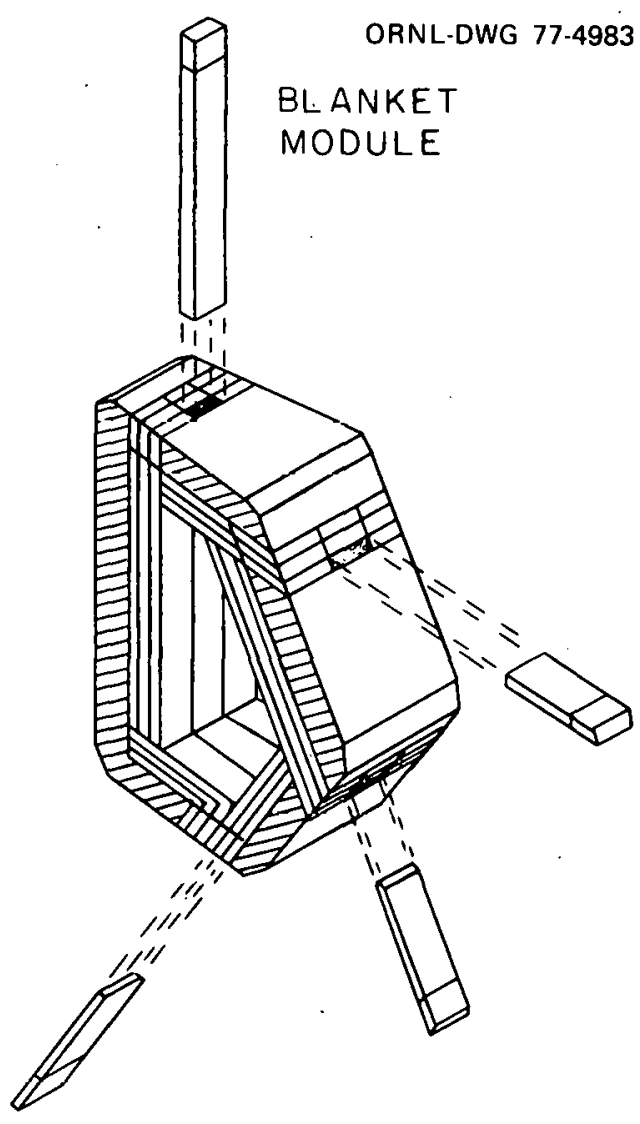

BLANKET SEGMENT

Fig. 4.7. Cassette blanket option.

portion of the cycle. The magnitude of the surface heat flux $\left(1 \mathrm{MW} / \mathrm{m}^{2}\right)$ in conjunction with the approximate number of full power cycles $\left(3 \times 10^{5}\right)$ and the structural material damage due to neutron irradiation may present unprecedented design challenges in comparison to comparable power plant structures such as heat exchangers.

This preliminary assessment was guided by the ASME Boiler and Pressure Vessel Code, Scction III, Nuclear Power Plant Components Subsections $N A, N B$, and $N G,{ }^{2}$ and is referred to in the following discussion as Section III, or, simply, the Code. The use of this Code is not related to its legal standing, but rests on the fact that it is a proven, highly reliable set of procedures to ensure safe design of metal components subjected to steady, varying, and/or alternating stresses. For this conceptual design, the intent was to limit the temperature of the first wall to about $400^{\circ} \mathrm{C}$ in order to minimize radiation-induced loss of ductility. The design rules and limits for austenitic stainless steels contained in the Code are applicable up to $427^{\circ} \mathrm{C}$ and should provide reasonable guidelines for this preliminary assessment. Where design to higher temperatures is required, Section III is supplemented by ASME Code Case 1592, ${ }^{3}$ RDT Standard F9-4T, ${ }^{4}$ and RDT Standard F9-5T, ${ }^{5}$ which provide design rules, allowable limits, and analys is guidelines for austenitic stainless steels for operation above $427^{\circ} \mathrm{C}$. These rules will, if appropriate, be used for portions of the blanket structure other than the first wall.

The Code and the above supplements do not contain specific provisions for environmental effects such as irradiation. The designer is thus not provided definitive design rules for those cases where irradiation damage and other environmental effects are significant. Available data ${ }^{6,7}$ do indicate that irradiation causes a decrease in ductility and fatigue life. Additionally, cold-working to achieve enhanced mechanical properties is not presently considered by the code to be a valid treatment because the resultant enhanced strengths may be lost by service exposure. Thus, for this preliminary assessment, irradiation effects have not been considered; the allowable limits contained in the Code, which are based on properties of annealed material, were used to evaluate these conceptual designs.

The conduction heat transfer of the heat load on the first wall results in a cyclic thermal stress with each burn pulse. For a first wall design composed of thin-walled tubes supported by a backing plate, the calculated thermal stress has two major components. The temperature drop through the wall thickness and the 


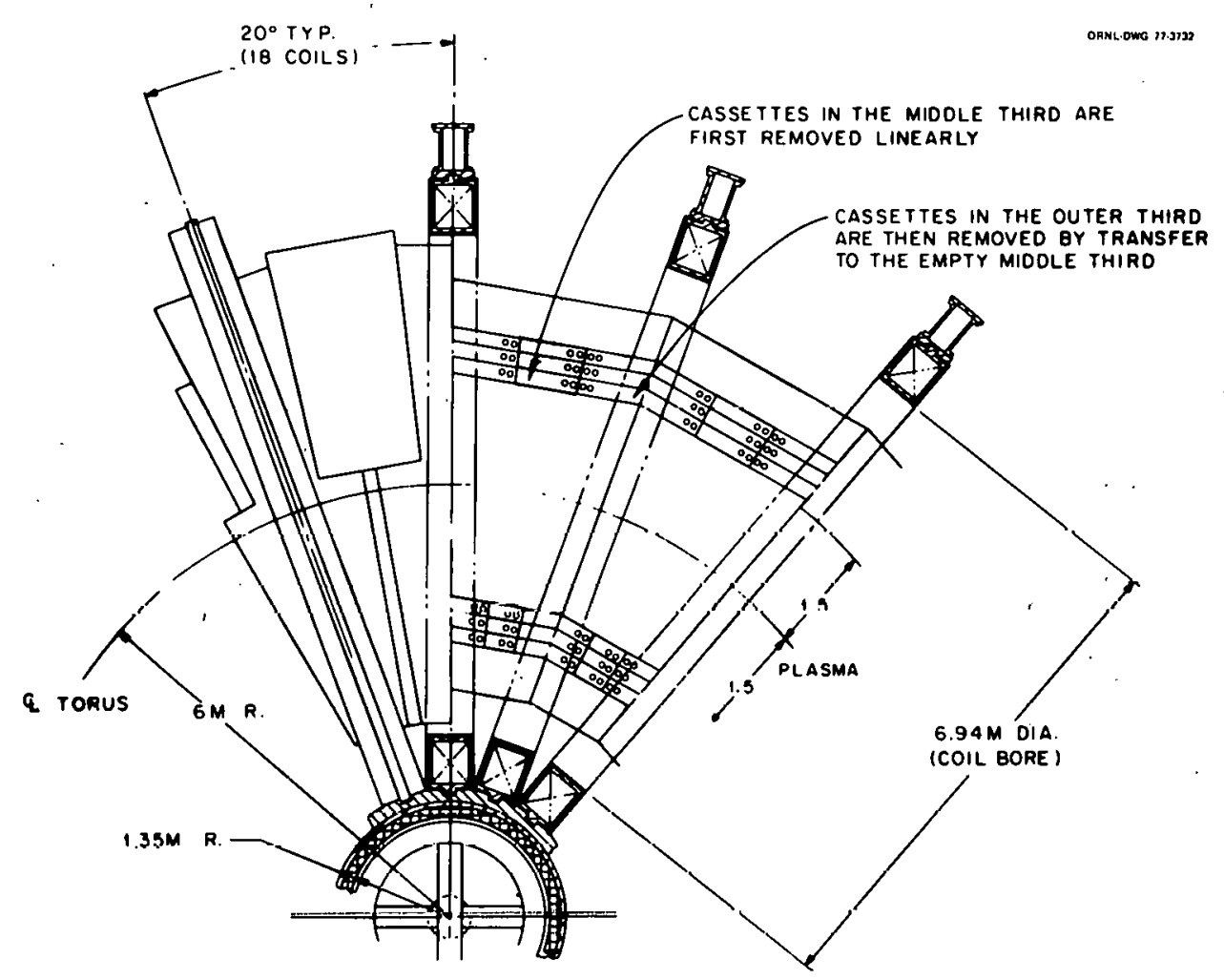

Fig. 4.8. Tokamak plan view cassette blanket.

temperature drop across the tube diameter combine to cause a maximum compressive stress at the first wall surface. The dominant stress is caused by the temperature drop across the tube diameter and is determined by the degree of restraint given to the ends of the heated wall. Because the tubes normally run between two larger manifolds, freedom from restraint may be difficult to achieve. However, two new concepts proposed later in this section may possibly reduce the probiem of temperature drop across the tube diameter and thus enhance the first wall design margin.

Based on the assumptions and simplifications used, it was found that the magnitude of the stresses in the first wall was below the Code allowables, although the margin was not large. The analysis for cyclic operation also indicated that the design is acceptable. However, the presence of a neutron flux will prob- abiy reduce fatigue life. While the magnitude of this reduction can only be estimated, it is probable that some or all of the margin on fatigue will be lost and that fatigue will be one of the most important mechanisms in setting the first wall life.

The above discussion points out the need for an effort directed at developing and verifying structural design criteria for application to fusion reactors. The essential features of a scoping study aimed at providing load definitions and required avenues for criteria development have been delineated. ${ }^{8}$ Comparable studies have been undertaken to develop design criteria and analysis methods for fission reactors. 9,10 These efforts could be a valuable source of preliminary design criteria or guidelines for development of design criteria and analysis methods applicable to fusion reactors. 


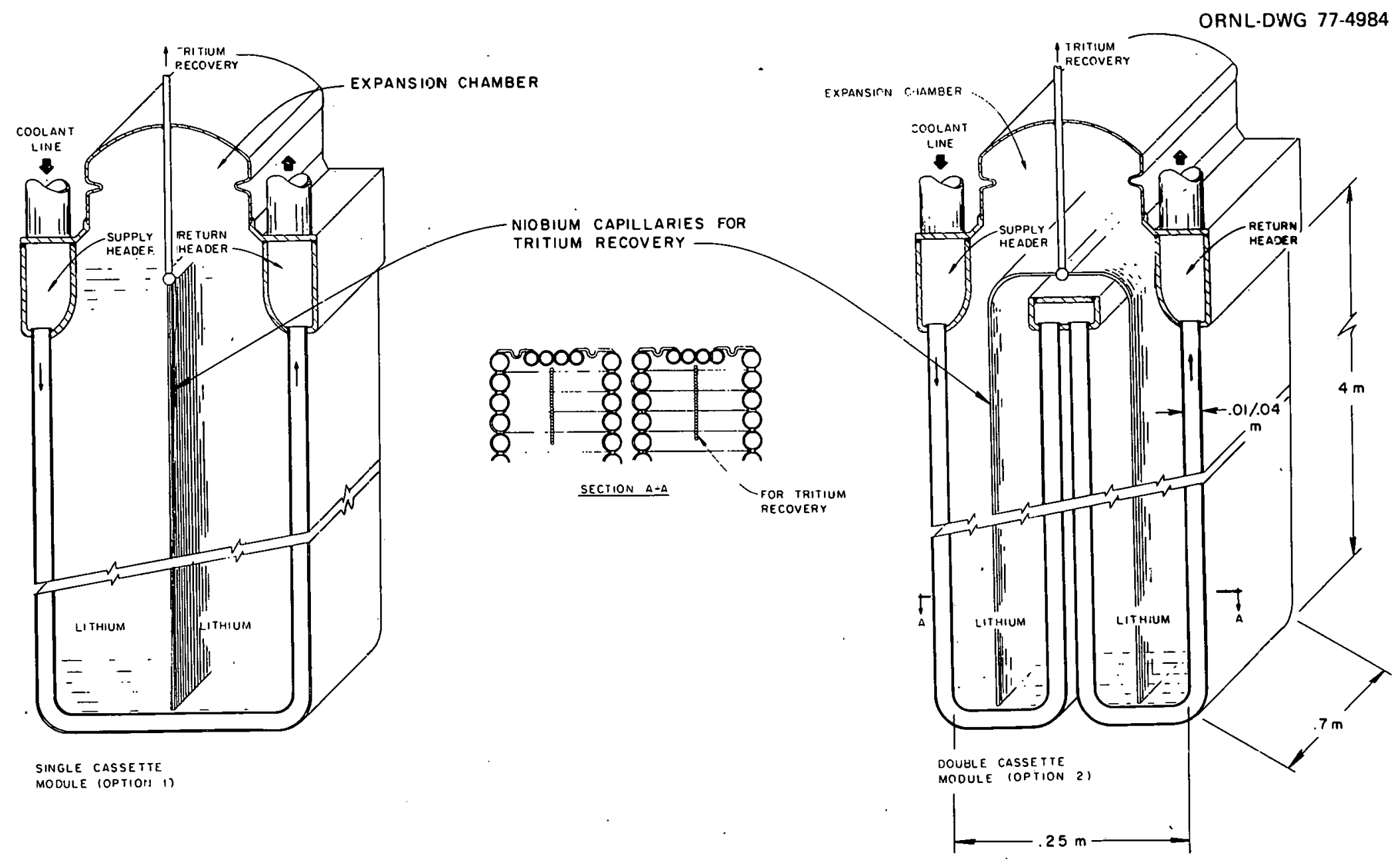

Fig. 4.9. Cassette blanket cross section. 
2. Section 111, Rules for Construction of Nuclear Power Plant Components, ASME Boiler and Pressure Vessel Code. The American Society of Mechanical Engineers, New York, 1974.

3. "Case 1592-7, Class 1 Components in Elevated Temperature Service," in Interpretations of ASME Boiler and Pressure vessel Code. The American Society of Mechanical Engineers, New York, December 22, 1975.

4. Requirements for Design of Nuclear System Components at Elevated Temperatures, RDT F9$4 T$, ERDA, Division of Reactor Development and Demonstration (January 1974).

5. Guidelines and Procedwres for Design of Nuclear System Components at Elevated Temperatures, RDT F9-5T, ERDA, Division of Reactor Development and Demonstration (March 1974).

6. J. M. Beeston and C. R. Brinkman, "Axial Fatigue of Irradiated Stainless Steels Tested at Elevated Temperatures," in Irradiation Effects on Structural Alloys for Nuclear Reactor Applications. American Society for Testing and Materials, Philadelphia, Pennsylvania, 1970.

7. L. D. Blackburn, Low Cycle Fatigue of Irradiated LMFBR Materials, HEDL-TME $\overline{7} \overline{6}-1 \overline{5}$, Hanford Engineering Development Laboratory, Hanford, California (January 1976).

8. Thermonuclear Division, Oak Ridge National Laboratory, Oak Ridge, Tennessee and Mechanics Research, Inc., Oak Ridge, Tennessee, "Working Paper on the Development of Tokamak Structural Design Criteria," prepared for Electric Power Research Institute, Palo Alto, California (March 16, 1976).

9. W. J. McAfee and T. W. Pickel, Pr.pliminary Elevated-Temperature Core Structures Design Criteria, ORNL/TM-4932, Oak Ridge National Laboratory, Oak Ridge, Tennessee (March 1976).

10. Fast Breeder Reactor Department, RDT Design Guideline/Criteria for LMFBR Components, Vol. 1 (draft), General
Electric Company, Sunnyvale, California (June 1976).

\subsection{NEW BLANKET DESIGN CONCEPTS}

Several new ideas have been proposed by the design team and are presented here as preliminary ideas with 7 imited design analysis. These concepts will be evaluated in some detail during the remainder of this year's study.

\subsubsection{The FBZ Approach}

In the first blanket zone (FBZ) design approach, we take advantage of the fact that radiation damage decreases as a function of depth into the blanket. For the reference design, a spatial distribution of damage characterized by atomic displacement rate and helium generation rate is illustrated in Fig. 4.10. It may be observed from this figure that in a distance of about $25 \mathrm{~cm}$, the atomic displacement rate has decreased by a factor of five and the helium generation rate has decreased by a factor of seven. We define this region, which represents volumetrically about $20 \%$ of the total blanket, as the first blanket zone. The FBZ is that part of the blanket which can be changed routinely when radiation effects dictate or when surface effects such as sputtering erosion require it. All other things being equal, the second blanket zone, i.e., the $80 \%$ remainder of the blanket, would last 5-10 times longer. This zoning approach to blanket maintenance is markedly superinr to the more common differentiation of having a main blanket and a separable first wall. There is little to be gaincd by changing a thin first wall and leaving behind other material that also has significant damage.

The coolant circuit for the FBZ of Fig. 4.11 may be one which is completely independent of the remainder of the blanket, or the outlet duct may feed to the second blanket zone. Piping connections in either case would be outboard of the shield. 


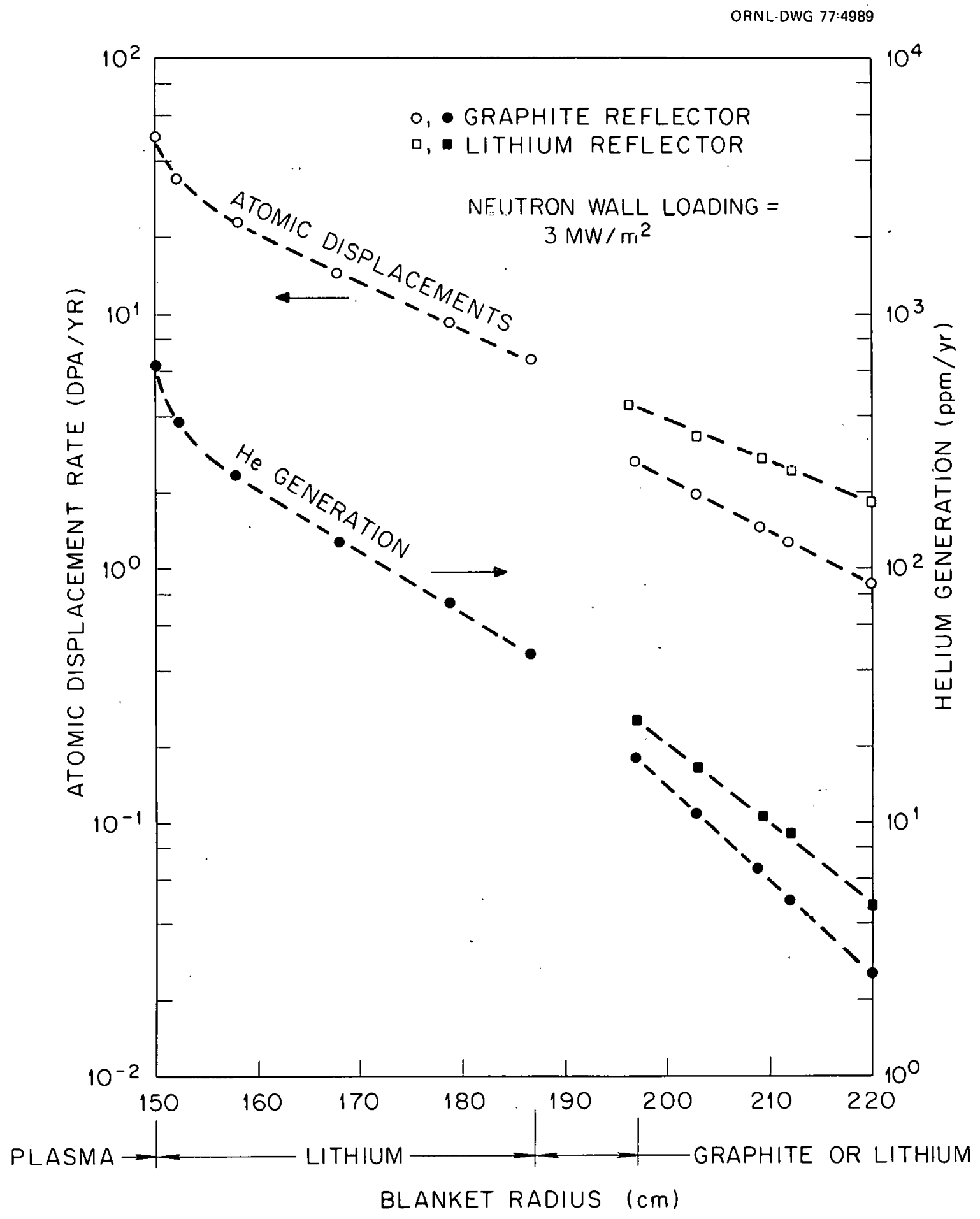

Fig. 4.10. Radiation damage vs blanket thickness. (Calculations and figure provided by R. T. Santoro.) 


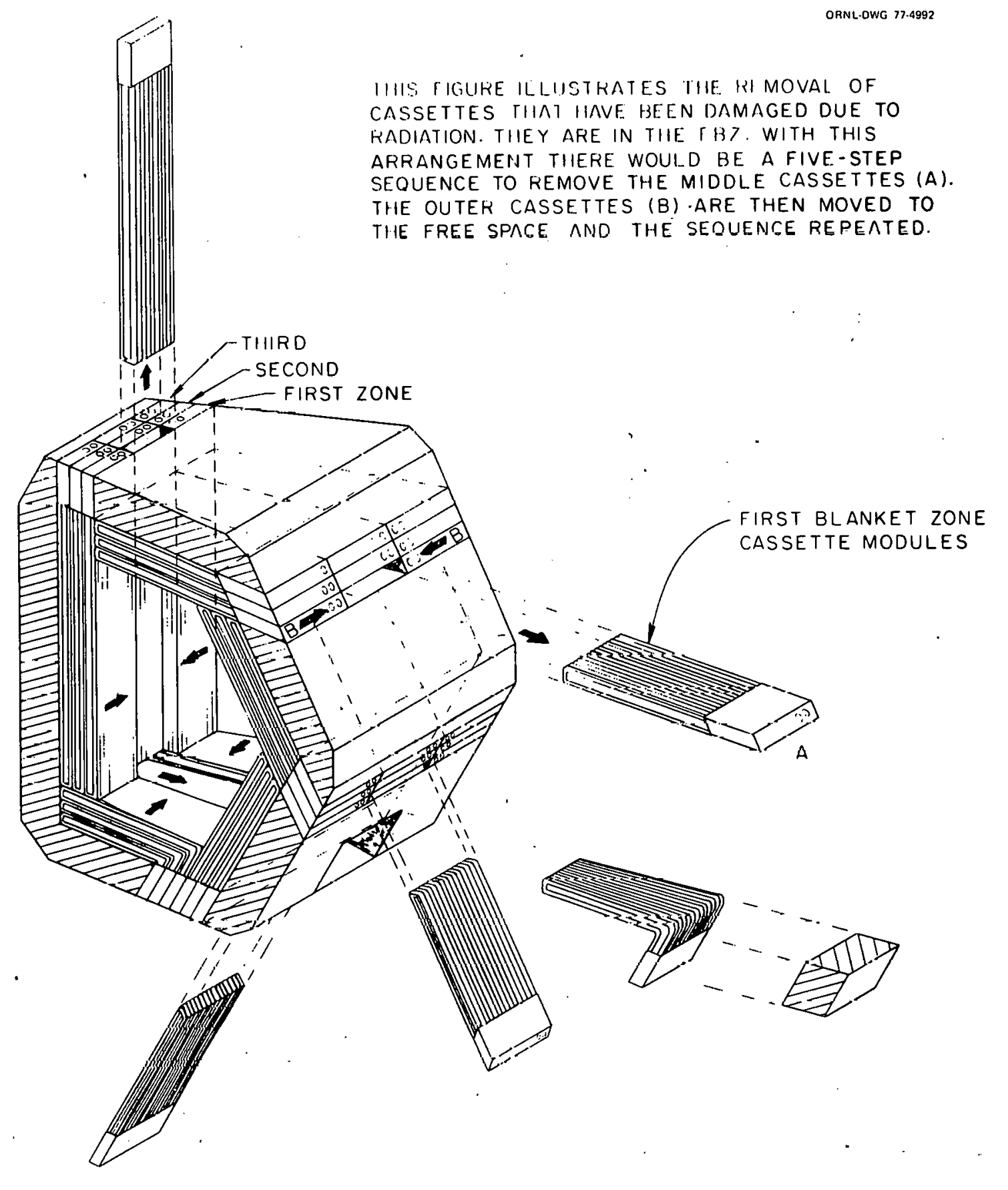

Fig. 4.11. The FBZ approach. 


\subsubsection{The Balanced Energy Input}

As discussed in the section on stress analysis, the heat load on a tubular first wall results in two components of thermal stress: one caused by $\Delta T$ through the wall thickness, another by $\Delta T$ across the tube diameter. The balanced energy input concept attempts to reduce the second component by balancing the heat flux on the first wall by heating the tube on the back face. The energy source is the neutronic heating of the lithium (see Fig. 4.12).

ORNL-DWG 77.4988

$\dot{q}_{a}=$ FIRST WALL a HEAT FLUX

$\dot{q}_{n}=$ HEAT FLUX FROM NEUTRON HEATING ${ }^{\circ} F$ L.ITHIUM

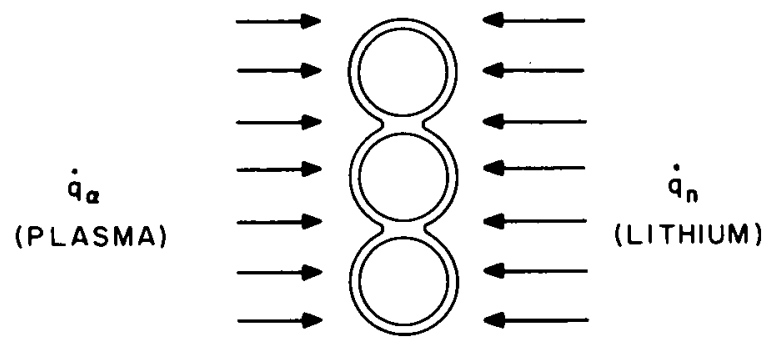

Fig. 4.12. First wall balanced energy input.

The equating of $q_{a}$ and $q_{n}$ will establish the required lithium thickness. Preliminary calculations indicate that $3-6 \mathrm{~cm}$ of lithium are required to balance the heat load for the reference wall loading of 2-4 MW/ $\mathrm{m}^{2}$. For steady-state operation, it is clearly advantageous to heat the tube uniformly from both sides; however, the transient conditions require further analysis.

\subsubsection{Modified Tube Wall Concepts}

Another possible approach to minimizing the thermal stresses due to the $\Delta T$ across the tube diameter is to locate the supply and return manifolds adjacent to each other and have the ducts forming the first wall follow an out and return path. Both legs of the duct will tend to bend in the same direction and nominally provide no restraint on each other.

Such an arrangement can be realized as a nested array of $\mathrm{U}$-like tubes or an array of coil-spring-like tubes. These are shown conceptualily in Figs. 4.13 and 4.14 .

\subsubsection{Internal Tritium Recovery}

The lithium volume contained within the Ushaped envelope of the cassette module has in it an independent wall that serves a dual role: (a) it acts as an adiabatic, energy-isolating surface between the coolant tube facing the plasma and the other half of the tube facing the secondary blanket zone, and (b) it is a means of tritium recovery. The barrier wall is made up of capillary tubes of niobium. Tritium is recovered by diffusion in the lithium and permeation through the niobium. The location of the barrier wall (see Fig. 4.9) is determined by heat transfer considerations, by the desired flux attenuation, and by the diffusion of tritium in lithium that may have zero fluid circulation due to magnetic field effects. A concept to incorporate this idea in the contour module will be developed if preiminary diffusion calculations show it to be viable.

\subsection{UNRESOLVED PROBLEM AREAS}

Several problem areas remain in the blanket system and will be studied during the remainder of this fiscal year. The major problems are described below.

\subsubsection{Start-Up}

Due to the relatively high melting point of the molten salt, $\sim 150^{\circ} \mathrm{C}$, some method will be required to preheat the blanket. Options under consideration include:

1) initial mixing of the salt with water 

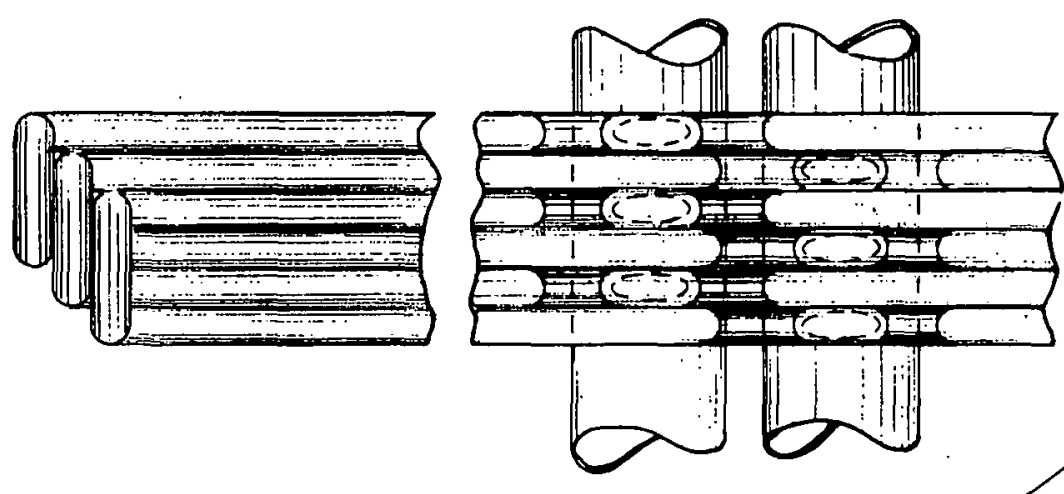

ORNL-DWG $\mathbf{7 7 - 3 7 3 0}$
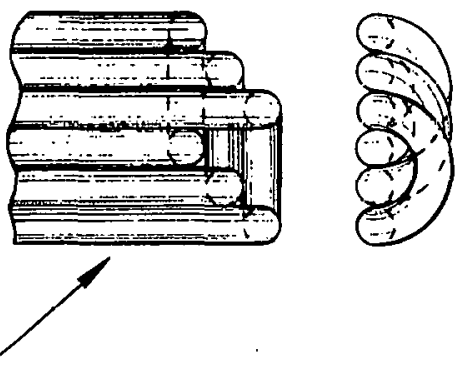

THIIS END DETAIL WILL MESH WITH A SIMILAR

DETAIL FROM RIGHT HAND SIDE WHICH WOULD

HAVE U'S UPWARD INETEAD OF DOWNWARD
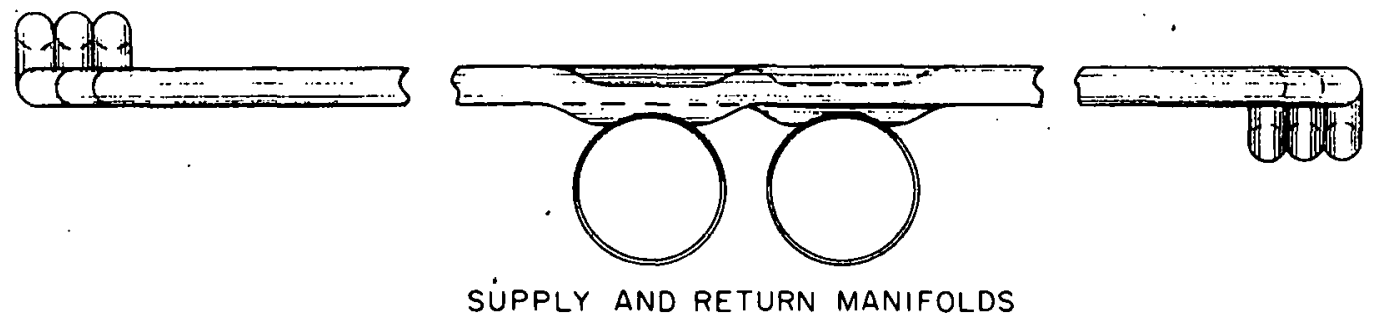

Fig. 4.13. Concept of modified U-tube first wall.
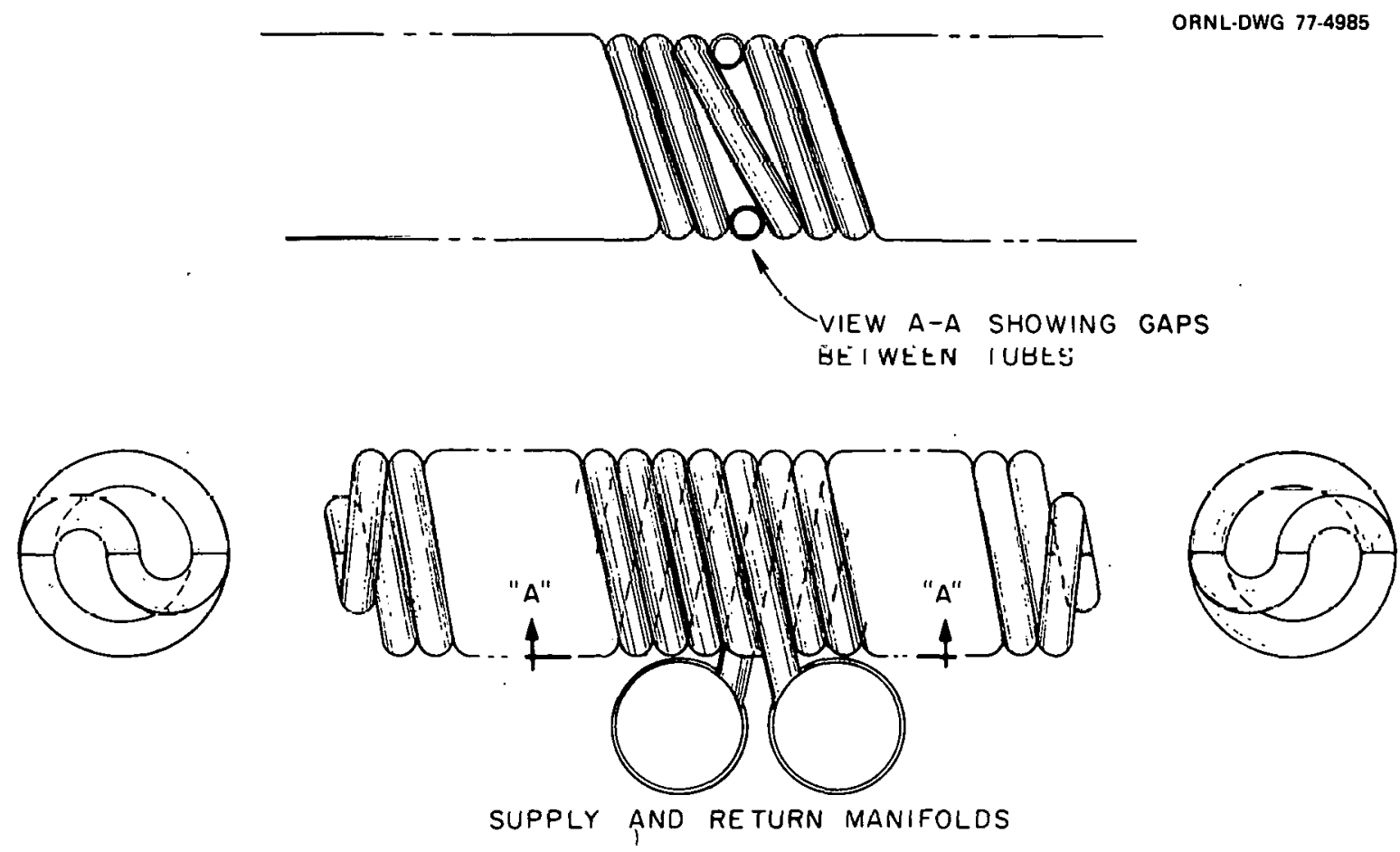

Fig. 4.14. Concept of coil-spring-like first wall. 
which would be removed after the preheat. This approach is in use in commercial application for both start-up and shutdown;

2) drain the molten lithium from the blanket upon shutdown and recharge it at a sufficiently high temperature to melt the solidified salt;

3) drain the salt circuit and reheat by circulating a mixture of sodium and potassium (NaK) through the salt circuit. The Nak can be removed by vacuum boil-off:

4) the same approach as option 3, except that hot gas, inert if necessary, would be used to accomplish heat-up; and,

5) use of electrical resistance heating either to supply heat radiantly or by contact with the blanket.

\subsubsection{First Wall Structural Design}

The life of the first wall in the region of high neutron flux will be determined largely by the acceptable limit for loss in material ductility. Based on present understanding of materials behavior, normal loading conditions, and design criteria, fabricated stainless steel should have sufficient ductility to accommodate the strains during initial start-up of the reactor, i.e., when structural components normally experience the most severe imposed loads. Under continued cyclic operation, as the material ductility decreases with increasing fluence, the structure will tend to shake down into a stable load deformation configuration that will limit accumulation of additional inelastic strain. The assumptions and simplifications used above in assessing first wall behavior must be further investigated. Also, acceptable design criteria must be developed and, ultimately, verified for this unique design case.

\subsubsection{Remote Maintenance}

Although the vacuum building approach (see Sect. 8) is expected to improve the remote maintenance problem, an in-depth analysis of this overall problem is still required. Equipment requirements and detailed design solutions are necessary to help guide and implement a much needed technology program.

\subsubsection{Internal PF Coils}

The internal poloidal field (PF) coils required for plasma shaping and control are an integral part of the blanket system. The problem here is in the design of a joint both for replacement of the coils and for access into the plasma chamber. A high voltage power source, which further complicates the coils by requiring many turns per current location, is desirable. There is presently no acceptable solution for this problem.

\subsubsection{Tritium Removal}

A potential problem resulting from MHD effects on the lithium has been identified. Portions of the lithium may be sufficiently immobilized to prohibit adequate removal of the tritium. Detailed calculations are under way to evaluate possible stagnant lithium regions and the extent to which motion is suppressed. The diffusion rate of tritium through the nonfolowing regions will also be evaluated.

\subsection{CONCLUSIONS}

We conclude that the basic design approàch for the power demonstration study in general is feasible for the blanket system and results in practical engineering concepts which are primarily applications of existing technology. However, as indicated throughout this section, the blanket concepts are in an early stage of development and represent only preliminary designs at this time. For the remainder of this fiscd year, we will perform additional in-depth analysis and layout design to ascertain the feasibility of the basic design concepts.

A summary of our specific conclusions from 
the blanket study to date follows.

1. A blanket heat exchanger using a low pressure salt coolant having satisfactory thermal/hydraulic performance which matches a conventional steam generator can be provided.

2. An acceptable breeding ratio for tritium can be obtained in a blanket thickness of $1 / 2-1 \mathrm{~m}$. Our first concept included a layer of graphite to reduce the thickness of lithium required. More recent neutronic calculations, however, show that the graphite provides only a slight improvement. Considering possible compatibility problems with graphite and some coolants such as salt, we eliminated the graphite.

3. A blanket first wall with reasonably long life under high thermal wall loading using conventional materials can be designed. Conservative limits on temperature and hydraulic loading are selected to reduce the impact of radiation damage.

4. The ASME Structural Design Code is reasonable as a starting point to assess the reliability of the structural design. Radiation damage occurs as a gradual loss in ductility and as such does not have as severe an impact on the design as a material with initial low ductility.

5. New design concepts such as the cassette module and FBZ approach (when coupled with a vacuum building) appear to be viable concepts for improved mechanical design for remote maintenance requirements. 


\section{BLANKET STRUCTURE}

J. L. Scott

\subsection{INTRODUCTION}

The structural material of the blanket is an important factor to consider in establishing the technical and economic feasibility of the tokamak concept for power generation. To demonstrate technical feasibility, one must establish that he can build and inspect the structure and ensure reliability. He must also have data indicating satisfactory performance (under service conditions) of temperature, stress, chemical environment, and flux and fluence of neutrons with the proper energy spectrum. One's ability to get the required data in time to have favorable impact on the design must be an important consideration. In considering economic feasibility, one must take into account the costs of fabricating and inspecting the blanket modules and weigh these costs against the lifetime of the particular structure. In addition, one must consider the costs for alloy development, radiation testing, and establishment of the required data base. Beyond this, one must be aware of the costs involved in creating new industrial capability for new materials and fabrication processes.

Keeping the above factors in mind, the following considerations were emphasized in the selection of the structural material:

1) demonstration of commercial feasibility in this century,

2) safe and reliable operation at minimum capital costs,

3) economically attractive thermodynamic efficiency (in the range of conventional light water reactors),

4) ability to develop a full data base, including end-of-life properties, in a time period consistent with each phase of commercialization, and

5) minimization of the number of new classes of materials, fabrication and joining processes, and industries.
The time period available for developing the engineering data base for design is set by the timing of three phases beyond the Tokamak Fusion Test Reactor (TFTR): (1) the ignition demonstration phase, (2) the power technology demonstration phase, and (3) the commercial prototype demonstration phase. The material choice for each phase must be made several years before the operating date. For the initial ignition phase, development time is limited; therefore, emphasis must be placed on existing commercial materials or improved versions of them. At the same time, the required lifetime and data base are less stringent for the initial ignition phase than for the commercial prototype demonstration phase. For the latter, there is more time for development and thus the choice of material may change. To minimize the number of new technologies required for demonstration, it would be highly desirable that the structural material for all three phases be based on the same class of materials. However, if results of the development program indicate that a new class of materials is required, then sufficient flexibility should exist in the program to allow the change to be made. For each phase, low cost and high reliability are obvious requirements.

The requirement that the full data base, including end-of-life properties, be available in a time period consistent with commercial demonstration in this century is especially difficult to satisfy. Fission reactor irradiations can provide much of the data base for iron- and nickel-base alloys, and these facilities are available now. If refractory metals are chosen as the structural material, a test facility with large volume, high flux, and high neutron energy will be required. The first such facility, the D-Li source, would have only a liter of test space. ${ }^{1,2}$ This is adequate for scoping studies, but grossly inadequate for providing the data 
base required for detailed design. Several D-Li sources or a magnetic fusion test facility would have to be built and utilized in order to test refractory metals. One D-Li source would be sufficient to verify the fission reactor results for iron- and nickel-based alloys so the development costs are much lower for these materials.

In selecting the structural material for each phase of the commercial feasibility demonstration, a number of additional factors must be considered. The economics analys is (Sect. 2) suggests that capital costs approach an optimum for neutron wall loadings in the range of 2-4 MW/m². Secondly, the required operating life increases with each successive demonstration phase. For commercial power operation, periodic replacement of the first wall is perceived as a difficult and costly process because it must be done remotely. Preliminary analysis suggests that plant availability is not seriously impacted for wall lifetimes of five years or greater. Thus, a desirable integral wall loading - which may be defined as the product of the neutron wall loading, the power factor, and the years of operation before replacement - is at least $10 \mathrm{MW} \mathrm{yr} / \mathrm{m}^{2}$ and hopefully hiyhlier.

The lifetime requirements, which vary with each demonstration phase will be limited by radiation damage. The primary effects of radiation are swelling and loss of ductility. As the lifetime increases, the atomic displacements and the helium and hydrogen contents increase, as indicated in Table 5.1 for type 316 stainless steel and $\mathrm{Nb}-1 \% \mathrm{Zr}$, which are typical of the two major classes of conventional and high temperature materials being considered. In addition to atomic displacements and gas content, the lifetime will be a strong function of metallurgical structure, operating temperature, and stress levels. At present, there are insufficient data to specify the integral wall loading of any material, but a desirable range would be $10-20 \mathrm{MW}-\mathrm{yr} / \mathrm{m}^{2}$.
In addition to radiation stability, the structural material must satisfy other requirements. One is fabricability. The size of the system will dictate that at least some of the assembly operations will have to be done in the field. Field assembly would be difficult for refractory metal systems because an inert atmosphere is required for welding. Smaller subsystems could be fabricated in glove boxes, but coolant piping and vacuum seal welds would be most easily done in air. The structure must. also be compatible with the coolant and with some form of lithium as a tritium-breeding material. Finally, the high power density will result in high heat fluxes, so the material must be capable of withstanding the resulting thermal stresses.

1. P. Grand (ed.), Proposal for an AcceleratorBased Neutron Generator, BNL 20159, Brookhaven National Laboratory, Upton, Long Island, New York (July 1975).

2. M. J. Saltmarsh and R. E. Worsham (eds.), INGRID: A Proposal for an Intense Neutron Generator for Radiation-Induced Damage Studies in the CTR Materials Program, (IRNI /TM-5733, Oak Ridge National Laboratory, Oak Ridge, Tennessee (January 1976).

\subsection{CANDIDATE STRUCTURAL MATERIALS}

A number of candidate structural materials were considered for the commercial fusion power application. These included:

1) austenitic stainless steels,

2) Ni-base alloys,

3) $\mathrm{Nb}-1 \% \mathrm{Zr}$,

4) $V$ alloys

5) Mo alloys, and

6) Al alloys.

\subsubsection{Austenitic Stainléss Steels}

In comparison with the other materials on the list, austenitic stainless steels have so many advantages that this class of materials 
Table 5.1. Atomic displacements and gas contents of structural materials at goal lifetimes of commercialization phases

\begin{tabular}{|c|c|c|c|c|c|}
\hline Material & Phase & $\begin{array}{l}\text { Goal lifetime } \\
\left(\mathrm{MW}-\mathrm{yr} / \mathrm{m}^{2}\right)^{a}\end{array}$ & $\mathrm{dpa}^{b}$ & $\mathrm{He}(\mathrm{appm})^{\mathrm{C}}$ & $H($ a ppm $)$ \\
\hline Type 316 stainless steel & Ignition & 2.5 & 27 & 320 & 1060 \\
\hline $\mathrm{Nb}-1 \% \mathrm{Zr}$ & Ignition & 2.5 & 18 & 73 & 260 \\
\hline Type 316 stainless steel & Power Demo and commercial & $10-40$ & $115-460$ & $1440-5750$ & $5330-21,300$ \\
\hline $\mathrm{Nb}-1 \% \mathrm{Zr}$ & Power Demo and commercial & $10-40$ & $73-290$ & $290-1160$ & $1050-4200$ \\
\hline
\end{tabular}

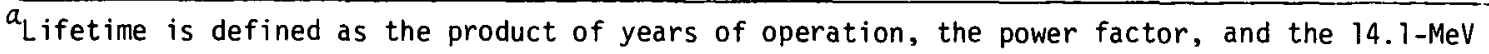
neutron wall loading.

bisplacements per atom.

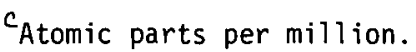

should be seriously considered unless some compelling reason exists to reject it. Several commercial alloys are readily available, and some have a history of use and testing under conditions that partly simulate those in a fusion reactor. Techniques for fabrication and welding stainless steels are well developed, and an unirradiated data base for design exists. Broad commercial experience with stainless steels provides a high degree of confidence in our ability to achieve a reliable device through their use - ignoring, for the moment, irradiation effects.

A significant advantage of a stainless steel as a structural material is the ability to simulate fusion reactor irradiation effects in a mixed-spectrum fission reactor. This unique value of fission reactors arises from the combination of displacement damage produced by fast neutrons and helium produced by a two-step thermal neutron reaction: ${ }^{3}$

$$
\begin{aligned}
& { }^{58} \mathrm{Ni}+n+{ }^{59} \mathrm{Ni}+\gamma, \\
& 59 \mathrm{Ni}+n \rightarrow{ }^{56} \mathrm{Fe}+\alpha .
\end{aligned}
$$

This approach recognizes that fusion reactor radiation effects at high fluence are best approximated by matching the amnunt of both helium production and displacement damage.
Results on type 316 stainless steel irradiated under these conditions are discussed in more detail in Sect. 5.3.

The major drawbacks to the use of austenitic stainless steels are a question of longterm chromium availability, relatively luw thermal conductivity, problems of waste disposal as a result of neutron activation, and a comparatively low upper operating temperature limit of $400-500^{\circ} \mathrm{C}$. The operating temperature limit can probably be increased by an alloy development program. Resource availability and waste disposal are problems which apply to nearly all the candidates and must be faced in the future. With proper design, many of these disadvantages can be accommodated.

It is unlikely that any presently available commercial austenitic stainless steel alloy is the optimum choice for commercial fusion power. Limited irradiation data obtained in mixed-spectrum fission reactors suggest that type 316 stainless steel may have adequate properties for the ignition phase. ${ }^{3}$ Information on its properties under irradiation is more extensive than for other alloys because it is the reference cladding material for the Liquid-Metal Fast Breeder Reactor (LMFBR). At the same time, preliminary data on experimental austenitic alloys indicate the 
potential for markedly improved irradiation resistance. Specifically, titanium additions ( 20.25 wt \%) to type 316 stainless steel result in improved postirradiation ductility and creep iife at $550^{\circ} \mathrm{C} .{ }^{4}$

It must be emphasized that the amount of testing thus far of austenitic stainless steels in a simulated fusion environment is extremely limited. In addition, our fundamental understanding of damage processes is 1 imited to that caused by atomic displacements in the lattice. The ettects of helium per se or synergistic effects of helium on displacement damage are not yet well understood. We believe that basic work leading to an understanding of processes and mechanisms together with empirical tests that generate engineering data will result in an alloy with properties superior to those of type 316 stainless steel.

Even though the optimum austenitic stainless steel may have a different composition from present commercial alloys, it should be recognized that the vast experience with commercial alloys will simplify the commercialization of the new ones. Important problems such as impurities in raw materials, melting practices, forming processes, inspection techniques, and joining w111 be easier to deal with for austenitic stainless steels and nickel-base alloys than for refractory metals.

3. E. E. BToom, F.W. Wiffen, P. J. Maziasz, and J. 0. Sticgler, Nucl. Technol. 31 (1), 115-122 (October 1976).

4. J. L. Scott (compiler), Magnetic Fusion Energy Materials Technology Proqram Annual Progress Report for Period Ending June 30 . 1976, ORNL-5189, pp. 5-8, 0ak Ridge National Laboratory, Oak Ridge, Tennessee (September 1976)

\subsubsection{N1ckel-Basé Al'ioys}

These ailloys have most of the advantages and disadvantages of stainless steels. Nickel alloy Inconel 718 has better fatigue resistance. than the austenitic stainless steels, and alloy PE 16 has demonstrated excellent resistance to radiation-induced swelling. Nickel is relatively soluble in lithium so that the maximum operating temperature for static capsules of nickel-base alloys and lithium is only 300$400^{\circ} \mathrm{C} .^{5}$ The use of an iron-base liner in cunjunction with a nickel-base structure was considered to be excessively expensive and difficult. Because nickel alloys are not compatible with lithium, they were not chosen as the primary structural material.

5. J. 0. Cowles and A. D. Pasternak, Lithium Properties Related to Use as a Nuclear Reactor Coolant, UCRL-50647, Lawrence Livermore Laboratory, Berkeley, California (Apri1 18, 1969).

\subsubsection{Niobium Alloys}

Niobium alloys were chosen for several early fusion reactor designs to exploit the high thermodynamic efficiency to be derived through thcir use (up to $1000^{\circ} \mathrm{C}$ ). ${ }^{6}$ This benefit is not unique to fusion devices and could be exploited by other central station power systems. Countering the potential advanlayes of high thermodynamic efficiency are the problems associated with the use of refractory metals - such as higher costs, higher reactivity with air, and greater difficulty in welding.

Although niobium alloys are commercially availahle, they are not available in the sizcs needed for commercial fusion power. A large expansion in the industrial capability would have to be effected. The associated investment would be difficult to justify without an assured market.

Last, but not least, the development of an irradiated data base for niobium alloys would be difficult to accomplish by the early 1990's. Even if one assumes that a D-Li source 
will be available in 1982-83, the test volume will be so limited that alloy optimization followed by the generation of the data base cannot be achieved.

In spite of their drawbacks, niobium alloys, especially $\mathrm{Nb}-1 \% \mathrm{Zr}$, have a much better thermal shock resistance than austenitic stainless steels. Some type of refractory metal should be carried as a backup to the austenitic stainless steels. It is also possible that a refractory metal may be required in fusion reactors for such special applications as limiters, neutral beam injector electrodes, or divertor targets.

6. A. P. Fraas, Comparative study of the More Promising Combinations of Blanket Materials, Power Conversion Systems, and Tritium Recovery and Containment Systems for Fusion Reactors, ORNL/TM-4999, Oak Ridge National Laboratory, Oak Ridge, Tennessee (November 1975).

\subsubsection{Vanadium Alloys}

Vanadium alloys were considered briefly as a cladding material for the LMFBR but were abandoned when it was found that they were not compatible with sodium of reactor purity. Lithium, unlike sodium, will extract oxygen from vanadium; thus the reasons for the rejection of vanadium alloys in the LMFBR do not apply. For fusion reactors, vanadium-base alloys are potentially attractive because of (1) reasonably good strength, useful to about $800^{\circ} \mathrm{C}$ in the absence of irradiation; (2) low activation rate compared with niobium alloys or stainless steels and thus greatly reduced problems with radioactive waste management; and (3) a demonstrated radiation resistance of vanadium-titanium alloys to displacementproduced swelling and embrittlement. ${ }^{7}$

lhe major drawback to valadium alloys is that at this point work on them is so limited that there are not enough data even for design of unirradiated structures. In addition, very little information can be found on fabrication methods or the sensitivity of properties to fabrication variables. At present, there is no commercial vanadium alloy; an industry would have to be created before this class of materials could be used. ${ }^{8}$ Thus, the selection of vanadium alloys as the primary structural material would be inconsistent with the guideline of minimizing the number of facilities and new technologies required for commercialization. At the same time, however, experimental work leading to their possible selection as backup materials to austenitic stainless steels should be continued on these materials.

7. J. Bentley and F. W. Wiffen, Nucl. Technol. 30(3), 376-384 (September 1976).

8. Refractory Metals Fabrication Technology as Applied to Fusion Reactors - A State-of-theart Assessment, Final Repont, BNWL-2053, Battelle-Northwest, Pacific Northwest Laboratory, Richland, Washington (May 15, 1975).

\subsubsection{Molybdenum Alloys}

Molybdenum alloys are attractive for fusion devices because of their excellent high temperature strength and good compatibility with helium coolant in comparison with most other refractory metals. These alloys also, however, have many serious disadvantages such as high costs, low ductility at room temperature, and lack of weldability. Because of these difficulties they were not identified as primary candidates for the structural material, although they may be used for certain components such as limiters and beam dumps.

\subsubsection{Aluminum Alloys}

Fusion reactors with relatively cold aluminum first. walls or high temperature sintered aluminum product (SAP) structures have 
been proposed, primarily because of the potential for low neutron activation blankets. 6,9 Because of the many problems associated with these approaches, such as low thermodynamic efficiency with aluminum alloys and inherent low ductility with SAP, these approaches have been rejected.

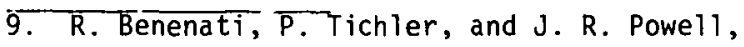
Trans. Am. Nucl. Soc. 23, 32-33 (1976).

\subsubsection{Summary of Candidate Alloy Comparisons}

Table 5.2 summarizes the relative advantages and liabilities of several candidate structural materials.

On the basis of this qualitative comparison, it is clear that austenitic stainless steels are the most promising choices for use in the ignition demonstration phase of commercial fusion power development. The choice of type 316 stainless steel as the reference structural material from this broader class rests on extensive experience with it in fission reactor applications and on its indicated potential of meeting the requirements. For subsequent phases, an austenitic stainless steel would be preferabie if the optimum alloy has acceptable properties. A refractory metal should be carried as a backup until high fluence irradiation data on austenitic steels have been obtained and evaluated.

Because existing irradiation data on type 316 stainless steel indicate that for a given fluence the ductility is higher at a lower irradiation temperature, the design tenperature of $400^{\circ} \mathrm{C}$ was considered to be a conservative maximum near the first wal1. ${ }^{3}$ Likewise, the maximum stress was also kept as low as possible to minimize the potential for fatigue failure. Because a high heat flux may exist at the first wall, the wall was kept as thin as possible and the coolant pressure stress was kept as low as possible. To minimize thermal-hydraulic stresses we emphasized the application of low pressure coolants. On this basis the reference coolant is a heat transfer salt (53\% $\mathrm{KNO}_{3}, 40 \% \mathrm{NaNO}_{2}, 7 \% \mathrm{NO}_{3}$ ); other promising fused salts are identified in Sect. 6 , which discusses the coolant choice in detail. If fused salts cannot be used as the coolant, then thermal stresses associated with the use of stainless steels will have to be minimized through clever designs for a system in which the total alpha energy is transported through the first wall.

\subsection{ESTIMATE OF WALL LIFETIME}

nt the nominal neutronic wall loading of 2-4 MW/ $/ \mathrm{m}^{2}$, the neutron flux at the first wall is $0.8-1.5 \times 10^{15}$ neutrons $/ \mathrm{cm}^{2} / \mathrm{sec}$, with about $20 \%$ of the neutrons having energies near $14 \mathrm{MeV}$. For type 316 stainless steel, about 23-46 displacements per atom (dpa) and 290580 appm He will be produced per year of operation. Data showing the swelling rates and tensile properties for annealed and cold-worked type 316 stainless steel irradiated in the High Flux Isotope Reactor (HFIR) at different temperatures to about $60 \mathrm{dpa}$ and $4000 \mathrm{appm}$ He are shown in Figs. 5.1 and $5.2 .^{J}$ This fluence is equivalent to about 18-36 months of operation in terms of displacement damage and 10-20 years of operation in terms of helium production.

For operating temperatures below about $600^{\circ} \mathrm{C}$, irradiation-produced swelling that. results from cavity formation is relatively temperature-independent, and cold-worked stainless stcel swclls at. a markedly lower rate than does solution-annealed material. This advantage will make the cold-worked structures more able to operate in flux gradients, where the relatively low swelling rates will minimize the differential swelling. If the swelling is controlled by displacement damage in irradiated cold-worked type 316 stainless steel, available data can be extrapolated to predict $5 \%$ swelling at $90 \mathrm{dpa}$ for irradiation at $530^{\circ} \mathrm{C} .{ }^{3}$ There are a number of assumptions in this extrapolation, discussed in Ref. 3. If further experimental work verifies this prediction, the integral wall loading, set by a swelling limit of $5 \%$, will be about $8 \mathrm{MW}-y \mathrm{r} / \mathrm{m}^{2}$. If the swelling is controlled 
Table 5.2. Identification of advantages and liabilities of typical possible structural alloys ${ }^{a}$

\begin{tabular}{|c|c|c|c|c|c|c|c|c|c|c|c|c|}
\hline & 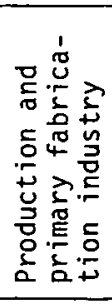 & 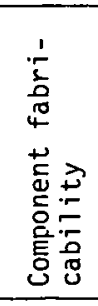 & 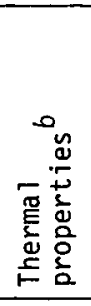 & 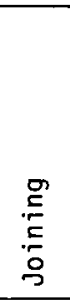 & 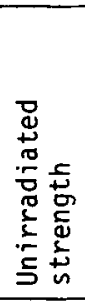 & 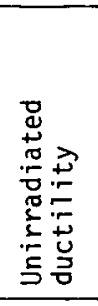 & 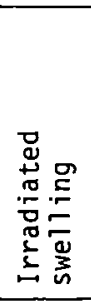 & 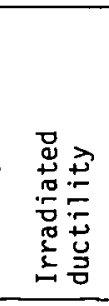 & 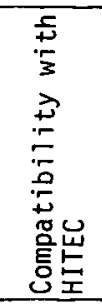 & 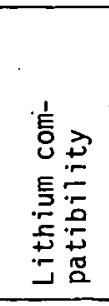 & 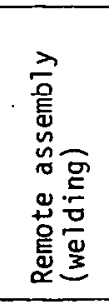 & 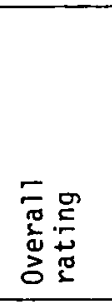 \\
\hline $\begin{array}{l}316 \text { stainless steel } \\
(\text { cold-worked })\end{array}$ & $E^{c}$ & E & $A^{d}$ & E & $G^{e}$ & G & $A$ & $M^{6}$ & G & A & G & $\dot{A}$ \\
\hline $\begin{array}{l}\text { Modified } 316 \text { stainless } \\
\text { steel (cold-worked) }\end{array}$ & $G$ & E & A & E & G & $G$ & A & A & G & $A$ & G & A. \\
\hline Inconel 600 & $\mathrm{E}$ & $E$ & A & G & G & E & M & A & G & (1) $)^{h}$. & G & (1) $\cdot \cdot$ \\
\hline PE 16 & G & G & A & A & E & $E$ & $A$ & A & G & (U) & M & (U) \\
\hline SAP $^{g}$ & $M$ & (1). & $E$ & (1) & G & M & $N^{i}$ & $\mathrm{~N}$ & $N$ & (U) & (1) & (11) \\
\hline $\mathrm{V}-20 \% \mathrm{Ti}$ & (1) & $A$ & $G$ & $M$ & $E$ & $E$ & $E$ & E & (11) & $E$ & (1) & (1) \\
\hline $\mathrm{Nb}-1 \% \mathrm{Zr}$ & M & G & $E$ & M & E & G & $A$ & A & (1) & $\mathrm{E}$ & (1) & M \\
\hline Mo & M & G & $E$ & (11) & G & M & A & (U) & $G$ & $E$ & (1) & (1) \\
\hline
\end{tabular}

$a_{A}$ relative ranking of this type is based on incomplete information on most alloys and on a large measure of subjective judgment.

${ }^{b}$ Ratio of elastic modulus $x$ coefficient of thermal expansion/thermal conductivity.

$c_{\text {Excellent. }}$.

$d_{\text {Acceptable. }}$.

e Good.

Garginal.

8 Sintered aluminum produrt.

hunacceptable.

iNot known.

by the helium content rather than by dpa level, the predicted swelling limit on wall Tifetime exceeds $30 \mathrm{MW}-\mathrm{yr} / \mathrm{II}^{2} \mathrm{~S}^{3}$

The mechanical properties of cold-worked material - yield strength, ultimate tensile strength, and ductility - were degraded as a result of irradiation. Below $550^{\circ} \mathrm{C}$, the yield strength is higher than that of annealed unirradiated material, so designs based on the yield point of unirradiated material should be conservative. The ductility decreases with increasing irradiation and test temperature, from nearly $4 \%$ at $350^{\circ} \mathrm{C}$ to $0 \%$ at about $650^{\circ} \mathrm{C}$.

Consideration of a reasonable design requirement of $2 \%$ elongation and the dependence of elongation on irradiation and test temperatures, shown in Fig. 5.2, set an upper temperature 1 imit of $2460^{\circ} \mathrm{C}$ fur a cold-worked 316 stainless steel first wall. For the lower 


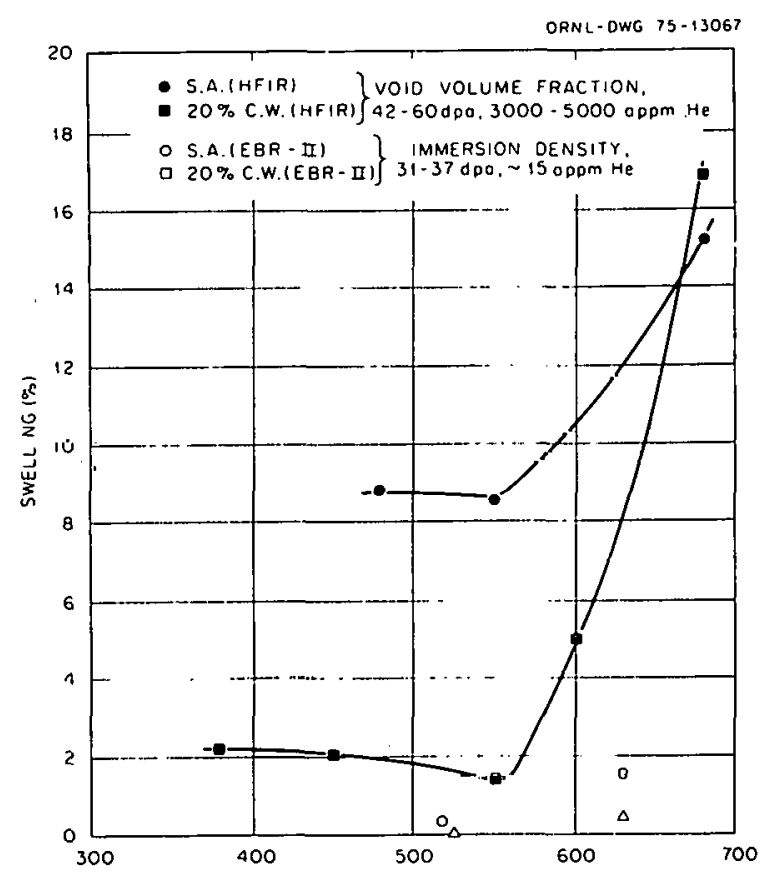

Fig. 5.1. Swelling of cold-worked and annealed type 316 stainiess steel in HFIR to 40-60 dpa and 3000-4330 appm He.

temperatures of this design, the irradiation conditions of Fig. 2 show acceptable elongation after irradiation to approximately 50 dpa $\left(\sim 4.4 \mathrm{MW}-y r / \mathrm{m}^{2}\right)$ and a helium content of approximately $4000 \mathrm{appm}\left(i 27 \mathrm{MW}-\mathrm{yr} / \mathrm{m}^{2}\right)$.

Prediction of a ductility-limited 1ifetime on the basis of a required $2 \%$ minimum elongation to failure is difficult with the scarcily of avallable data. A very complete set of uald has bcen published by rish el a) ${ }^{10}$ This shows that, for solution-annealed type 304 stainless steel irradiated and tested at $370^{\circ} \mathrm{C}$, the elongation dropped with increasing fluence to a fluence near $3 \times 10^{22}$ neutrons $/ \mathrm{cm}^{2}$. However, the ductility did not further decrease when irradiation was continued to fluençes to $1.1 \times 10^{23}$ neutronns $/ \mathrm{cm}^{2}$. A similar treatment of data on cold-worked

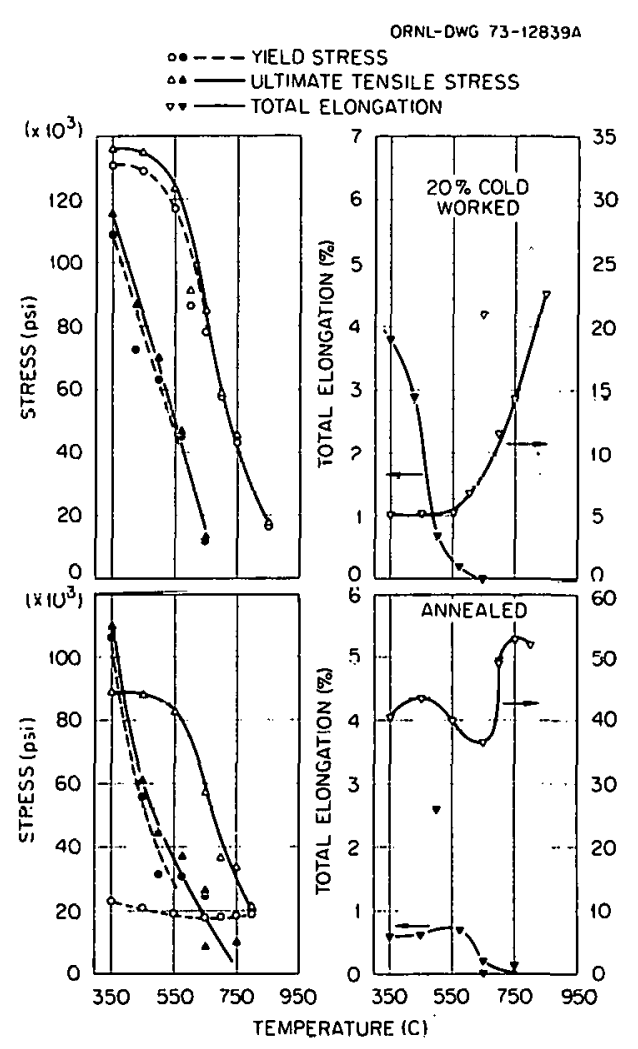

Fig. 5,2. Tensile properties of type 316 stainless steel after irradiation in HFIR to 40 $60 \mathrm{dpa}$ and 3000-4300 appill He. Data are plotted at test temperatures; irradiation temperatures were slightly higher than test temperatures for each data polnt. The open points are for unirradiated samples, and the closed points are for irradiated samples.

316 irradiated to produce both high levels of displaccment damage and of hellum is given in Fig. 5.3, The trend curves are drawn by analogy to data of Fish et al. and cannot be supported solely on the basis of the available HFIR results. However, if these projections are supported by future experimental work, the elongation of the first wall will remain above $2 \%$ for high fluence reactor operation and will not be lifetime-limiting. 


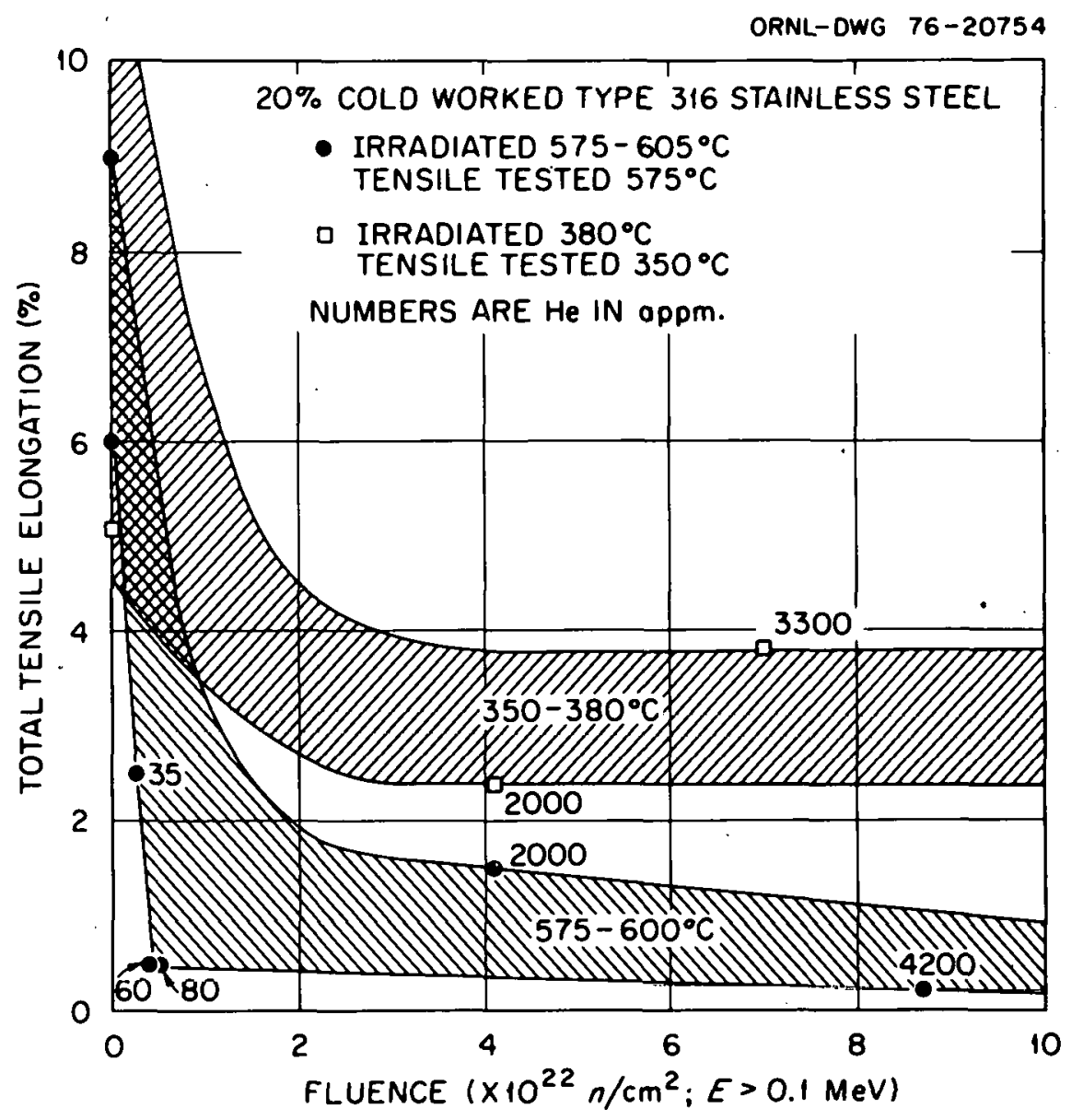

Fig. 5.3. Fluence-dependence of total elongation in HFIR-irradiated, cold-worked type 316 stainless steel. Trend curves were drawn based on the data of Fish et al.10

Among other properties that may be affected by irradiation are the irradiation creep rate and fatigue lifetime of stressed components. LMFBR program results on irradiation creep of cold-worked type 316 stainless steel suggest that at a design stress of 16,000 psi, creep rates on the order of $0.1 \%$ per year may be expected at the nominal neutronic wall loading. 11 Because irradiation creep is approximately linearly dependent on stress and only weakly temperature-dependent, local deviations from design nominal values of either stress or temperature will have modest effects on the irradiation creep rates. Data on which to assess the fatigue response of the irradiated structure do not exist. The lifetime fatigue load of $3 \times 10^{5}$ pulses is a demanding requirement and must be considered experimentally. Cramer et al. have estimated the wall lifetime of UWMAK I based on creep, fatigue, and crack-growth rates in addition to swelling and ductility loss. ${ }^{12}$ (The maximum combined stress for the UWMAK I design was $49,000 \mathrm{psi}$, and the maximum operating temperature was $558^{\circ} \mathrm{C}$.) These potential limitations must be reevaluated at lower temperatures as the experimental data base on materials performance becomes available. 
10. R. L. Fish, J. L. Straalsund, C. W. Hunter, and J. J. Holmes, "Swelling and Tensile Property Evaluations of HighFluence EBR-II Thimbles," p. 149 in Fffects of Radiation on Substructure and Mechanical Properties of Metals and Alloys, ASTM-STP 529, American Society for Metals and Testing, Philadelphia, Pennsylvania, 1973.

11. See, for example, data by Gilbert and McVay, reviewed in r. W. Wiffen, The Eforests of CTR. Irhadiation on the Mechanical Properties of Structural Materials, ORNL/TM-5624, Oak Ridge National Laboratory, Oak Ridge, Tennessee (November 1976).

12. B. A. Cramer, J. W. Davis, R. C. Kinder, and D. A. Bowers, "An Approach for Determining the Lifetime of a First Wall Structure in a Tokamak Reactor," paper presented at the Second ANS Topical Meeting on the Technology of Controlled Nuclear Fusion, Richland, Washington, Sept. 21-23, 1976 (TK Report in press).

\subsection{QUALIFICATION OF AUSTENITIC STAINLESS} STEELS FOR COMMERCIAL FUSION POWER

The design parameters of a neutronic wall loading of 2-4 MW/m at temperatures in the range of $250-400^{\circ} \mathrm{C}$ and the desired design lifetime of $10-20 \mathrm{MW}-\mathrm{yr} / \mathrm{m}^{2}$ form a severe materials requirement. The data described above on $20 \%$ cold-worked 316 stainless steel (showing acceptable properties at $400^{\circ} \mathrm{C}$ or lower for 4-6 MW-yr/m $\mathrm{m}^{2}$ of displacement damage and 20-30 MW-yr/m $\mathrm{m}^{2}$ of helium) suggest that an austenitic stainless steel that will be adequate for use as the structural material can be developed. We think that the operating temperature can be increased by alloy optimization. However, the present higher temperature data are so limited that this must be regarded only as a speculation.
Experimental work on austenitic stainless steels is required in the following areas of interest as functions of both composition and microstructure.

1) Swelling:

a) establish the basic kinetics and mechanisms of swelling,

b) confirm and extend the evaluation of the dependence of swelling on irradiation temperature,

c) establish the relationships between dpa level and helium content on controlling swelling,

d) establish the influence of alloy modification and fabricated microstructure in suppressing the swelling of alloys,

e) establish the fluence-dependence of swelling under fusion reactor irradiation conditioning.

2) Ductility and strength properties:

a) confirm the dependence of ductility on irradiation and test temperature,

b) confirm the "saturation" of ductility 1033 for high fluence irradia. tions,

c) establish the influence of alloy modification on postirradiation ductility,

d) cstablish the role of displacement damage level and helium content on loss of ductility at the lower temperatures of interest,

e) evaluate the dependence of elongation on strain rate, including the ductility under creep-rupture conditions,

f) establish the loss in strength of cold-worked materials on irradiation, both in reduced tensile strength and in reduced rupture life.

3) Irradiation creep:

a) establish irradiation creep rates under simulated fusion reartor randitions. 
4) Cyclic loading effects:

a) evaluate postirradiation fatigue properties of irradiated stainless steel,

b) establish crack growth rates in irradiated materials.

5) Weidment properties:

a) all properties listed above must be established for prototypic weld material and for weldaffected zones of the reference material.

\subsection{CONCLUSIONS}

An analysis has been made of the candidate structural materials together with design requirements for a series of fusion devices leading to commercial fusion power. Austenitic stainless steels appear to be compatible with a design based on first wall operating temperatures in the range of $400-500^{\circ} \mathrm{C}$ with lithium as the tritium-breeding material and a molten salt as the coolant. Their desired lifetimes are proiected to be in the range of $10-20 \mathrm{MW}-\mathrm{yr} / \mathrm{m}^{2}$. It must be emphasized that data on irradiated austenitic stainless steels with both high displacement levels and high helium content are very limited. An extensive program of alloy development and irradiation testing will be required in order to find a usable alloy and to demonstrate its performance capability.

The selection of some type of austenitic stainless steel should minimize the number of new technologies needed to achieve commercial fusion power. Although it is unlikely that the optimum alloy will be one of the present commerical alloys, the extensive experience on ore reduction, melting practice, forming, joining, and inspection can be applied directly with this class of alloys.

Another important advantage of the use of austenitic stainless steels is that they minimize developmental costs. An extensive data base is required for irradiation effects on any structural material. Because of the fortunate circumstance that helium is produced from nickel in a thermal neutron environment, much of the data can be obtained in existing fission reactors. Thus, large expenditures for test facilities are not required. It must be recognized, however, that the results of the fission reactor irradiations must be verified in the actual fusion reactor neutron spectrum. This verification can be carried out in one D-Li neutron source. There is not sufficient volume in such a source to develop a complete data base for one conventional alloy, but relatively few samples would provide adequate verification. If a nonnickel-bearing alloy such as $\mathrm{Nb}-1 \% \mathrm{Zr}$ or $\mathrm{V}-20 \% \mathrm{Ti}$ should be required for commerical fusion power, then expenditures of $\$ 500$ million or more would be required just to provide the test facilities - not to mention the operating and developmental costs. ${ }^{13}$ At the same time, it would be difficult to provide these facilities in a time period consistent with the goal of commercial fusion power by the end of this century.

Nickel-base alloys are incompatible with lithium above $300^{\circ} \mathrm{C}$, so they must be protected or another breeding material must be selected if they are used as fusion reactor structural materials.

With regard to refractory metals, we believe that the development program required would be much more extensive than that associated with austenitic stainless steels. In addition, the costs of providing test facilities would be much greater. On the other hand, it must be recognized that it is possible that no austenitic stainless steel will be adequate for commercial fusion power. Consequently, we propose that work be continued on refractory metals - especially niobium- and vanadium-base alloys - until we can be assured that they will not be needed. In fact, even if these materials are not required as the structural material, they may be used in special components or applications; in that case more information on their irradiation behavior would be required. 
13. J. R. Powell et al. (eds.), Proceedings of the Magnetic Fusion Energy Blanket and Shield Workshop: A Technical Assessment, ERDA-76/117/1, CONF-760343, p. 13

(August 1976). 


\section{BLANKET COOLANT}

H. E. McCoy

\subsection{INTRODUCTION}

The blanket coolant for commercial power application must be stable under high gamma and neutron fluxes at temperatures of $2500^{\circ} \mathrm{C}$, must be compatible with the strur.tural materials, and must be capable of transferring the desired quantities of energy. It is also. desirable that a coolant operates at low pressure; has a low power requirement for pumping, a high boiling point, and a low melting point; and be nonhazardous and low in cost. These requirements are stated rather qualitatively and can take on values only when considered in light of specific blanket designs (Sect. 4) and blanket structural materials (Sect. 5). For a neutron wall loading of $\sim 3 \mathrm{MW} / \mathrm{m}^{2}$, an austenitic stainless steel as the structural material, a gamma flux of $10^{4} \mathrm{R} / \mathrm{sec}$, and a neutron flux on the order of $10^{15}$ neutrons/ $\mathrm{cm}^{2} / \mathrm{sec}$, the coolant must be compatible with austenitic stainless steel and the heat transfer coefficient of the fluid side should be approximately $1.14 \times 10^{4} \mathrm{~W} / \mathrm{m}^{2} \cdot \mathrm{K}(2000 \mathrm{Btu} / \mathrm{hr}$ $\left.f t^{2} \cdot{ }^{0} \mathrm{~F}\right)$. However, these coolant requirements are oversimplified, and some attention must be given to the various trade-offs between designs, structural materials, and coolants. For this reason, each factor is discussed in mare detail below.

\subsubsection{Irradiation Stability}

Irradiation stability of the coolant is of concern because dissociation can lead to high pressures in the coolant circuit (e.g., water dissociating to form $\mathrm{H}_{2}$ and $\mathrm{O}_{2}$ ) or can form undesirable solid products (e.g., organic coolants dissociatiny to form tar). The dissociation reaction requires that the entire blanket be designed to withstand high pressure, and chemical adjustments are usually required to maintain the desired coolant composition. Dissociation which leads to solid reaction products is of concern because of fouling and its associated detrimental effects on heat transfer and ability to pump the coolant. One further aspect of neutronic performance is that the coolant must not significantly degrade the neutron flux elther by scattering or by parasitic absorption, since this would reduce the ability of the system to produce tritium.

\subsubsection{Coolant/Structural Material Compatibility}

Compatibility between the coolant and the structural material is necessary to maintain system integrity. One complicating factor is the effect of strong magnetic fields on corrosion. Studies have shown that magnetic fields influence both transport-controlled and activation-controlled reactions. 1 Further work will be needed to define the magnitudes of these effects for each coolant/structural metal combination. Another area of concern is the consequences of mixing of the coolant with lithium, an event which could occur if the coolant tubes failed. These factors are discussed in greater detail in Sect. 6.2.

1. E. J. Kelly, "Magnetic Field Effects on Electrochemical Reactions 0ccurring at Metal/Flowing-Electrolyte Interfaces," to be published in J. Electrochem. Soc.

\subsubsection{Heat Transfer Properties}

The ability of the coolant to transfer heat is an obvious requirement, since this is the means by which the thermal eneryy is used to produce electricity. Therefore, the coolant must have a high thermal conductivity and other attractive physical properties which allow maintenance of a high heat transfer coefficient nn the fluid side. The fluid's physical prop- 
erties must not create a requirement for unreasonable amounts of power for circulation.

\subsubsection{Operation at Low Pressure}

It is most important that the coolant circuit be able to operate at low pressures. The entire coolant circuit, and particularly the first wall, will operate under rather severe conditions. The first wall will receive intense pulses of thermal energy and particle irradiation, which lead to cyclic thermal stresses in the presence of irradiation; the magnitude of the thermal stresses may be reduced by a reduction of the thickness of structural members making up the first wall. However, use of a high pressure coolant would require that members be thick to contain the high pressure coolant. Thus, there is a conflict between the need for thin structural members to minimize thermal stresses and the need for thick structural members to accommodate high hydraulic stresses. The design simplicity and first wall integrity are improved markedly by the use of a low pressure coolant.

\subsection{CANDIDATE FLIJIDS}

Several specific fluids are discussed and their roles as prospective coolants for commercial fusion application are assessed.

\section{6.¿̌.l Helium}

On the basis of general radiation and thermal stability, ease of handling, and absence of hazardous conditions, there is much to recommend the use of a gas as coolant. There is considerable engineering experience with helium-cooled systems. ${ }^{2-4}$

Helium in its pure form is inert and thus has excellent compatibility with all prospective structural materials. However, it is difficult to maintain the purity of helium in a pumped pressurized system. Small amounts of oxygen, nitrogen, water, carbon monoxide and dioxide, and methane would probably be present due to some air leaking in and making contact with lubricated seals, and hydrogen and tritium would be present due to permeation through the inner wall. Thus, the grade of helium actualiy used would have some level of impurities which would not pose a problem for iron- or nickelhase alloys but would probably be reactive with metals such as niobium, titanium, and vanadium. At $400^{\circ} \mathrm{C}$ the extent and consequences of the reaction or each reaclive metal with impure helium must be considered in detail. ${ }^{5}$ oxygen contamination of niobium has also been shown to have detrimental effects on the corrosion of niobium by lithium. ${ }^{6}$

In order to make helium attractive as a heat transfer medium, it is necessary to operate the system at high pressures, ${ }^{3}$ typically above 1000 psi. This will require that $2-3 \%$ of the thermal energy be used for pumping power and will complicate the design by requiring that the coolant circuit operate at high pressures.

Helium is gaseous nver the entire service temperature; therefore, its use would greatly simplify start-up. It is questionable whether this feature is worth the added pumping power and the complication of a high pressure system associated with the use of helium.

2. Stuart McLain, "Commerical Power Reactors Cooled With Gas or Light Water," p. 1 in Reactor Technology, ed. by Leonard E. Link, USAEC Division of Technical Information Extension, Oak Ridge, Tennessee, 1964.

3. Samuel Glasstone and Alexander Sesnnske, Nuclear Reactor Engineering, p. 407, Van Nostrand Reinhold Co., New York, 1967.

4. P. C. Davidge et al., "Gas Coolants", p. 979 in Reactor Handbook, Vol. I: Materials, ed. by C. R. Tipton, Jr., Interscience, New York, 1960. 
5. J. E. Selle, The Effects of Helium Impurities on Superalloys, to be published as an ORNL/TM.

6. R. L. Klueh, "Penetration of Refractory Metals by Alkali Metals," p. 177 in Corrosion by Liquid Metals, ed. by J. E. Draley and J. R. Weeks, Plenum Press, New York, 1970.

\subsubsection{Water}

Water can be used as a coolant at elevated temperatures if it is pressurized so that it remains a liquid. At $200^{\circ} \mathrm{C}$ the minimum pressure required to maintain water as liquid is $225 \mathrm{psia}$; at $300^{\circ} \mathrm{C}$ the pressure is $1246 \mathrm{psia}$; and at the critical temperature of $374^{\circ} \mathrm{C}$ the pressure is 3206 psia. Thus, the pressure increases sharply with increasing temperature. Determination of the optimum operating temperature using water as a coolant would involve an evaluation of the trade-offs between system pressure and coolant temperature. The pumping power required for water is quite acceptable, and the experience of the entire Pressurized Water Reactor (PWR) industry is relevant to the use of pressurized water as a coolant. 2,7,8

Water is not very aggressive toward most structural metals, but it is generally used with a number of impurities present in quantities measured in parts per million or parts per billion. These impurities are combated with a number of additives used to remove the impurities or to adjust the oxidation potential $(\mathrm{pH})$ of the fluid. Although this technology is very specialized, the experience with PWR's and with steam cycle power plants has produced a wealth of operating experience, and the corrosion problem is manageable with most structural materials (such as iron, nickel, and copper), but not with reactive metals (such as niobium).

When water and lithium are mixed, a number of reactions can occur. ${ }^{9}$ These include:

$$
\begin{array}{ll}
\frac{1}{4} \mathrm{H}_{2} \mathrm{O}+\mathrm{Li} \rightarrow \frac{1}{4} \mathrm{Li}_{2} \mathrm{O}+\frac{1}{2} \mathrm{LiH} & \Delta \mathrm{H}_{700 \mathrm{~K}}=-30.3 \mathrm{kcal} \\
\mathrm{H}_{2} \mathrm{O}+\mathrm{Li} \rightarrow \mathrm{LiOH}+\frac{1}{2} \mathrm{H}_{2} & \Delta \mathrm{H}_{700 \mathrm{~K}}=-57.5 \mathrm{kcal} \\
\frac{1}{2} \mathrm{H}_{2} \mathrm{O}+\mathrm{Li} \rightarrow \frac{\mathrm{L}}{2} \mathrm{Li}_{2} \mathrm{O}+\frac{1}{2} \mathrm{H}_{2} & \Delta \mathrm{H}_{700 \mathrm{~K}}=-43.1 \mathrm{kcal} .
\end{array}
$$

When water is the excess phase, water reacts vigorously with Iithium to form lithium oxide and hydrogen. 8,10 If lithium is the excess phase, the products will be lithium oxide and lithium hydride. Under real operating conditions, the water coolant would be leaked into the 1 ithium. This would probably result in the formation of corrosive lithium oxide and lithium hydride with localized heating due to the exothermic nature of the reactions. Continued leaking could lead to sufficient water for hydrogen to be released. Thus, design and operating procedures must take into account the water-lithium mixing problem.

Water can be maintained as a liquid over the proposed service temperature range, so start-up could be accomplished easily. However, it is doubtful that this feature compensates for the other shortcomings of water as a coolant for fusion systems.

7. Samuel Glasstone and Alexander Sesonske, Nuclear Reactor Engineering, p. 401, Van Nostrand Reinhold Co., New York, 1967.

8. L. P. Bupp, "Maintenance of Coolants," p. 307 in Reactor Handbook, Vol. IV: Engineering, ed. by Stuart McLain and John H. Martens, 2nd ed., Interscience, New York, 1964.

9. J. Brynestad (Oak Ridge National Laboratory), private communication.

10. Samuel Glasstone and Alexander Sesonske, Nuclear Reactor Engineering, p. 405, Van Nostrand Reinhold Co., New York, 1967.

\subsubsection{Liquid Metals}

The liquid metals of potential use in fusion systems are lithium, sodium, and potassium, with melting temperatures of $179^{\circ} \mathrm{C}, 98^{\circ} \mathrm{C}$, and $64^{\circ} \mathrm{C}$, respectively. ${ }^{11}$ These elements have 
relatively high boiling temperatures of $1317^{\circ} \mathrm{C}, 883^{\circ} \mathrm{C}$, and $760^{\circ} \mathrm{C}$. 11 The wide temperature range over which these elements are $1 i$ quid and their high thermal conductivity make them particularly attractive as potential coolants. If the liquid metals are free of oxygen, they are compatible in flowing systems up to $600^{\circ} \mathrm{C}$ with the austenitic stainless steels and other iron-base alloys, and may be acceptably compatible up to $\sim 400^{\circ} \mathrm{C}$ with nickel-base alloys. 11 They are compatible with nióbium às lóng às they àre kept reasonably pure; they are totally incompatible with aluminum and copper. 11

These elements have been widely used as heat transfer fluids in nonfusion devices with very favorable results. However, the fusion application subjects the fluid to strong magnetic fields, and the high electrical conductivity of lithium, sodium, and potassium causes strong forces which oppose flow in any direction not parallel with the magnetic field. ${ }^{12,13}$ This would require that the fluid be pumped at pressures in excess of the magnetic forces, but this is viewed as requiring such high pressures that it is impractical. Several methods have been proposed for reducing the magnitude of this effect, and these proposals need to be investigated further because of the attractiveness of having a common coolant and breeding material. The strong magnetic forces also present a problem with respect to heat transfer. Atomic mobility with the fluids is reduced so that heat transfer must be largely by conduction rather than by convection. This effect will limit the ability to transfer heat by these metals.

11. R. N. Lyon, "Liquid Metals," p. 994 in Reactor Handbook, Vol. I: Materials, ed. by C. R. Tipton, Jr., Interscience, New York, 1960.
12. George H. Miley, Fusion Energy Conversion, p. 251, American Nuclear Society, Hinsdale, Illinois, 1976.

13. W. R. Grimes and S. Cantor, "Molten Salts. as Blanket Fluids in Controlled Fusion Reactors," p. 161 in The Chemistry of Fusion Technology, ed. by Dieter M. Gruen, Plenum Press, New York, 1973.

\subsubsection{Lithium and Beryllium Fluoride Salts}

Molten fluoride salts of the LiF-BeF, system have been studied extensively: $3,12-15^{2}$ There is an eutectic composition of about equal molar ratios of $L i F$ and $B_{2} F_{2}$ which has a melting point of $364^{\circ} \mathrm{C}$. Although this salt has the lowest melting point in the system, it has a high viscosity. Salt of the composition of LiF-34 mole \% BeF 2 has more attractive properties, except for its relatively high melting temperature of $459^{\circ} \mathrm{C}$. This salt is compatibie with nickel- and iron-base alloys and molybdenum, but is probably not compatible with aluminum, titanium, and niobium. ${ }^{16-18}$ Thus, molybdenum is probably the only structural material that could be used for a high temperature system cooled with LiF-BeF, due to the temperature 1 imilaliuns impused un irun- and rickel-base alluys by Irradlation embrittlement.

Intermixing with lithium would result in the reaction

$\mathrm{Li}_{2} \mathrm{BeF}_{4}+2 \mathrm{Li} \rightarrow 4 \mathrm{LIF}+\mathrm{Be} \Delta \mathrm{HH}_{700 \mathrm{~K}}=-39.7 \mathrm{kCid}$. Th1s would precipitate berylitum metal and increase the melting temperature of the coolant. Intermixing would result in a cleanup problem should leakage occur, but would not pose a safety problem.

Two main factors place limits on use of this fluid as a coolant. First, the high melting temperature would require an operating temperature of $600^{\circ} \mathrm{C}$, well in excess of that allowed for iron- and nickel-base structural materials on. the basis of irradiation damage. Second, the supply of beryllium is limited, and it is questionabie whether sufficient 
quantities exist to support a viable fusion industry. For these reasons it is felt that salts of the LiF-BeF 2 system will not find widespread use in fusion reactor applications.

14. W. R. Grimes and D. R. Cuneo, "Molten Salts as Reactor Fuels," j. 425 in Reactor Handbook, Vol. I: Materials, ed. by C. R. Tipton, Jr., Interscience, New York, 1960.

15. S. Cantor and W. R. Grimes, "Fused-Salt Corrosion and Its Control in Fusion Reactors," Nucl. Techno1. 22, 120 (1974).

16. H. E. McCoy, "The INOR-8 Story," ORNL Review 3(2), 35 (1969).

17. J. R. Keiser and E. J. Laurence, "Salt. Corrosion Studies," p. 75 in Molten-Salt Reactor Program Semiannual Progress Report for Period Ending February 29, 1976, ORNL-5132, Oak Ridge National Laboratory, 0ak Ridge, Tennessee (August 1976).

18. J. H. DeVan, Effect of Alloying Additions on Corrosion Behavior of Nickel-Molybdenum Alloys in Fused Fluoride Mixtures, ORNL/TM-2021, Oak Ridge National Laboratory, 0ak'Ridge, Tennessee (1969).

\subsubsection{Sodium-Potassium-Nitrate-Nitrite Mixtures}

Sévera1. salts composed of various portions of sodium and potassium nitrates and nitrites are used industrially as heat transfer media. ${ }^{19,20}$ One of the most popular is a commercial salt patented by Du Pont and trademarked HITEC, which contains $53 \%$ potassium nitrate, $40 \%$ sodium nitrite, and $7 \%$ sodium nitrate. The liquidus of this salt is $143^{\circ} \mathrm{C}$ and the rate of thermal decomposition becomes excessive above $538^{\circ} \mathrm{C}$. Although the salt has been used as a heat transfer medium for over 30 years, detailed corrosion data are not available. The fluid has been suitably contained in several iron- and nickel- base alloys with nominal corrosion rates of $24.8 \times 10^{-8} \mathrm{~mm} / \mathrm{sec}(1 \mathrm{mil} / \mathrm{yr})$, but does not appear to be compatible with copper. Since the salt is oxidizing, it is quite unlikely that it will be compatible with reactive metals such as niobium and titanium. The heat transfer properties, physical properties, and pumping power requirements for the salt are excellent. The salt is cheap and readily available and does not contain any materials. having limited availability.

The potential problems with the salt include accelerated dissociation under irradiation and reaction with lithium upon intermixing. The reaction which occurs by thermal decomposition is

$5 \mathrm{NaNO}_{2} \rightarrow 3 \mathrm{NaNO}_{3}+\mathrm{Na}_{2} \mathrm{O}+\mathrm{N}_{2}$.

This reaction results in a partial pressure of $\mathrm{N}_{2}$ which increases with increasing temperature. Brynestad ${ }^{9}$ proposes that additional decomposition products will include $\mathrm{Na}_{2} \mathrm{O}_{2}$ and $\mathrm{K}_{2} \mathrm{O}_{2}$, which are both very corrosive. Unless irradiation greatly accelerates the decomposition, the pressure of nitrogen over the salt system should not be excessive.

When lithium and HITEC are mixed, vigorous reactions are expected in which both nitrate and nitrite will be decomposed to $\mathrm{N}_{2}$ and either oxygen or lithium oxide: 21

$$
\begin{array}{r}
\mathrm{Li}+\mathrm{NaNO}_{3} \rightarrow \frac{1}{2} \mathrm{Li}_{2} \mathrm{O}+\frac{\mathrm{L}}{2} \mathrm{Na}_{2} \mathrm{O}+\frac{1}{2} \mathrm{~N}_{2}+\mathrm{O}_{2} \\
\Delta \mathrm{H}_{700 \mathrm{~K}} \simeq-20 \mathrm{kcal} \\
\mathrm{SLI}+\mathrm{NaNO}_{3} \rightarrow \dot{2} \frac{1}{2} \mathrm{Li}_{2} \mathrm{U}+\frac{1}{2} \mathrm{Na}_{2} \dot{\mathrm{U}}+\frac{1}{2} \mathrm{~N}_{2} \\
\Delta \mathrm{H}_{700 \mathrm{~K}} \simeq-300 \mathrm{kcal} .
\end{array}
$$

The first reaction would likely occur with. smali quantities of $\mathrm{Li}$, and the second reaction would occur with an excess of Li. The quantity of energy released is reasonably high, but measurements of the rate of reaction are needed to assess the extent of the problem.

The only known data on the irradiation stability of HITEC were reported by Hoffman 22 on the observations made by 0 . Sisman at $0 R N L$ on the stability of three specimens of HITEC. The samples received a thermal dose of $3.3 \mathrm{x}$ $10^{18}$ neutrons $/ \mathrm{cm}^{2}$ and an epithermal dose of 
somewhat less than half the thermal dose. Examination of the irradiated samples indicated that the salt was rendered more hygroscopic by radiation and that it also underwent some breakdown, yielding, in part, gaseous decomposition products. Since the temperature of the irradiation was not given, it is very difficult to interpret the results, and a more definitive experiment is clearly needed.

HITEC is a strong oxidant and can probably detonate under certain conditions. Beite $1^{23}$ has studied the combustion of sodium nitrate under a variety of conditions and made several important observations.

1) Energetically, sodium nitrate is capable of exothermicaliy oxidizing almost any organic material, but rate-controlling variables limit the possibility of a self-supported exothermic reaction.

2) Sodium nitrate was stable below $380^{\circ} \mathrm{C}$ and did not support combustion. The compound boils at $380^{\circ} \mathrm{C}$ and some of the decomposition products $\left(\mathrm{NaO}, 0, \mathrm{O}_{2}, \mathrm{NO}, \mathrm{NO}_{2}\right.$, or $\left.\mathrm{NO}_{3}\right)$ participate in the oxidation.

3) Moisture concentrations above $22 \%$ prevented combustion in all mixtures.

4) In mixtures of sodium nitrate and charcoal, combustion did not occur in the presence of $>95 \%$ or $<35 \%$ sodium nitrate.

5) Sodium nitrate cannot decompose exothermically by itself at any temperature. Any exothermic reaction with sodium nitrate must be supported by a fuel.

HITEC contains only $7 \%$ sodium nitrate, but contains $53 \%$ potassium nitrate, the chemical characteristics of which are similar to those of sodium nitrate. [The sodium nitrite (40\%) would be less oxidizing.] Therefore, it is felt that the observations made on sodium nitrate are applicable to HITEC. Beitel's study indicates that HITEC would react vigorously only above $2380^{\circ} \mathrm{C}$ in the presence of $5-65 \%$ organic material. This condition does not seem likely in our present concept of a fusion energy device without graphite. Should it be necessary to use graphite as a reflector, further evaluation must be made of the consequences of graphite-HITEC interaction.

19. E. G. Bohlmann, Heat Transfer Salt for High Temperature Steam Generation, ORNL/TM3777, Oak Rivige Natiunal Laboratoi-y, Oak Ridge, Tennessee (1972).

20. M. D. Silverman and J. R. Engel, Survey of Technology for Storage of Thermal Energy in Heat Transfer Salt, ORNL/TM-5682, Oak Ridge National Laboratory, Oak Ridge, Tennessee (1977).

21. C. F. Baes (Oak Ridge National Laboratory), private communication.

22. H. W. Hoffman and S. I. Cohen, Fused Salt Heat Transfer - Part III. Forced-Convection Heat Transfer in Circular Tubes Containing the salt Mixture $\mathrm{NaNO}_{2}-\mathrm{NaNO}_{3}-\mathrm{KNO}_{3}$, ORNL-2433, Oak Ridge National Laboratory, Oak Ridge, Tennessee (1960).

23. G. A. Boite1, Sodium Nitrate Comhustion Limit Tests, ARH -LD 123, Atlantic Richfield Hanford Co., Richland, Washington (April 1976).

\subsubsection{Lithium-Sodium-Potassium Hydroxides}

Pure hydroxides of 1 ithium, sodium, and potassiuiii nièt at $471^{\circ} \mathrm{C}, 320^{\circ} \mathrm{C}$, and $400^{\circ} \mathrm{C}$, re= spectively, but eutectic hydroxide mixtures of $\mathrm{Na}-44$ mole \% $\mathrm{K}$ and $\mathrm{Na}-27$ mole \% Li melt at $187^{\circ} \mathrm{C}$ and $219^{\circ} \mathrm{C}$, respectively. ${ }^{24}$ these eutectic mixtures have acceptable physical properties and would require reasonable amounts of pumping power. They are quite cheap and do not contain materials of limited availability. The elutertic mixtures can be used up to at least $800^{\circ} \mathrm{C}$, and they have been shown to be acceptably stable under irradiation up to the same temperature. ${ }^{24}$ 
The most serious limitation of the hydroxides as coolants is their corrosiveness. The conclusion of rather extensive research for a container material is that all the metals and alloys tested so far are attacked to some degree; ${ }^{24}$ the most corrosion-resistant materials are nickel, silver, gold, and chromium. In general, objectionable rates of attack occurred above $550^{\circ} \mathrm{C}$. These materials exhibited mass transfer in the presence of a temperature gradient, and it was recommended that the maximum temperature be 1 imited to $550^{\circ} \mathrm{C}$ and that the temperature differential not exceed $60^{\circ} \mathrm{C}$. The compatibility of structural materials with the hydroxides must be studied in more detail before these fluids can be seriously considered as coolants.

Since the hydroxides are oxidizing, it is quite likely that they would be incompatible with reactive metals such as niobium, titanium, and vanadium. Their oxidizing nature suggests that their reaction with lithium would be

$2 \mathrm{NaOH}+2 \mathrm{Li} \rightarrow \mathrm{Na}_{2} \mathrm{O}+\mathrm{Li}_{2} \mathrm{O}+\mathrm{H}_{2}$

$$
\Delta \mathrm{H}_{700 \mathrm{~K}} \simeq-49.6 \mathrm{kcal} \text {. }
$$

This reaction is exothermic with a modest energy release, but the equilibrium overpressure of hydrogen will be on the order of $10^{14}$ atm. ${ }^{9,21}$ As long as lithium and sodium hydroxide are available, the reaction will proceed with the development of a high overpressure of hydrogen which must be vented to maintain the integrity of the coolant system. The area of intermixing lithium and sodium hydroxide needs further exploration before the hydroxides could be used.

24. M. W. Mallett and John H. Stang, "Hydrides and Hydroxides," p. 955 in Reactor Handbook, Vol. I: Materials, ed. by C. R. Tipton, Jr., Interscience, New York, 1960.

\subsubsection{Chlorides}

Numerous chlorides exist whose melting temperatures are in the $100-200^{\circ} \mathrm{C}$ temperature range. 25-26 Many of these chlorides have acceptable vapor pressures over the service temperature range and have very attractive heat transfer properties. Furthermore, many chlorides are composed of common materials which are available and cheap.

Corrosion data are very limited on chlorides with melting points in the range of interest. Limited testing by DeVan et al. ${ }^{27}$ showed that nickel-base alloys had corrosion resistance superior to that of iron-base alloys and that the corrosion rates were comparable to those observed in fluorides. However, laboratory experience by $\mathrm{Smith}^{28}$ has shown that the corrosivity of the different chiorides varies greatly, with the variation depending largely about the ease with which impurities such as water are removed from the salt. Thus, an experimental program directed at compatibility studies on chlorides with physical properties of interest for fusion applications must be manned before a specific chloride system can be chosen or before the potential of chlorides can be assessed.

The consequences of intermixing chlorides and lithium must be evaluated for each specific chloride. If the chloride coolant contains a metal chloride that is less stable than lithium chloride, intermixing would result in the formation of lithium chloride and free metal from the chloride. If the metal in the chloride has a melting point above the service temperature range or is insoluble, solids could be precipitated in the molten lithium. If the metal chloride is more stable than lithium chloride, intermixing would probably be inconsequential. There is sufficient flexibility in the choice of chlorides that chlorides can probably be found for which intermixing with lithium does not pose a serious problem.

Specific data on the irradiation stability of the chlorides were not found in the literature, However, the British have considered 
using the chlorides in fast reactors, and this indicates that the chlorides probably have acceptable irradiation stability. If the chlorides do dissociate slightly in an irradiation field, small amounts of free atomic chlorine, which is very corrosive, will be released. Smith ${ }^{28}$ has observed that the recombination of thermally dissociated species occurs very rapidly upon cooling, so species dissociated by irradiation would most probably recombine in the parts of the coolant circuit uulside the high irradiation field.

25. Paul V. Clark, Fused Salt Mixtures: Eutectic Compositions and Melting Points, $S C-R-68-1680$, Fused Salts Information Center, Sandia Laboratories, Albuquerque, New Mexico (1968).

26. W. R. Grimes and D. R. Cuneo, "Molten Salts as Reactor Fuels," p. 440 in Reactor Handbook, Vol. I: Materials, ed. by C. R. Tipton, Jr., Interscience, New York, 1960.

27. J. H. DeVan (Oak Ridge National Laboratory), private communication.

28. G. P. Smith (Oak Ridge Nationa1 Laboratory), private communication.

\subsubsection{Organic Coolants}

The use of organic coolants for fusion applications was reviewed by J. L. Snee et a1. 29 (Considerable attention has also been given to these coolants for fission reactor applications.) The most attractive fluids for nur.lear coolants seem to be mixtures or diphenyl and terphenyl solutions. These materials are inexpensive and readily available. They are solid at room temperature, but melt at the relatively low temperature of $266^{\circ} \mathrm{C}$ $\left(150^{\circ} \mathrm{F}\right) .^{30}$ The thermal stability of the organic coolants is good; thermal decomposition is not a problem below $425^{\circ} \mathrm{C} .31$ The vapor pressure of Santowax $R$, a typical organic coolant, is 34 psia at $427^{\circ} \mathrm{C} .31$ The heat transfer characteristics are not outstanding, but are acceptable. ${ }^{3,30}$ Aluminum and iron alloys are suitable structural materials. ${ }^{30}$

The most serious problem associated with the organics is their decomposition by nuclear radiation. 3,29-31 This decomposition will require that fresh coolant be added to replace the decomposed coolant, and this was estimated as $1.1 \mathrm{lb} / \mathrm{MWhr}$ at $357^{\circ} \mathrm{C}\left(675^{\circ} \mathrm{F}\right)$ for one organically cooled and moderated reactor design. 3 This decomposition also leads to fouling on heat transfer surfaces and buildup of particulate matter in the coolant. ${ }^{31}$ Although proponents of the organically cooled and moderated reactor felt that the problem was manageable, an organic coolant circuit must include side streams for the addition of new coolant and removal of particulate matter. The high radiation ficld associated will a fusion device would require that these side streams be processed at a very rapid rate. The high dissociation of the organics in an irradiation field and the resulting particulate matter, which fouls piinips and liedi iransfer surtaces, lead us to conclude that the fluids have very little potential as coolants.

29. J. L. Snee et al., Organic Coolant Summary Repont, AECl-4922, Atomic Energy Commission, Washington, D. C. (August 1975).

30. L. P. Bupp, "Maintenance of Coolants," p. 336-339 in Reactor Handbook, Vol. IV: Engineering, ed. by Stuart McLain and John H. Martens, 2nd ed., Interscience, New York, 1964.

31 Chad J. Pascman and lenn ir enl, "Cumnercial Power Reactors Cooled with Sodium, Heavy Water, or Organic Liquids," p. 121 in Reactor Technology, ed. by Leonard E. Link, USAEC Division of Technical Information Extension, Oak Ridge, Tennessee, 1964. 


\subsubsection{Lithium-Sodium-Potassium Carbonates}

Among the carbonates in the lithiumsodium-potassium system having acceptable physical properties, the one with the lowest melting point contains $\mathrm{Li}_{2} \mathrm{CO}_{3}-31.5$ mole \% $\mathrm{Na}_{2} \mathrm{CO}_{3}-25$ mole \% $\mathrm{K}_{2} \mathrm{CO}_{3} \cdot 32^{2}$ This salt is inexpensive and readily available and has good heat transfer properties. The main shortcoming is its high melting point of $397^{\circ} \mathrm{C}$. There may be other carbonates with lower melting points, but none in the literature consisted of reasonable elemental combinations. This point needs to be investigated further. The carbonates are compatible with nickel-and iron-base alloys, but are likely to be incompatible with reactive metals such as niobium.

Since the carbonates are oxidants, they will react with lithium by the reaction $\mathrm{Na}_{2} \mathrm{CO}_{3}+4 \mathrm{Li} \rightarrow \mathrm{Na}_{2} \mathrm{O}+2 \mathrm{Li}_{2} \mathrm{O}+\mathrm{C}$

$$
\Delta \mathrm{H}_{700 \mathrm{~K}} \simeq-126 \mathrm{kcal} \text {. }
$$

This is an energy release of $32 \mathrm{kcal}$ per mole of lithium, which is comparable to that obtained with lithium and water.

The high melting points of the lithiumsodium-potassium carbonates make these materials unusable with iron- and nickelbase alloys where the maximum operating temperatures must be restricted to the 400 $500^{\circ} \mathrm{C}$ range. Because of the oxidizing nature of the carbonates, they would probably not be usable with reactive metals such as niobium at higher temperatures. Thus, it is doubtful that the carbonates will be useful as coolants unless carbonates with lower melting points can be found.

\footnotetext{
32. J. P. Sanders (Oak Ridge National Laboratory), private communication, 1971.
}

\subsection{DISCUSSION}

In the presentations of the nine coolant candidates, a number of strong and weak points were mentioned for each coolant. There are a number of properties which are common to several coolants, and some cross comparisons among the coolants would be useful.

Helium offers the ultimate in chemical inertness and is unique among the coolants in this regard. The only fundamental question about helium is whether the heat can be transferred without unbearable effects on system design and economics. For helium to operate as a reasonable heat transfer medium, the coolant circuit must operate at a pressure of about 1000 psi. This would necessitate designing the coolant system to withstand this pressure and may result in thick sections which are overstressed by thermal stresses. The pumping power requirement of several percent of the system power output may have a significant degrading effect on the system economics. Clearly, a decision concerning the potential of helium as a coolant can only be made after a detailed study has been made of the trade-offs between system pressure, lifetime (based on thermal fatigue), and total power cost.

Water is similar to helium in that a pressurized system would be required, al though the operating pressure for water could be lower. Since the pressure required to maintain water as liquid increases markedly with increasing temperature, it will be necessary to evaluate the trade-offs between system temperature, system pressure, thermal stresses, and plant thermal efficiency. Increasing the system temperature will increase the plant thermal efficiency, increase the system pressure, and increase thermal stresses in the structural members of the coolant circuit (due to the larger section sizes imposed by the higher pressure). Decreasing the system temperature will have the desirable effects of reducing the system pressure and the thermal stresses, but will have the undesirable effect of reducing the plant thermal efficiency. The main disadvantage of water is its 
reaction with lithium, which produces corrosive lithium oxide or lithium hydroxide, hydrogen, and $250 \mathrm{kcal}$ of heat energy per mole. of lithium. This reaction would pose both operational and safety problems.

The liquid metals, particularly lithium, normally function extremely well as coolants, but the presence of strong magnetic fields makes them very difficult to pump and limits their flow turbulence in a way that would reduce the quantity of heat that they could transfer. A number of methods have been proposed for mitigating these effects and it is recommended that developments in this area need to be followed very closely because of the attractiveness of a combined breeding and cooling circuit.

The organic coolants lack the stability required for operation at elevated temperatures in an irradiation field. They do not merit further investigation.

The sodium-potassium-nitrate-nitrite mixtures, the lithium-sodium hydroxides, and the lithium-sodium-potassium carbonates are all oxidizing and would react with lithium to produce corrosive lithium oxide and release a sizable amount of energy varying from $60 \mathrm{kcal}$ per mole of lithium for nitrate-nitrite mixtures to $25 \mathrm{kcal}$ per mole of lithium for the hydroxides. The hydroxides are very corrosive and would probably require nickel-base alloys, but the other two coolants could be contained in iron- and nickel-base alloys. Upon mixing with lithium, the nitrate-nitrite mixtures would evolve $\mathrm{N}_{2}$, and the hydroxides would evolve $\mathrm{H}_{2}$. The nitrate-nitrite mixtures undergo thermal decomposition, which is probably accelerated to some unknown degree by irradiation. All three coolants are solid at ambient temperatures, but only the carbonates melt at too high a temperature to be used in a system with the restraint of a maximum first wall temperature of $400-500^{\circ} \mathrm{C}$. It is possible that there are other carbonates with lower melting temperatures. However, further evaluation must be made of the consequences of intermixing these oxidizing salts with lithium before the potential of these coolants for fusion systems containing lithium can be assessed.

The fluorides, best represented by LiF-34 mole $\% \mathrm{BeF}_{2}$, have such high melting temperatures that they cannot be used in an iron- or nickelbase alloy where the maximum first wall temperature is restricted to $400-500^{\circ} \mathrm{C}$. The fluorides are reasonably well known, and it is unlikely that there is a salt which has properties more attractive than those of LiF-34 mole \% BeF 2 .

The chlorides have not been studied as extensively as the fluorides, but there are several chloride salts with melting points in the range of interest. The compatibility of the chlorides with iron- and nickel-base alloys has not been studied in much detail, but it is quite likely that a suitable container material exists among the iron- and nickel-base alloys. Thus, it is felt that the chlorides are worthy of further evaluation.

Several specific areas have been enumerated for the various coolants in which additional information is needed to make decisions about the usefulness of each coolant. These areas are described for each coolant, and it is recommended that future work on coolants concentrates on these spêcytic areás.

1) Helium. Evaluate trade-offs between system pressure, therma? fatigue, and total power cost.

2) Water. Evaluate the consequences on operation and safety of intermixing with lithium.

3) Liquid metals. Maintain an awareness of new developments related to the abllity to pump in strong magnetic fields.

4) Lithium and beryllium fluoride salt mixtures. No further evaluation is required since the present information is adequate.

5) Sodium-potassium-nitrate-nitrite mixtures. Evaluate the rate of decomposition in a strong irradiation field. 
Evaluate the consequences (experimentally) of intermixing these mixtures with lithium.

6) Lithium-sodium hydroxides. Perform corrosion experiments with potentially suitable iron- and nickelbase alloys. Evaluate safety consequences of intermixing with lithium.

7) Chlorides. Review chloride phase diagrams and choose chloride systems with melting points and compositions for further evaluation. Perform compatibility experiments with potentially suitable iron- and nickelbase alloys. Perform experiments to evaluate stability in an irradiation field.

8) Organic coolant. No further evaluation is required due to the documented dissociation and fouling which occurs in an irradiation field.

9) Lithium-sodium-potassium carbonates. Make extensive review of literature to determine whether carbonates exist which have melting points and compositions of interest.

\subsection{CONCLUSIONS}

Many uncertainties exist concerning the exact performance requirements of coolants for fuston devices and the capabilitics of the various coolants. For these reasons, it. seems inappropriate to make inflexible decisions about which coolants are best. However, it is appropriate and necessary for progress that we identify the more promising coolants and that we periodically reexamine the data on coolant requirements and capabilities. The service requirements associated with commercial fusion power applications and the known properties of the candidate coolants have been critically reviewed. The following conclusions seem in order.

1) The salt candidates, HITEC, sodium hydroxide, and chlorides, appear to offer the most promise based on the guideline of low pressure operation. The sodium-potassium-nitrate-nitrite salt mixtures have been used most widely; therefore, primary emphas is is given to these salts. Much further experimental work is needed in the areas of corrosion and stability before a final assessment can be made of their potential usefulness for fusion applications.

2) In terms of stability and compatibility, helium is the coolant with the most potential, but it must be shown that helium can remove the heat from the first wall without imposing intolerable thermal stresses.

3) Water is potentially useful as a coolant, but it will require a pressurized system. It will also react vigorously with lithium and the consequences of this reaction must be evaluated further.

4) The liquid metals are excellent from a compatibility standpoint, but the strong magnetic fields of fusion devices increase the pumping power required and decrease the heat transfer capabilities of these fluids. Proposals for mitigating these effects should be investigated further in order to determine the applicability of liquid metals.

5) Both the LiF-BeF 2 salts and the carbonates have melting points which are too high for near-term applications involving iron- or nickel-base alloys where the maximum temperature must be restricted to the $400-500^{\circ} \mathrm{C}$ range.

They may be useful for higher temperature systems but should be reassessed with a specific system in mind.

6) The organic coolants dissociate under irradiation and form tars which interfere with heat transfer and pumping. There does not seem to be a suitable short-term solution to this problem, and these fluids are not recommended for fusion applications. 


\section{THIS PAGE}

\section{WAS INTENTIONALLY LEFT BLANK}


7. TOROIDAL FIELD COIL OPTIONS

W. C. T. Stoddart

\subsection{INTRODUCTION}

The coil system of a tokamak power reactor consists of the toroidal field (TF) coils, the ohmic heating solenoid, and additional poloidal field (PF) windings for plasma shaping and control. Three options are available for the conductor in the design of these coils: normal resistive windings, cryoresistive windings, and superconducting windings. The current generation of experimental tokamaks have provided a technology base for both resistive and cryoresistive coils, while the Large Coil Program at ORNL' will provide the technology base for large superconducting coils.

Resistive, cryoresistive, and superconducting windings have all been considered for the PF systems of tokamak reactors; ${ }^{2,3}$ nowever, only superconducting TF systems have been considered in these reactor studies because of the unfavorable power balance that would result from the use of resistive coils. Figure 7.1 shows the variation of plant efficiency with the ratio of thermal fusion power to coil power for a steam cycle efficiency of $35 \%$. It appears that the power balance begins to look attractive when the thermal fusion power is at least an order of magnitude greater than the TF coil power requirements. In this regard it is interesting to note that the ratio of thermal fusion power to compression coil power in the Reference Theta-Pinch Reactor ${ }^{4}$ is 118 ; the compression coif employs room temperature resistive windings in this design. The theta-pinch can achieve an acceptable power balance with resistive coils because it operates with a relatively high fusion power density. In general, previous tokamak reactor designs have operated with too low a fusion power density to allow an attractive power balance with resistive windings in the TF system. $2,5-10$ The fusion.

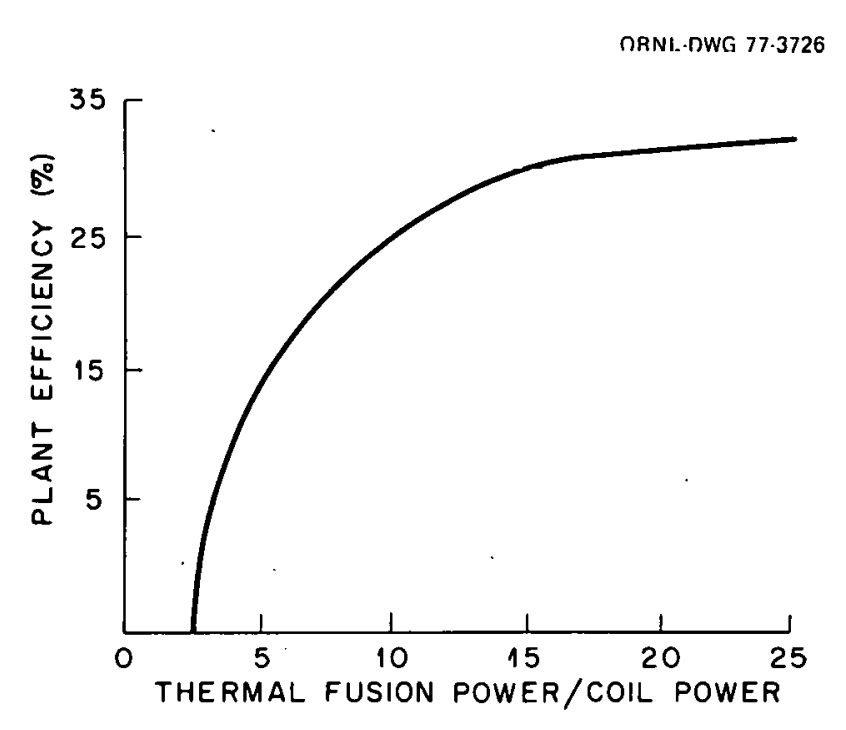

Fig. 7.1. Effect of coil power consumption on plant efficiency for a steam cycle efficiency of $35 \%$.

power density in the representative tokamak reactor considered in this study is significantly greater than that of previous tokamak reactor designs (see Table 7.1). Therefore, we have conducted a preliminary design study to determine to what extent resistive windings can be incorporated into the design of the TF system. The incentive for such a study is that resistive coils may ease certain maintenance and engineering problems in a commercial reactor. Table 7.2 presents the design parameters used in this study. 
Table 7.1. Comparison of power density in various fusion reactor studies

\begin{tabular}{lccc}
\hline $\begin{array}{l}\text { Reactor } \\
\text { design }\end{array}$ & $\begin{array}{c}\text { Fusion power } \\
(\mathrm{MW})\end{array}$ & $\begin{array}{c}\text { Plasma volume } \\
\left(\mathrm{m}^{3}\right)\end{array}$ & $\begin{array}{c}\text { Power density } \\
\left(\mathrm{MW} / \mathrm{m}^{3}\right)\end{array}$ \\
\hline & & & \\
ANL/FPR & 798 & 544 & 1.47 \\
ORNL/EPR & 513 & 675 & 0.91 \\
GA/EPR & 513 & 300 & 1.71 \\
UWMAK-I & 5000 & 6400 & 0.78 \\
UWMAK-II & 5000 & 6415 & 0.70 \\
UWMAK-III & 5000 & 2370 & 2.11 \\
PPPL & 5305 & 2190 & 2.42 \\
Th1S Study & 2000 & 266 & 7.52 \\
\hline
\end{tabular}

\footnotetext{
acorresponding to $\sim 22 \mathrm{MeV} /$ fusion event.

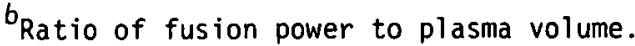

${ }^{c}$ The figures presented here differ from those in Sect. 2 due to the aśsumption of a circular plasma.
}

Table 7.2. Resistive toroidal magnet system design parameters

$\begin{array}{lr}\text { Coil shape } & \text { circular } \\ \text { Plasma radius } & 1.5 \mathrm{~m} \\ \text { Major radius } & 6 \mathrm{~m} \\ \text { TF coil inside diameter } & 5 \mathrm{~m} \\ \text { Field on axis } & 3.92 \mathrm{~T} \\ \text { Number of coils } & 18 \\ \begin{array}{l}\text { Electrical power } 0 \text { 100\% } \\ \text { duty factor }(\max )\end{array} & 2150 \mathrm{MW}(\mathrm{e})\end{array}$

$a_{\text {The assumption of circular coil and }}$ plasma shape results in a change in the required toroidal field from the $3.6 \mathrm{~T}$ reported in Sect. 2 . The plasma volume and total thermal power are al so reduced.

1. P. N. Haubenreich, "Subprogram I, Large Coil Project," in Program for Development of Toroidal Superconducting Magnets for Fusion Research, ORNL/TM-5401, Oak Ridge National Laboratory, Oak Ridge, Tennessee (April 1976).
2. B. Badger et al., UWMAK-III, A Noncircular. Tokamak Power Reactor Design, IJWFDM-150, University of Wisconsin, Madison, Wisconsin (Ju1y 1976).

3. Fusion Engineering Staff, Cunceptual Design Study of a Noncircular Tahamah Demonstration Fusion Power Reactor, GA-A13992, General Atomic Company, San Diego, California (November 1976).

4. An Engineering Design Study of a Reference Theta-Pinch Reactor (RPTR), LA-5336, ANL8019, joint report of Argonne National Laboratory, Argonne, IIlinois and Los Alamos Scientific Laboratory, Los Alamos, New Mexico (Marsh 1774).

5. W. M. Stacey, Tokamak Experimental Power Reactor Conceptual Design, ANL-CTR-76-3, Argonne National Laboratory, Argonne, I11 inois (August 1976).

6. D. G. McAlees et al., Plasma Engineering in a Deuterium-Tritium Fueled Tokamak, ORNI /TM5573, Oak Ridge National Laboratory, Oak Ridge, Tennessee (October 1976). 
7. C. C. Baker et al., Experimental Fusion Power Reactor Conceptual Design Study, GA-A14000, General Atomic Company, San Diego, California (July 1976).

8. B. Badger et al., UWMAK-1, A Wisconsin Toroidal Fusion Reactor Design, UWFDM-68, University of Wisconsin, Madison, Wisconsin (November 1973; revised March 1974).

9. B. Badger et a1., UWMAK-11, A Conceptual Tokamak Power Reactor Design, UWFDM-112, University of Wisconsin, Madison, Wisconsin (October 1975).

10. R. G. Mills (ed.), A Fusion Power Plan, MATT-1050, Princeton Plasma Physics Laboratory, Princeton, New Jersey (August 1974).

\subsection{DESIGN DESCRIPTION}

A preliminary design! of a resistive toroidal magnet system was developed for the parameters given in Table 7.2. Note that the coil shape was assumed to be circular;

Fig. 7.2 illustrates the basic coil geometry assumed. In carrying out this study, an evaluation of alternatives was made in the areas of materials selection, electrical insulation, cooling technique, and structural design approach; these alternatives were evaluated on the basis of fabrication requirements, development needs, capital and operating costs, and risk. Preliminary findings are summarized below.

11. R. J. Averi1T, R. D. Hay, W. G. Lampton, and E. J. Rappenport, Preliminary Engineering Study of Toroidal Magnets to Operate at Elevated Temperatures, contractor's report prepared by Magnetic . [ngincering $\Lambda$ ssociates, Cambridge, Massachusetts (November 1976).

\subsection{MATERIAL SELECTION}

The fundamental requirement for the conductor material is high electrical conductivity, but when raw material costs are also considered, the conductor materfal choice is basically limited to copper, aluminum, or their alloys. Structural integrity is another important consideration because of the high internal forces generated within the conductor; structural parameters of importance are the modulus of elasticity and yield strength.

Table 7.3 includes the range of copper and aluminum alloys considered as reasonable alternatives; Table 7.4 is a summary of their physical properties. The Glid-Cop copper alloys (formed by the dispersion of fine particles of aluminum oxide in high purity copper) have the most attractive electrical and structural properties. Manufacturing development is necessary to produce the large sections required for the TF coils, but the material is presently available in small billets. This alloy system was chosen for the conductor of the reference design.

The individual turns of the TF coils must be electrically insulated from each other. The electrical insulation, in addition to its major function of resisting an electrical stress on the order of $300-3000 \mathrm{~V} / \mathrm{cm}$, may also be subject to mechanical stress of a complex nature at room- to slightly-elevated temperatures. The additional requirement of resistance to radiation damage limits the choice of materials that may be considered. Combinations of organic materials such as the polyimide KAPTON and inorganics such as micas or ceramics seem to be appropriate choices.

The choice of Glid-Cop as the electrical conductor precludes the need for interleaved or lumped structural material, as will be discussed in a later paragraph. 
ORNL.DWG 77.3727

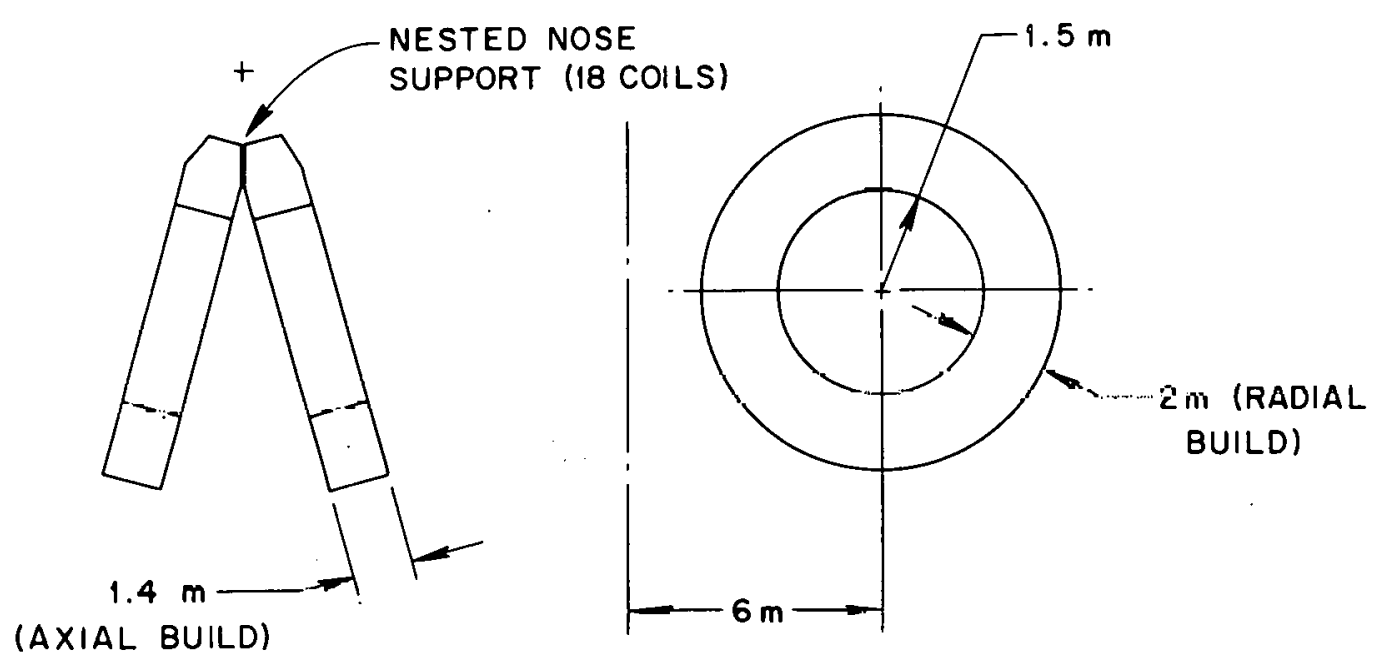

Fig. 7.2. TF coil geometry.

\subsection{STRUCTURAL DESIGN AND FABRICATION}

The structural design of a resistive coil is determined by allowable stress, mechantcal loading, design lite of the coil, and allowable space envelope for the coil. The general philosophy of the Princeton Large Torus TF coils was used in the preliminary design of the TF coils. The coils are considered to be supported by wedging at the tapered coil nose and resistance to the hoop stresses within the magnet itself. No consideration was given to out-of-plane loading on the TF coils. A stress analysis of the proposed coil design was performed using the computer program STARDYNE. For the reference design, the following stress levels are estimated for a homogenized structural model:

$\begin{array}{ll}\text { maximum principal stress } & 4720 \text { psi, } \\ \text { minimum principal stress } & 3560 \text { psi, } \\ \text { maximum shear stress } & 4070 \text { psi, } \\ \text { maximum von Mises stress } & 7260 \text { psi. }\end{array}$

These stresses are generally acceptable for a preliminary design. A detailed examination of the heterogeneous nature of the coil would be required for a detailed design.

The materials proposed and their usage in the coil design do nul constitute an unsupportable extrapolation from current technology such as the Tokamak Fusion Test Reactor (TFTR) TF coils. The incorporation of special mechanical and electrical coolant flow paths would require dppropriace detaliled consideration, but it appears that no insurmountable problems exist.

\subsection{COOLING METHOD}

In this initial evaluation we did not try to recover the heat generated in the TF coils but. considered only the cooling requirement for electrical and structural integrity. We considered several alternatives for the coolant, including helium gas, organic liquids, molten salts, and pressurized water. Pressurized water appears to be the obvious choice, considering flow rates, corrosion, temperature effects on conductor resistivity, strength, and reliability. To minimize resistance heating, we used low current 
Table 7.3. Nominal chemical compositions, weight percentages, and relative costs of selected coppers and copper alloys and aluminum and aluminum alloys

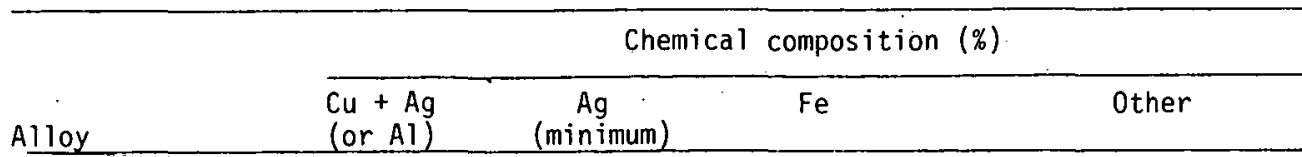

Copper-based

\begin{tabular}{|c|c|c|c|c|}
\hline CDA 102 & $99.95^{a}$ & - & - & - \\
\hline CDA 110 & $99.90^{a}$ & - & - & - \\
\hline CDA .116 & $99.90^{a}$ & 0.085 & - & - \\
\hline $\operatorname{CDA} 150$ & $99.80^{a}$ & - & - & $0.15 \mathrm{Zr}$ \\
\hline CDA 162 & 99.00 & - & $0.02^{6}$ & $1.0 \mathrm{Cd}$ \\
\hline CDA 175 & 96.9 & - & $0.10^{b}$ & $2.5 \mathrm{Co} ; 0.6 \mathrm{Be}$ \\
\hline CDA 182 & 99.1 & - & $0.10^{b}$ & $0.9 \mathrm{Cr}$ \\
\hline CDA 185 & 99.2 & 0.08 & - & $0.7 \mathrm{Cr}$ \\
\hline CDA 194 & 97.5 & - & 2.4 & $0.13 \mathrm{Zr} ; 0.04 \mathrm{P}$ \\
\hline CDA 195 & 97.0 & - & 1.5 & $0.8 \mathrm{Co} ; 0.6 \mathrm{Sn} ; 0.1 \mathrm{P}$ \\
\hline Glid-Cop $A 1-20$ & 99.6 & - & - & $0: 4 \mathrm{Al}_{2} \mathrm{O}_{3}$ \\
\hline Glid-Cop A1-35 & 99.3 & - & - & $0.7 \mathrm{Al}_{2} \mathrm{O}_{3}$ \\
\hline Glid-Cop Al-60 & 98.9 & - & - & $1.1 \mathrm{Al}_{2} \mathrm{O}_{3}$ \\
\hline
\end{tabular}

Aluminum-based

EC-HI9

$99.45^{a}$

5005- 119

6101-T61

$a_{\text {Minimum value. }}$

baximum value.

density, which will require a relatively small percentage of the conductor cross section for cooling channels.

The heat deposition due to nuclear heating of the conductor is small compared with that due to resistive heating: The heat transfer between the blanket and the TF coils may be slgnificant if inadequate thermal barriers are present. It is felt that this heat flow may be kept to a reasonable limit by an appropriate choice of insulation type and geometry. $7.6^{\circ} \cos T$

There are generaliy two costs to be considered relative to the TF coil: operating and capital. For our purposes, the power consumed by the TF coils will be viewed in terms of its effect on power balance. A simple estimate of the power required per coil may be obtained from the following equation:

$P_{c}=\frac{\pi}{4} \times 10^{14} \frac{B^{2} R^{2}}{N_{C}} \frac{\rho}{\lambda} \frac{D+b}{b h}$,

where $P_{C}$ is the power required per coil in watts,

$B$ is the on-axis, field in tesla,

$R$ is the plasma major radius in meters,

$\rho$ is the conducior's conductivity in ohmmeters, 
Table 7.4. Properties of copper alloys of high electrical conductivity and strength characteristics. Aluminum alloys given for reference. Temperature base is room temperature $\left(70^{\circ} \mathrm{F}\right)$

\begin{tabular}{|c|c|c|c|c|c|c|}
\hline & $\begin{array}{l}\text { Electrical } \\
\text { conductivity } \\
\text { annealed } \\
(\% \text { IACS) }\end{array}$ & $\begin{array}{c}\text { Yield } \\
\text { strength } \\
\text { annealed } \\
\text { (psi) }\end{array}$ & $\begin{array}{l}\text { Yield } \\
\text { strength } \\
\text { (cold-worked } \\
\text { to half hard, } \\
\text { or aged) }\end{array}$ & $\begin{array}{l}\text { Fatigue } \\
\text { strength } \\
\text { (psi for } \\
10^{8} \text { cycles) }\end{array}$ & $\begin{array}{l}\text { Annealing } \\
\text { temperature } \\
\left({ }^{8} \mathrm{C}\right)\end{array}$ & $\begin{array}{l}\text { Cost } \\
\text { index } \\
\text { (volume basis }\end{array}$ \\
\hline
\end{tabular}

Copper-based

\begin{tabular}{|c|c|c|c|c|c|c|c|}
\hline $\begin{array}{ll}\text { CDA } & 102 \\
\text { CDA } & 110 \\
\text { CUA } & 110 \\
\text { CDA } & 150 \\
\text { CDA } & 162 \\
\text { CDA } 175 \\
\text { CDA } 182 \\
\text { CDA } 185 \\
\text { CDA } 194 \\
\text { CDA } 195 \\
\text { G1id-Cop } \\
\text { Glid-Cop } \\
\text { Glid-Cop }\end{array}$ & $\begin{array}{l} \\
\text { A1 }-20 \\
\text { Al }-35 \\
\text { Al }-60\end{array}$ & $\begin{array}{l}101 \\
101 \\
100 \\
93 \\
90 \\
45 \\
80 \\
80 \\
65 \\
50 \\
89 \\
85 \\
78\end{array}$ & $\begin{array}{r}10,000 \\
10,000 \\
10,000 \\
6,000 \\
7,000 \\
25,000 \\
14,000 \\
14,000 \\
24,000 \\
65,000 \\
53,000 \\
61,000 \\
65,000\end{array}$ & $\begin{array}{l}36,000 \\
36,000 \\
36,000 \\
6 n, 0 n n \\
45,000 \\
60,000 \\
42,000 \\
42,000 \\
50,000 \\
80,000 \\
72,000 \\
80,000 \\
=83,000\end{array}$ & $\begin{array}{c}13,000^{b} \\
13,000^{b} \\
- \\
- \\
30,000^{d} \\
35,000^{c} \\
- \\
- \\
21,000^{d} \\
26,000^{d} \\
220,000 \\
- \\
-\end{array}$ & $\begin{array}{c}375-650 \\
375-650 \\
475-750 \\
c \\
425-750 \\
c \\
c \\
c . \\
375-650 \\
400-600 \\
650 \\
700 \\
800\end{array}$ & $\begin{array}{l}1.05 \\
1.00 \\
1.01 \\
2.60 \\
1.05 \\
2.70 \\
1.35 \\
- \\
0.99 \\
1.07 \\
22.6 . \\
22.6 \\
22.6\end{array}$ \\
\hline
\end{tabular}

Aluminum-based

$\begin{array}{lcccccc}\text { EC-H19 } & 62 & 4,000 & 24,000 & >7,000 & 345 & 0.15 \\ 5005-\mathrm{H} 19 & 54 & 6,000 & 229,000 & - & 345 & 0.15 \\ 6101-\mathrm{T} 61 & 58 & - & 28,000 & - & : & -\end{array}$

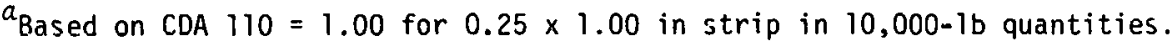

${ }^{b}$ For half hard moterial.

CReyuires solution and aging.

$d_{\text {For hard material. }}$.
}

D is the coil inside diameter in meters",

$b$ is the coil radial build in meters,

$h$ is the coll axial build in meters,

$\lambda$ is the coil packing fraction,

$N_{C}$ is the number of coils.

Substitution of the previously determined coil parameters indicates a power demand of $135 \mathrm{MW}$ for the coil system, which is generally within the range stated in Table 7.2. The plant officiency of such a system would be less than $15 \%$ (see Fig. 7.1).

The capital cost of such a large copper magnet system is difficult to estimate.

Based on the limited data available, the manufacturing and fabrication costs on a nonrommercial basis are estimated to be on the order of $\$ 20 / 1 \mathrm{~b}$ in 1976 dollars. The estimated weight of the installed copper is $17.5 \times 10^{6} \mathrm{lb}$; cost would thus be on the order of $\$ 350$ million.

In summary, about 19\% of the generated power (using a $35 \%$ thermal efficiency) would be dissipated in the coils and the capital cost would be a significant portion of the total plant cust. Fur reference, the cost of a comparable superconducting coil system is estimated to be about $\$ 90$ million. 


\subsection{DISCUSSION}

The electrical power requirements and the capital costs of a resistive TF coil set may be excessive even for the high power density system considered here. However, a study of overall plant assembly and maintenance reveals that it may be advantageous to use superconducting coils in regions where access to the internal regions is not required and resistive coils where disassembly is necessary. Specific areas where resistive coils may be required are the locations of neutral beam injectors or large vacuum ports. The resistive coils would require development of a new electrical joint design beyond current experience in terms of size and ampere turns.

The TFTR program at Princeton Plasima Physics Laboratory will identify some of the major difficulties in dealing with large resistive TF coil sets. Special needs of power-producing devices such as the joints or interfacing to superconducting systems are being addressed to some degree in The Next Step (TNS) program. The questions of how the goals may be accomplished are thus being considered at several locations. The reliability of such large resistive coils is not entirely certain; however, they seem to be within a reasonable extrapolation of current practice, i.e., a factor of about two compared to TFTR.

\subsection{CONCLUSIONS}

The TF coil set for commercial fusion power does not appear to be economically attractive if totally resistive. However, there may be some advantage to utilizing both resistive and superconducting coils in the design of the toroidal field system. The next period of study will address the questions of total system power balance, space allocation for the several required magnetic systems, and the concept of a coupled superconducting and resistive TF magnet system. 


\section{THIS PAGE \\ WAS INTENTIONALLY \\ LEFT BLANK}




\section{THE VACUUM TOPOLOGY}

R. W. Werner

\subsection{INTRODUCTION}

It is a prime objective of the Demo study to profitably exploit the unique features of the fusion energy source. This means that the nuclear island of a commercially viable fusion power plant must be constructed around its own peculiar characteristics. It cannot look like a fission plant, an LMFBR, or a fossil plant. Neither can it afford the pitfall of copying, on an upgraded scale, the characteristics of machines designed for experimental physics. This latter problem is evidenced in virtually all reactor designs to date. One of the specific things that can be recognized as being in this "hand-me-down" category is that of locating immediately next to the plasma the closed surface that separates the "hard" vacuum of the plasma zone from atmospheric pressure. This closed surface used in such a way contains hundred to thuusands of lineal meters of welds or complex mechanical seals. once the last weld has been made, some fusion power has been generated, and radioactive parts have been produced, then the system becomes difficult to repair as a direct consequence of its own assembly. If the closed surface develops a pinhole leak in the irradiated, cyclically stressed welds, it is doubtful that it can be repaired without unreasonable difficulty. When the surface must be replaced, a long-term major shutdown is involved.

In this study we address the idea of enclosing the entire reactor in a vacuum building. We thus completely change the character of this closed surface from one requiring absolute vacuum integrity and an extremely long life expectancy to one that need have only high pumping impedance - it can be slightly leaky because the pressures on either side are about the same - and a shorter life requirement because it comes apart. Two vacuum zones are proposed: the ultraclean vacuum of the plasma zone and the vacuum of the remainder of the volumie. These would be differentially pumped. It is likely that there would also be a ternary guard vacuum between the interior surface of the main building and an inside shell. In addition to the assembly, disassembiy, and repair advantages there are others worth citing. Inevitably, there are also disadvantages.

\subsection{THE TECHNICAL ADVANTAGES}

The principal gains we see at this time are listed below.

\subsubsection{Elimination of All Remote Field Welding in the Reactor Region}

The primary vacuum in many of the present reactor concepts is established by peripheral seam welds generally made between adjacent blanket modules. The total length of these welds that must have $100 \%$ integrity against leakage can be thousands of meters. In the event of a leak, it must first be found - no small task - and then repaired. In the event of replacement of blankets, the entire weld must be cut. All the operations (leak hunting, repair, cutting, and replacement) almost certainly must be done remotely. This is an incredibly difficult task. Furthermore, these weld zones will be subject to both thermal stress and thermal cycling with almost certain leakage in time. These welds are not necessary and can be eliminated by moving the primary vacuum to the room temperature enclosure.

\subsection{2 "Hands-On" and Remote Handling Compati- bility}

The reasonable concern of experimentalists that a vacuum enclosure is inhibiting and causes unreasonable difficulty for some experiments is satisfactorily answered by. the fact that pumpdown time from atmospheric pressure to $10^{-6}$ torr 
is $10 \mathrm{hr}$ for facilities having a larger volume than would be required for a fusion reactor, such as the NASA Plum Brook space chamber. 1 Thus, work or experiments requiring "hands-on" operation (neglecting the problems of radiation) could be done within a 24-hr period. For the remainder of the experiments, tests, routine maintenance, etc., the vacuum could be retained. One must not, however, lose sight of the fact that a commercial reactor is not an experiment, and there cannot be "hands-on" operation anyway on a day-to-day or week-toweek basis.

1. Space Power Facility: Description and Capabilities, NASA, Lewis Research Center, Plum Brook Station, Sandusky, Ohio (June 1974).

\subsubsection{Replacement Ease - Blanket Module}

With the blanket modules assembled as a nested set with a minimum of mechanical connections and no welded connections, it is possible to visualize remote module replacement that will have a minimum amount of difficulty. The optimum replacement technique could be one using simple translation of the first blanket zone (FBZ) or of the total blanket units exiting between the toroidal coils. (A rectangular blanket using $F B Z$ units and taking advantage of this total vacuum topology is discussed in Sect. 4.)

\subsubsection{Remote Handling}

In addition to the blanket modules, there is remote handling involved in a significant number of other reactor components - such as injectors - that probably can be repaired or replaced in a total vacuum environment more readily than in one where the vacuum is in only the plasma zone. In fact, anything that penetrates the reactor vessel to communicate in one way or another with the plasma (pressure transducers, temperature transducers, plasma diagnostic probes, etc.) can be much more readily replaced when it does not have to pass through a vacuum-tight intervening wall.

\subsubsection{Reduction of Physical Size}

The elimination of welds which would have established the primary vacuum in the plasma region if a vacuum building were not used also eliminates the need to provide access space to these welds. Eliminating this access space can reduce the total reactor diameter by as much as 2-3 m.

\subsubsection{Operation Time}

The effective on-line time of the rcactor should improve with the use of a vacuum enclosure since the need to let the plasma zone up to air or up to argon is eliminated. This should decrease markedly the "bake-in" or outgassing times

\subsubsection{Tritium Control and Accidental Release}

The use of a vacuum vessel operating at room temperature creates a highly effective diffusion barrier against tritium release. If there is an accidental release of tritium from the reactor zone, it can be collected on the enveloping cold wall and recovered in a controlled way.

\subsubsection{Relaxation of Pressure Loads}

The welding of the blanket modules, one to the next, creates a structure that is effectively an exterially loaded pressure vessel. This high temperature vesscl is subject to creep buckling. The problem may have a divergent solution; if the walls are thin for good neutronics, good tritium breeding, and minimum neutron heating, they may fail by buckling. If the walls are thick enough to resist buckling at. some temperature $(T)$, then the additional neutron heating of the thicker material causes the temperature to rise to $T+\Delta T$, lowering the sreep hurkling resistance. A serias of nestod blanket modules physically assembled side by 
side circumvents this potential problem.

\subsubsection{More Effective Control of Heat. Transfer}

The proximity of $4-K$ toroidal field coils and divertor coils to $1000-K$ blankets, $500-K$ shields, room temperature vertical field coils, etc. creates a heat transfer problem that absolutely must be minimized. The penalty paid because of energy trarisfer into a cryogenic coil and the consequent refrigerator load is $\sim 500 \mathrm{~W} / \mathrm{W}$. The most effective means for decoupling the energy exchange is to reduce it to a problem of radiation heat transfer and introduce the use of inexpensive thin foil radiation shields. At a penalty of $500 \mathrm{~W} / \mathrm{W}$, $100 \%$ of the plasma power generated is nonproductively used for refrigeration when the thermal energy loss from the blanket or other thermal surfaces to the coil is equal to only $0.2 \%$. We can perhaps afford a heat leak of $0.002 \%$ of the total blanket energy, or about $20 \mathrm{~kW}$ thermal loss to the cryogenic coils in a $1000-\mathrm{MW}(t)$ reactor. Since this energy can come from any heat source, not just the blanket, thermal isolation is extremely important.

\subsubsection{Environmental Protection for Refrac- tories}

The refractory metals which are candidates for blanket zone materials - niobium, vanadium, molybdenuill, tungsten, titanium, and tantalum - cannot be used at elevated temperatures without a protective atmosphere. Cover gases such as argon may be acceptable, but considering the need to minimize all convective and conduction heat transfer, a vacuum background is a better solution.

\subsection{THE TECHNICAL DISADVANTAGES}

The disadvantages and possible means of circumventing them are listed below.

\subsubsection{Large Surface Areas and Continuous Out- gassing}

The differential pumping of the plasma zone and the remaining volume minimizes this problem. simple, high impedance closures such as spring clips, baffles, 0-rings, or metal bonds can be made. These can be intrinsically part of a module or, if not, can be designed to be easily replaced or removed.

\subsubsection{Components that "Abhor" Vacuum}

There are components that function more effectively in a normal pressure environment. These are parts with low vapor pressure characteristics such as lubricated bearings, certain parts of injectors that may arc or have corona discharge, etc. These parts are outside of the blanket shield zone and can be individually pressurized or sealed. Fortunately, the number of sensitive components is small.

\subsubsection{Vacuum Welding In Situ}

Within the blanket area with its nested modules, there is a problem that adjacent parts operating at high temperature may vacuum-fuse together if they are initially in physical contact. The simple closures mentioned in Sect. 8.3.1 must therefore include a coating or barrier that prevents the weld. Further study is needed here.

\subsubsection{The Vacuum Building Itself}

The building of a large vacuum enclosure is not trivial. However, the approximately $2 \mathrm{~m}$ of concrete which will be required as a biological shield can also be used as structure. There can be no substantial difference in the building size required for the reactor whether it is constructed for use as a vacuum building or used at atmospheric pressure.

\subsubsection{Construction Beyond Current Technology}

There may be a fear or reservation that vacuum enclosures of the physical size needed to house a fusion reactor are structurally 
unreasonable or visionary. This incorrect assumption is countered by the existence of the NASA Plum Brook facility. A cross section of that facility is reproduced in Fig. 8.1. Registered on the figure are the approximate dimensions of the representative tokamak reactor specified in Table 2.3. Clearly the volume, the dimensions, and the shielding would be adequate.

Figure 8.2 shows a plan view of the Plum Brook facility including assembly areas, disassembiy areas, hót celis, ottıces, cryogenic areas, etc.; everything needed in a representative way for a fusion reactor facility. Plum Brook, as a total facility, cost $\sim \$ 29$ million in 1962 dollars, as indicated in the cost breakdown of Table 8.1. In terms of 1976 dollars, using an average escalation rate of $6.5 \%$ for labor and materials, the cost would be $\$ 70$ million. A check mark ( $V$ ) indicates those items on the cost breakdown uniquely related to the vacuum system. They amount to about $33 \%$ of the total. These added costs may be more than recovered by savings in the reactor capital cost.

\subsection{THE VACUUM SYSTEM AND PUMPDOWN TIMES}

As a first approximation to gage the pumping power, and assuming the NASA Plum Brook facility to be more than that required for housing a fusion reactor, then the vacuum system, the vacuum levels attainable, and the pumpdown times actually realized for that station all have encouraging values. A summary of the characteristics is reproduced here.

\subsubsection{Vacuum System of Plum Brook.}

The basic vacuum system consists of thirtytwo 48-in.-diam $\mathrm{LN}_{2}$-baffled diffusion pumps mounted in the chamber floor plus two roughing trains of five stages each. Ëach roughing train consists of:

Stage 1 Two 1000-hp Roots Blowers

Stage 2 One 500-hp Roots Blower

Stage 3 One 300-hp Roots Blower
Stage 4 One 200-hp Roots Blower

Stage 5 Three Beach-Russ rotary piston-type mechanical vacuum pumps

[Approximate total power: Roughing $=6 \mathrm{MW}$, Diffusion pumping $=1.2 \mathrm{MW}$, Total $=7.2 \mathrm{MW}$ (Author)]

\subsubsection{Current Achievable Vacuum Level}

Vacuum capability: For clean chamber and spacecraft with $L N_{2}$ baffles operating $I \times 10^{-8}$ torr.

Current operating experience: For high level of outgassing from test support equipment and test article (no $\mathrm{LN}_{2}$ baffles operating) $-5 \times 10^{-7}$ to $1 \times 10^{-6}$ torr.

Roughing pump performance per train:

Stage 130,500 cf 111

Stage $218,300 \mathrm{cfm}$

Stage $3 \quad 9,900 \mathrm{cfm}$

Stage $4 \quad 4,720 \mathrm{cfm}$

Stage $5 \quad 2,160 \mathrm{cfm}$

Typical pumpdown times:

Atmospheric pressure to 20 torr $2 \mathrm{hr}$ $10^{-3}$ torr $6 \mathrm{hr}$ $10^{-6}$ torr $10 \mathrm{hr}$

\subsection{DISCUSSION}

The burden of proof as to whether the vacuum building concept is a good idea remains unresolved. Citing, more or less in a philosophical way, the advantages and disadvantages serves to bring lhe idea Into focus but solves nuthing.

It seems that there is an economical opfurlunity to test the concept and compare it with competing concepts as far as remote maintenance, assembly, disassembly, gas control, etc. are concerned by making use of the existing Plum Brook vacuum chamber. This chamher would be suitable for testing in whatever way was appropriate - mock-ups of portions of a rcactor a quadrant or octant for instance. The advantage of the facility is that lesting by remote means can be done either in a vacuum or at atmospheric pressure. 


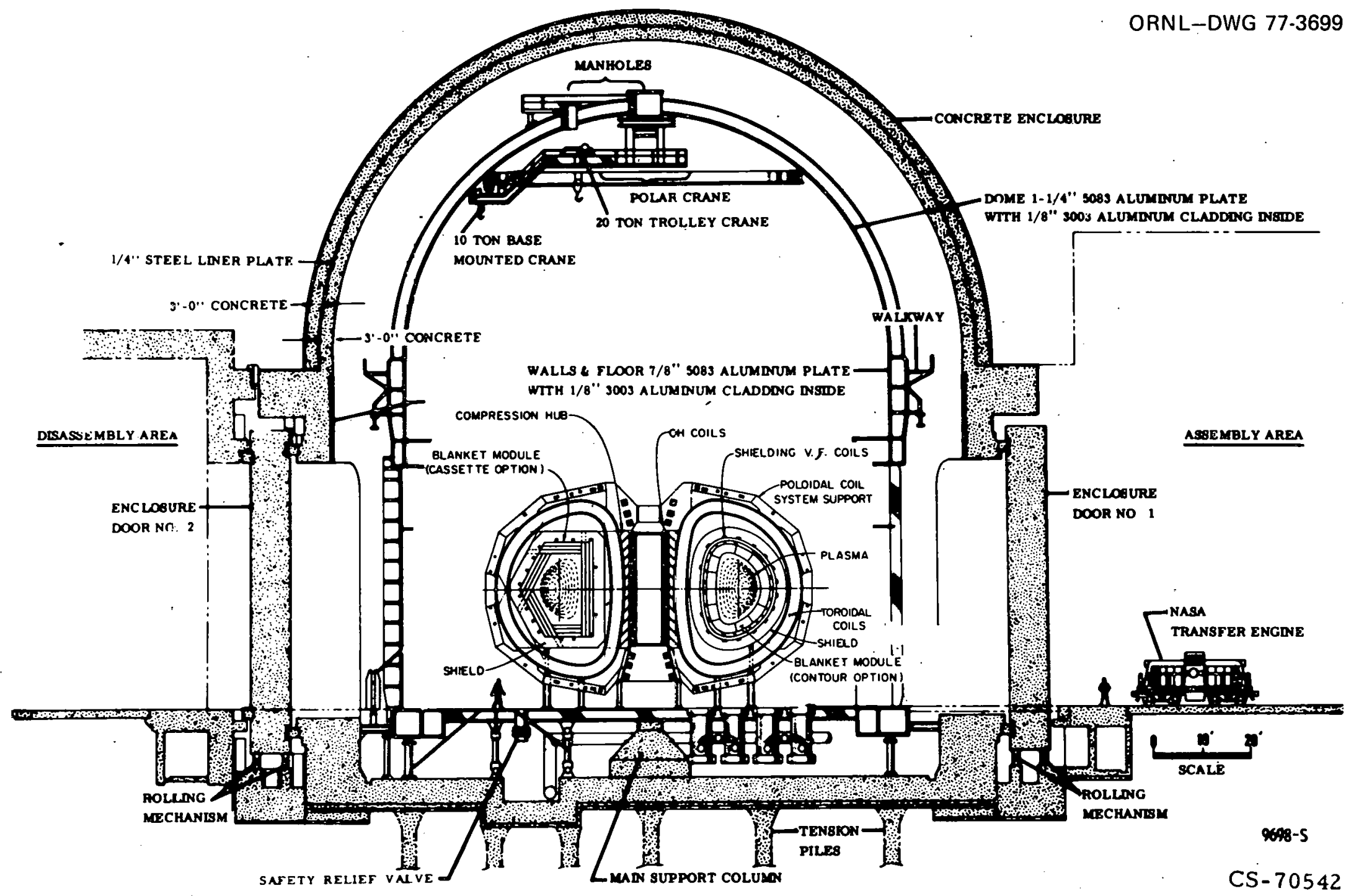

Fig. 8.1. Cross section through test chamber - Space Power Facility. 


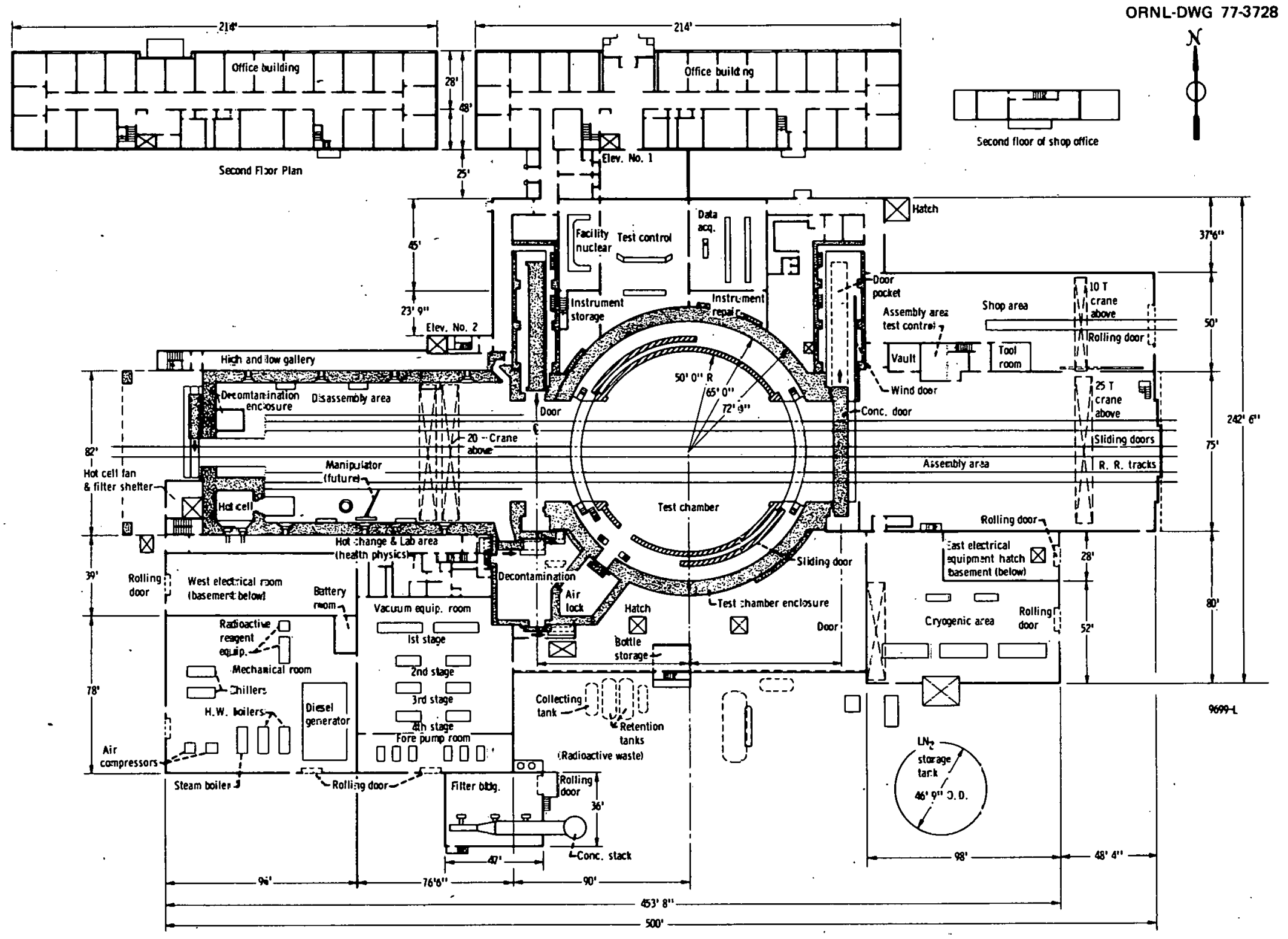

Fig. 8.2. Plan View - Space Power Facility. 
Table 8:1. Actual construction costs at Plum Brook space power facility representative of 1962-63 dollar values

Site development

Electrical installation

Water, sewer, and gas installations

Steam distribution system

Maintenance, assembly, and disassembly area

Operationis and shop area

office area

Control area

Security and monitoring area

Concrete housing and shield for test chamber

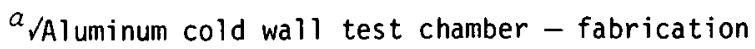

$\checkmark$ Aluminum cold wall test chamber - cryogenic piping

$\sqrt{ }$ Aluminum cold wall test chamber - cleaning, leak

checking, insulation

$\checkmark$ Cryogenic and other cooling systems

$\checkmark$ Pumping systems

Instrumentation and controls

Water treatment system

Safety and radioactivity monitoring equipment

cranes

Special foundations for equipment

Decontamination equipment

Mechanized entry doors

Slavemasters and manipulators

Special tools for shop in hot area

Design and engineering

TOTAL
$\$$

$407,516.63$

$626,000.00$

$230,688.00$

$85,562.48$

$3,803,657.27$

$1,882,261.84$

$440,028.49$

$473,073.79$

$58,000.00$

$4,570,580.91$

$4,649,933.80$

$641,324.67$

$398,085.02$

$2,385,292.53$

$1,659,607.90$

$1,224,302.02$

$153,668.58$

$-0-$

$175,514.75$

$100,000.00$

$50,000.00$

$2,562,871.47$

$1,091.86$

$7,554.89$

$2,250,468.14$

$\$ 28,845,085.00$

$a_{\sqrt{ } \text { Indicates those }}$ items uniquely related to the vacuum system. 


\section{THIS PAGE}

\section{WAS INTENTIONALLY}

LEFT BLANK 


\section{POWER CONVERSION SYSTEM}

R. L. Reid

\subsection{INTRODUCTION}

The thermal power liberated during the burn portion of the representative reactor unit is $2260 \mathrm{MW}(\mathrm{t}): 1422 \mathrm{MW}(\mathrm{t})$ from thermalization of the 14.1-MeV neutrons, $353 \mathrm{MW}(\mathrm{t})$ from 3.5MeV alpha particles, and $485 \mathrm{MW}(\mathrm{t})$ from exothermic reactions in the blanket. The burn is estimated to be $95 \%$ of the operating cycle (20-min burn, 1 min off), which results in an equivalent steady-state power of $2150 \mathrm{MW}(t)$, all of which is assumed to be available to the power conversion system.

Heat is transferred from the blanket of the reactor to a steam power cycle by way of an intermediate heat transport loop. The primary purpose of this loop is to prevent pressurizing the low pressure blanket by high pressure steam should there be a tube leak in the steam generator. The coolant for both the intermediate heat transport loop and the blanket is a molten salt composed of sodium and potassium nitrates.

The initially selected blanket coolant inlet and exit temperatures were $500^{\circ} \mathrm{F}$ and $900^{\circ} \mathrm{F}$; these values were primarily set by the freezing and decomposition temperatures of the salt. The temperature differences across the primary loop to the intermediate loop heat exchanger were set at $50^{\circ} \mathrm{F}$ on the hot side and $18^{\circ} \mathrm{F}$ on the cold side. The temperatures of the molten salt entering and exiting the steam generator in the intermediate loop were therefore $850^{\circ} \mathrm{F}$ and $482^{\circ} \mathrm{F}$, respectively.

\subsection{HEAT BALANCE}

A heat balance was determined for the steam cycle for $2150 \mathrm{MW}(t)$ delivered to the steam generator by molten salt at $850^{\circ} \mathrm{F}$ inlet and $482^{\circ} \mathrm{F}$ exit temperatures. The steam turbine selected is an 1800-rpm tandem compound, two-flow high pressure section, four-flow low pressure section, with five slages of feed- water heating configuration. Four moisture removal sections are used in the low pressure turbine which drains to the feedwater heaters.

The saturation temperature of the steam generator was set at $540^{\circ} \mathrm{F}$, which corresponds to a boiler pressure of $963 \mathrm{psia}$. This is the current region of operation for steam generators for nuclear applications. Two hundred degrees of superheat were assumed, which results in a steam exit temperature of $740^{\circ} \mathrm{F}$. The steam generator inlet feedwater temperature was set at $377^{\circ} \mathrm{F}$ in order to maintain a minimum temperature difference of $10^{\circ} \mathrm{F}$ at the "pinch point" within the steam generator, i.e., at the boiler inlet section. Figure 9.1 shows the temperatures of the water and molten salt within the steam generator.

A condenser pressure of $2.5 \mathrm{in.}$ of mercury in conjunction with a mechanical draft cooling tower was selected. This corresponds to a condenser saturation temperature of $108.7^{\circ} \mathrm{F}$. Cooling tower water flow was determined based on a range of $20^{\circ} \mathrm{F}$, a wet bulb temperature of $70^{\circ} \mathrm{F}$, and an approach to the wet bulb of $10^{\circ} \mathrm{F}$.

A heat balance for this cycle, generated by the ORCENT computer code, shows a net thermal efficiency of approximately $35 \%$. A heat balance diagram (Fig. 9.2) shows the temperatures, pressures, flow rates, and extraction arrangement for this cycle. An overall energy schematic for the power conversion system (primary loop, intermediate loop, and secondary loop) is shown in Fig. 9.3. The steam cycle design parameters are presented in Table 9.1.

The heat balance presented is representative but not necessarily optimum. Trade studies to evaluate the effect of coolant temperatures on blanket design and plant efficiency should be performed. Also variations to the steam cycle - such as including steam reheaters between the high pressure and low pressure turbines - should be evaluated. 


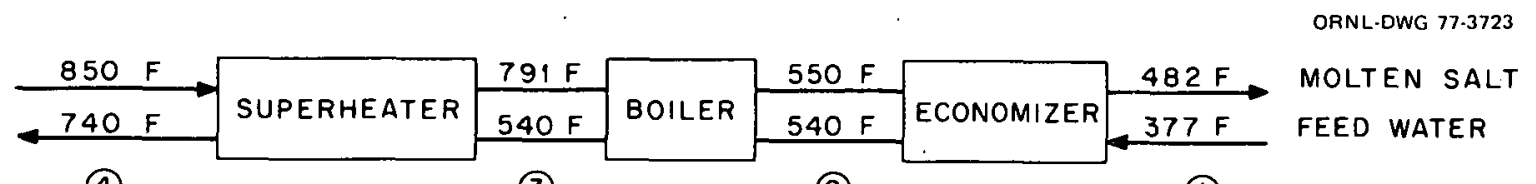

(4)

(3)

(2)

(1)

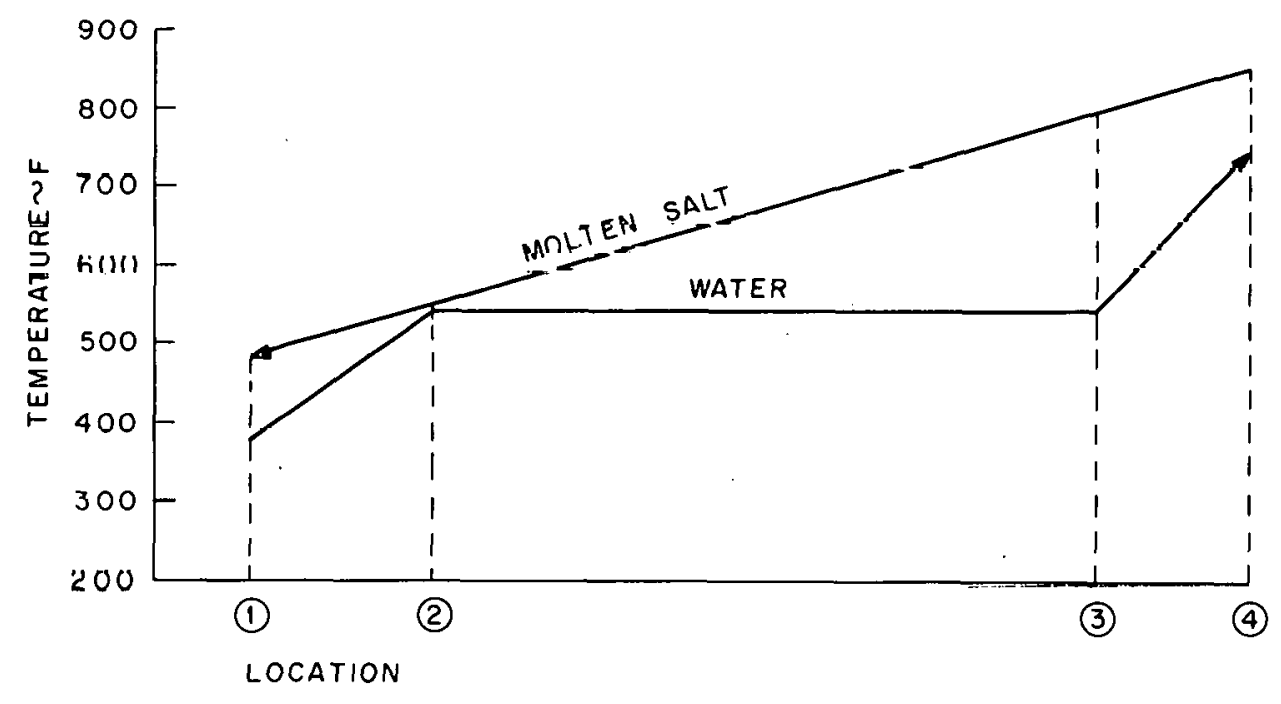

Fig. 9.1. Steam generator coolant temperatures.

\subsection{ENERGY STORAGE SYSTEM}

The operating cycle for the representative reactor unit utilizes a 20 -min burn followed by a 1 -min downtime to pump out and recharge the torus and charge the ohmic heating transformer. This cyclic or pulsed mode of operation presents two problems: the first involves the steam turbine, for which the steam inlet temperature and pressure must be maintained constant during the entire cycle; the second concerns minimizing thermal cycling in the blanket cooling system and structure. Supplying constant steam conditions to the turbine throttle is imperative. Blanket life will be increased if thermal cycling is minimal; however, minimizing thermal cycling is not absolutely essential to the operation of the prant.

To provide constant power to the steam turbine for this intermittent plasma operation, a coolant storage system is proposed. The principle employed is storage of the coolant in the iintermediale luup al a hiylı lemineralure durlny the burn. This hot coolant (molten salt) is then introduced into the circuit in a controlled manner during the off part of the cycle. An equal volume of the stored hot salt is stored in a tank after it has passed through the steam gerierialur. The cuulanl pumn In the Intermedtate loop runs at a constant speed so that the steam generator is supplied with a constant heat input, which is $95 \%$ of the thermal power being produced. The oneration is schematically depicted in Fig. 9.? and is described as follows. One of three identical coolant loops for the blanket is shown in the figure. The coolant flow rate is about $2700 \mathrm{ft}^{3}$ per minute, and each of the two storage tanks will hold a little over $2700 \mathrm{ft}^{3}$. The cold storage tank is full of cold salt when the plasma burn is initiated. When the salt temperature from the intermediate heat 


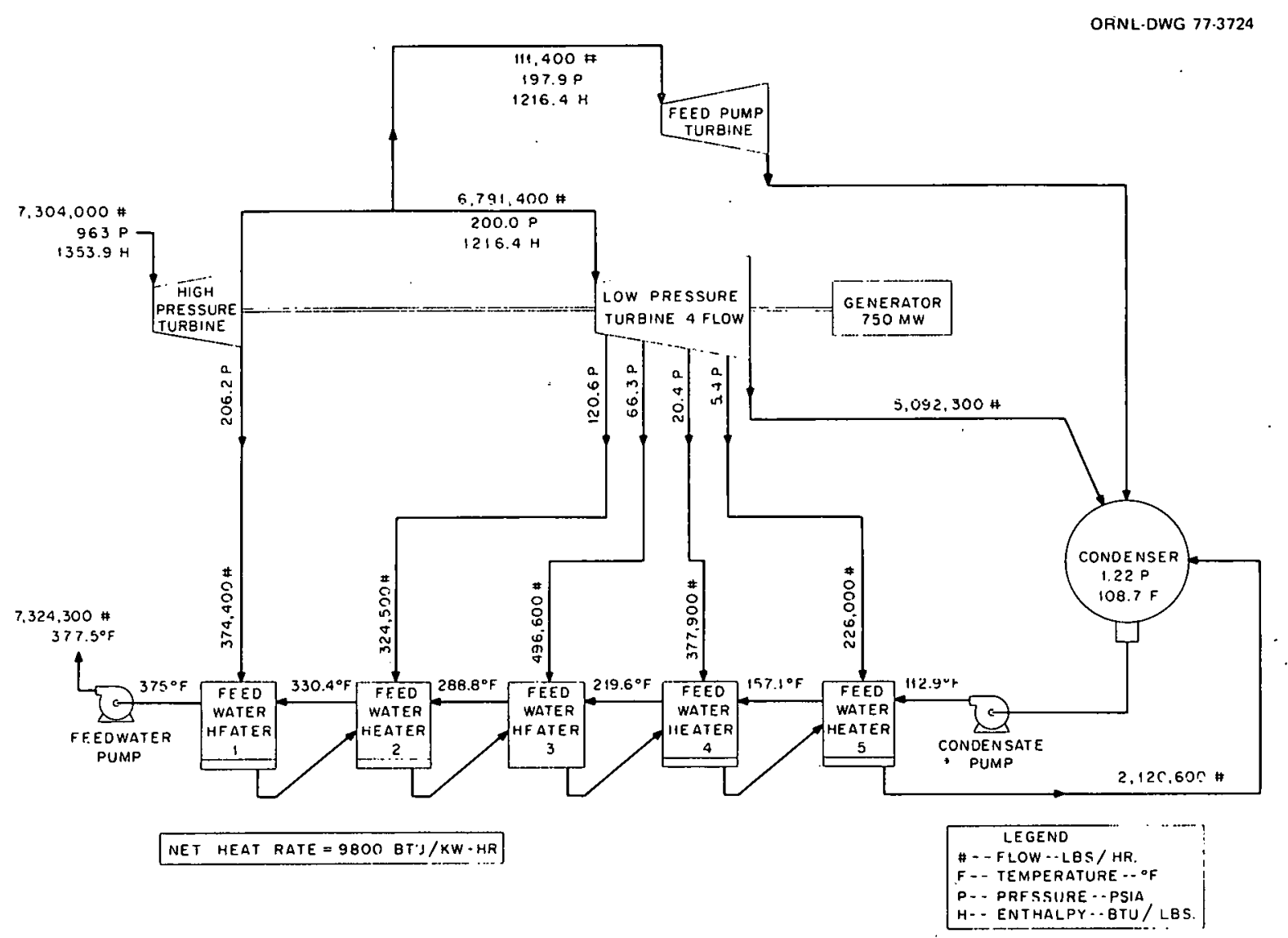

Fig. 9.2. Heat balance diagram.

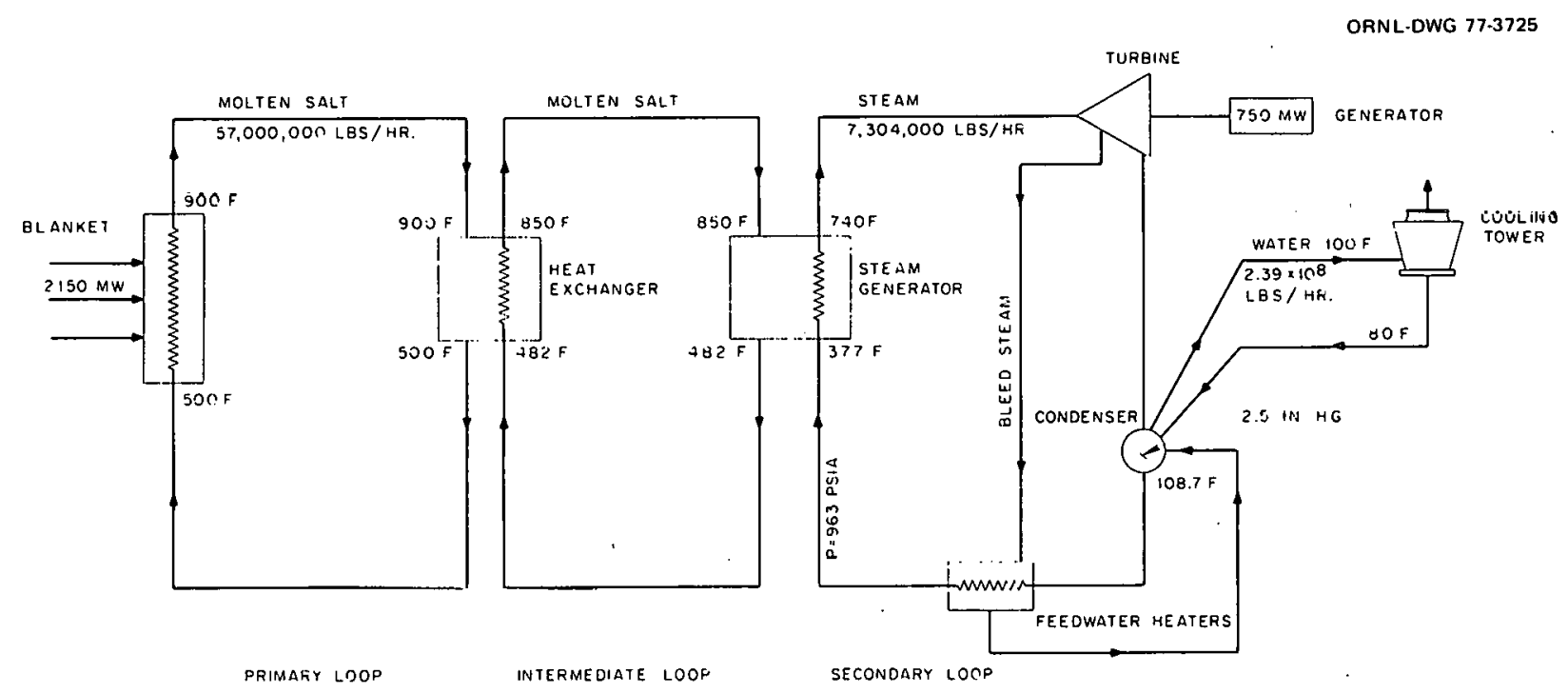

Fig. 9.3. Overall energy schematic for the power conversion system. 
Table 9.1. Representative reactor steam cycle design parameters

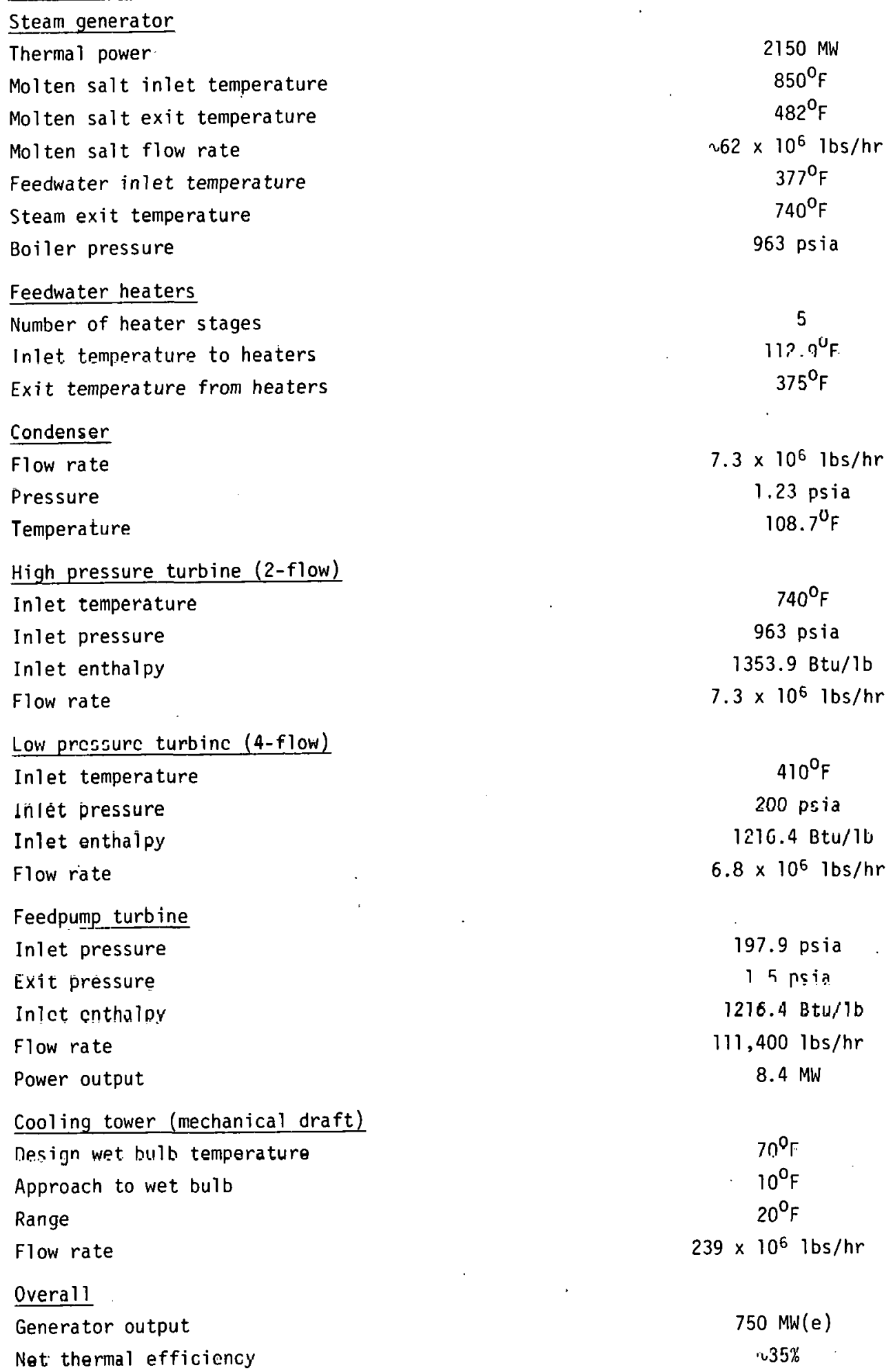




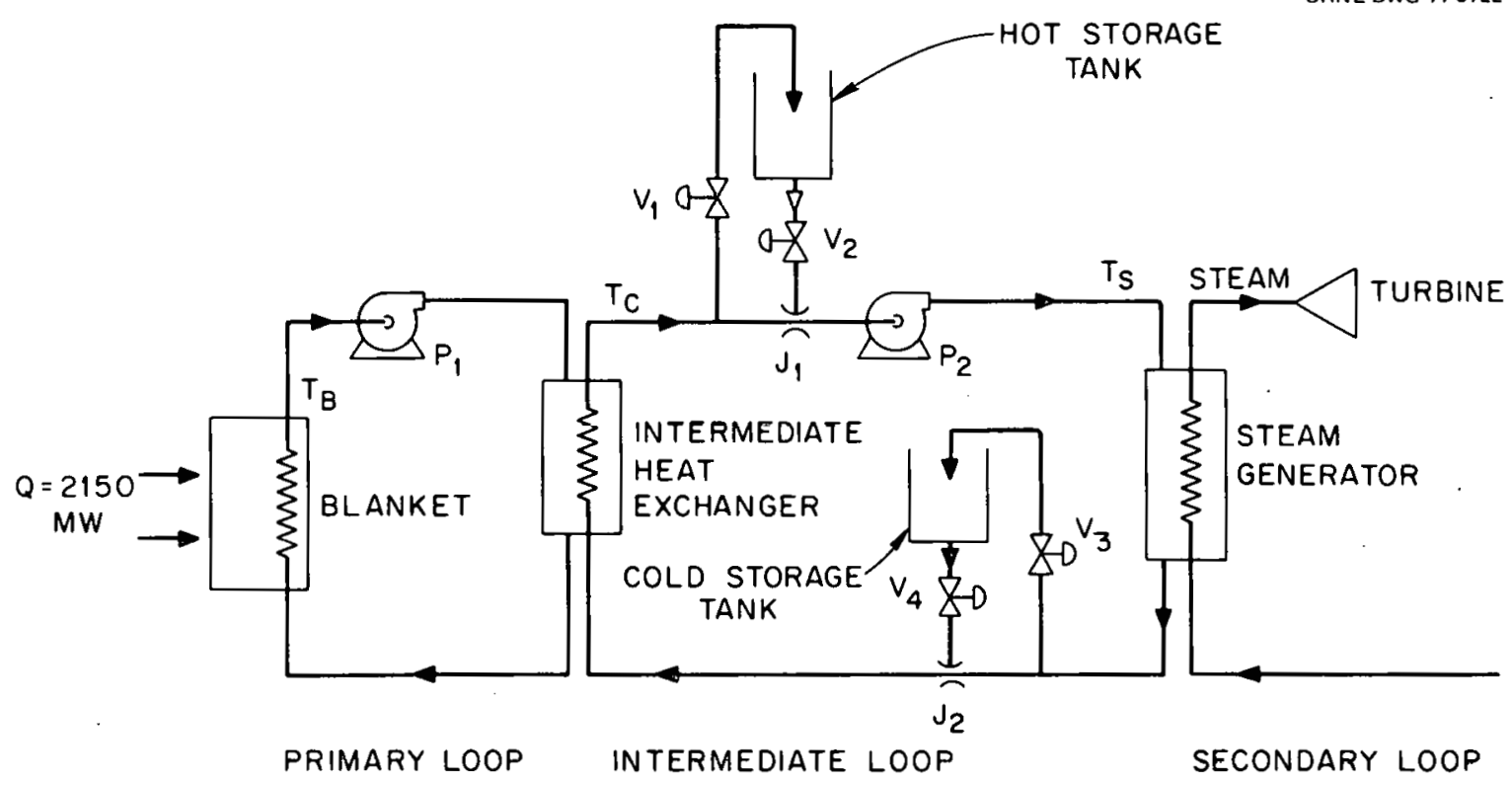

Fig. 9.4. Energy storage system schematic.

exchanger, $T_{c}$, reaches operating temperature, valves $V_{1}$ and $V_{4}$ (the valves into and out of the hot and cold storage tank, respectively) are opened proportionally to permit $5 \%$ of the flow through the intermediate heat exchanger to flow out of the cold storage tank and into the hot storage tank. The flow out of the hot storage tank through the exit valve $V_{2}$ and into the cold storage tank through inlet valve $V_{3}$ is regulated by the temperature of the salt going into the steam generator, $T_{s}$, to hold this temperature constant at the design value. While the coolant pump in the intermediate loop, $P_{2}$, runs at constant speed, the pump in the primary loop, $P_{1}$, is capable of running at variable speed in order to reduce the coolant flow through the blanket when the plasma is off. The speed of pump $P_{1}$ is controlled by the temperature drop across the blanket to hold this $\Delta T$ as nearly constant as possible and minimize the thermal cycling of the blanket.

\subsection{CONCLUSIONS}

1. For the temperature range of the molten salt reactor coolant (inlet temperature $\sim 500^{\circ} \mathrm{F}$, exit temperature $\left.\sim 900^{\circ} \mathrm{F}\right)$; a net thermal efficiency in the range of $35 \%$ can be arhievard.

2. The heat balance for the power conversion system is representative but was not optimized.

3. An energy storage system, consisting primarily of tanks to store hat molten salt coolant during the burn and to release the hot salt during the downtime of the tokamak sycle, appears feasible as a means of providing constant heat input to the steam generator. 
THIS PAGE

WAS INTENTIONALLY

LEFT BLANK 


\section{A.I INPUT PARAMETERS}

The input parameters employed in the economics model are given in Table A.1. Geometrical relationships are shown in Fig. A.l.

Table A.1. Parameters required for economics model

\section{Parameter}

Neutron wall Toading, $\mathrm{MW} / \mathrm{m}^{2}$

Average plasma beta

Aspect ratio, $R_{0} / a$

Distance from plasma edge to TF coil, m

Space between plașma edge and first wall, m

Blanket thickness, m

Space between blanket and shield, m

Shield thickness, m

Space betweeri shield and TF coil along the major radius, $m \quad \Delta_{E}$

Plasma elongation, b/a $\quad \sigma_{p}$

TF coil elongation

Vertical distance from plasma edge to TF coil, $\mathrm{m}$

Effective $Z$ of plasma

anput either $\sigma_{T F}$ or $\Delta_{V}$. $\sigma_{T F}^{a}$

Symbol

L

B

A

$\Delta$

$\Delta_{\text {so }}$

${ }^{\Delta} \mathrm{B}$

$\Delta_{A}$

$\Delta_{S}$

$\Delta_{\mathrm{E}}$

$\sigma_{p}$

\section{A.2 PLASMA SIZE SCALING MODEL}

The following equations are employed in the plasma parameter scaling model. The equations for plasma radius and field on axis are based on trapped ion mode scaling and are normalized to the TNS plasma parameters. ${ }^{1}$ Also, the plasma temperature is held constant at the TNS value.

$S(p l a s m a$ shape factor $)=\sqrt{\frac{1.0+\sigma_{p}^{2}}{?}}$

a (plasma radius, $m)=\frac{29.06 B^{0.4} \sigma_{p}^{0.6}}{L^{0.6} \mathrm{AS}^{1.4} \mathrm{Z}^{0.4}}$

$B_{T}($ field on axis, $T)=\frac{0.524 L^{0.4} S^{0.6} A^{0.25} Z^{0.1}}{B^{0.6} \sigma_{p}^{0} .{ }^{4}}$

$R_{0}$ (major radius, $m$ ) $=a A$

$P($ thermonuclear power, $M W)=4 \pi^{2} a^{2} \operatorname{ASL}\left(\frac{17.6}{14.1}\right)$

$P_{0}$ (thermal power, $\left.M W\right)=P\left(\frac{22.4}{17.6}\right)$

$b(p$ lasma height, $m)=a \sigma_{p}$

1. TNS Engineering Progress Report for the Month of August 1976, WFPS-TN-025, Westinghouse Electric Corp., Fusion Power Systems Division, Pittsburgh, Pennsylvania (September 1976).

\section{A.3 COMPONENT COST SCALING MODEL}

The following equations are employed in the cost scaling model. Refer to Fig. A.l for geometrical relationships. 
ORNL.DWG $77-4993$

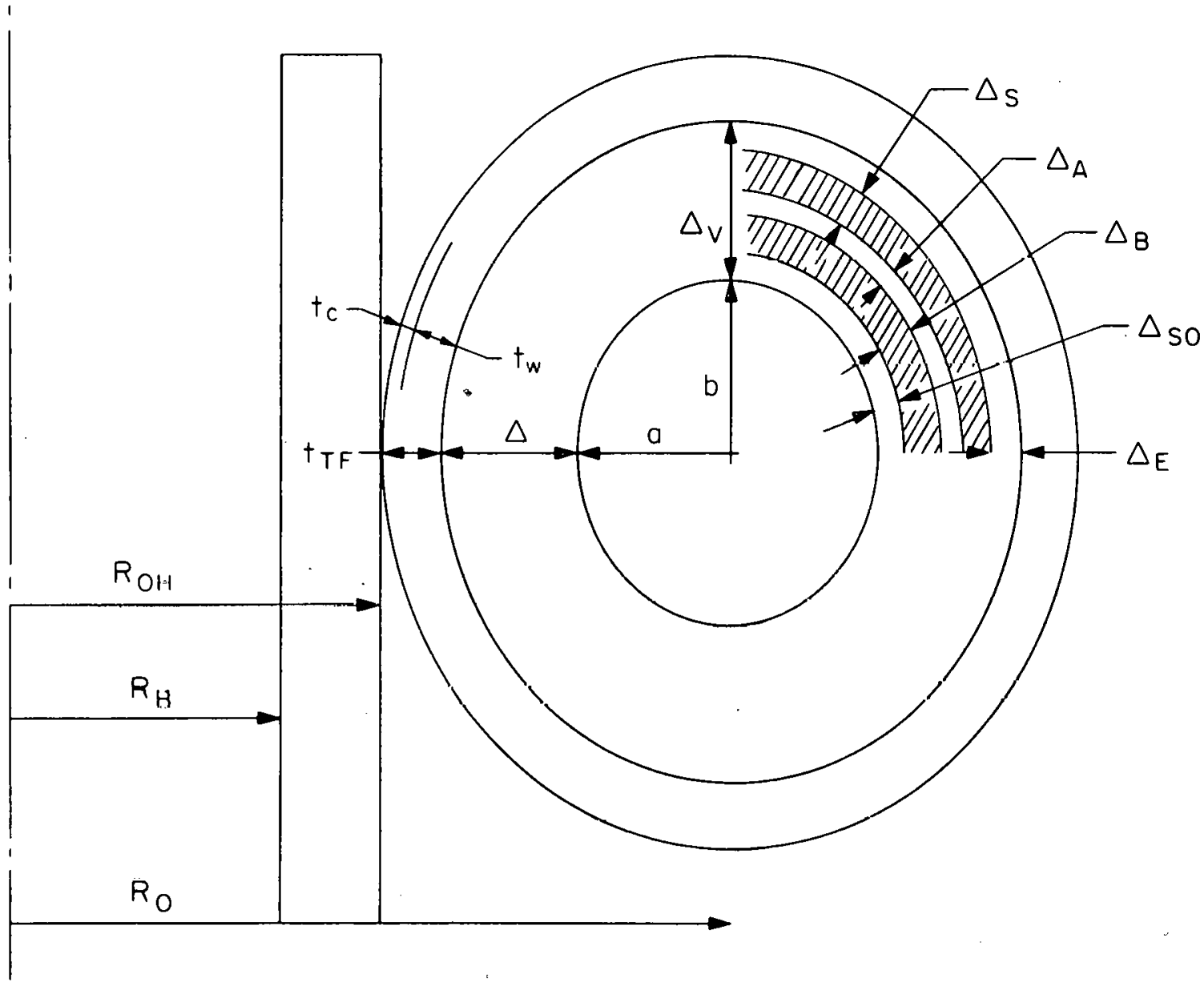

Fig. A.1 Simplificd tokamak geometry.

Blanket Cost

Cost scales as the blanket volume.

$a_{B}$ (blanket radius, $\left.m\right)=a+\Delta_{s u}$

$b_{B}$ (blanket vertical radius, $\left.m\right)=b+\Delta_{50}$

$V_{B}$ (blanket volume, $\left.m^{3}\right)=R_{O} a_{B} \Delta_{B} \times$

$\left[1.0+\frac{b_{B}}{a_{B}}+\frac{\Delta_{B}}{a_{B}}\right](19.74)$

$c_{B}($ blanket cost, $\$)=63,100\left(V_{B}\right)$

\section{Shield Cost}

Cost scales as the shield volume. $a_{s}($ shield radius, $m)=a_{B}+\Delta_{B}+\Delta_{A}$

$b_{S}$ (shield vertical radius, $m$ ) $=b_{B}+\Delta_{B}+\Delta_{A}$

$v_{s}$ (shield volume, $\left.m^{3}\right)=R_{0} a_{s} \Delta_{s} \times$

$$
\left[1.0+\frac{b_{s}}{a_{s}}+\frac{\Delta_{\delta}}{a_{s}}\right](19.74)
$$

$c_{s}($ shield cost, $\$)=51,050\left(v_{s}\right)$

\section{Toroidal Field roil cost}

Cost scales as the stored energy to the 0.8 power. The TF coil elongation, $\sigma_{T F}$, is used as the inpul value or is calculated as 
$\sigma_{T F}=\frac{b+\Delta_{v}}{a+\Delta}$, if $\Delta_{v}$ is input.

$R_{c}($ coil radius, $m)=a+\Delta$

$X$ (geometry factor $)=1.0-\sqrt{1.0-\left(R_{c} / R_{0}\right)^{2}}$

$E\left(\right.$ stored energy, MJ) $=15.7 B_{T}^{2} R_{0}^{3} \sigma_{T F} X$

$C_{T F}($ cost of TF coils, $\$)=43,000 E^{0.8}$

\section{Poloidal Field Coil Cost}

Cost scales as coil volume which is approximated as the major radius, $R_{0}$, times the plasma current, $I$, assuming a constant current density in the coil conductor.

$I$ (plasma current, $A) \sim \frac{{ }^{a B} T}{A}\left(\frac{1+\sigma_{p}^{2}}{2}\right)$

$\frac{C_{P F}}{P}$ (unit cost $\left.P F, \$ / M W\right)=77,850 \frac{B_{T} S}{\frac{B_{A}}{L A}}$

$C_{P F}($ cost of $P F$ coils $)=\frac{C_{P F}}{P} \times P$

\section{Poloidal Field Driving System (PFDS) Cost}

Cost scales as plasma volt seconds, LI .

$L(p$ lasma inductance, henries $) \sim R_{0}(\ln 8 \times A$

$-1.75)$

$\frac{C_{\text {PFDS }}}{P}$ (unit cost PFDS, $\$ / M W$ ) $=$

$$
\frac{90,800 B_{T} S}{L A}(\ln 8 \times A-1.13)
$$

$C_{\text {PFDS }}(\cos t$ of PFDS, $\$)=\frac{C_{\text {PFDS }}}{P} \times P$

\section{Vacuum System Cost}

Cost scales as the surface area of the torus.

$\frac{C_{v}}{p}$ (unit cost of vacuum system, $\$ / M W$ )

$$
=\frac{58,400}{L}
$$

$C_{v}$ (cost of vacuum system, $\left.\$\right)=\frac{C_{v}}{P} \times p$

\section{Tritium Handling System Cost}

Cost scales as the surface area of the torus.

$\frac{\mathrm{C}_{\mathrm{T}}}{\mathrm{P}}$ (unit cost of tritium handling system, $\$ / \mathrm{MW}$ )

$=\frac{76,800}{L}$

$\mathrm{C}_{\mathrm{T}}$ (cost of tritium handling system, \$)

$=\frac{C_{T}}{P} \times P$

Neutral Beam System Cost

Cost scales as the thermonuclear power of the plasma.

$C_{\text {beam }}($ cost of beams $)=87 \times P \cdot \times 1000$

Turbine System Cost

Cost scales as the thermal power to the 0.8 power.

$C_{\text {tur }}$ (cost of turbine system, \$)

$$
=33\left(\frac{P_{0}}{3285}\right)^{-0.20} \times P_{0} \times 1000
$$

\section{Conventional Electrical System Cost}

Cost scales as the thermal power, to the 0.6 power.

$\mathrm{C}_{C E}$ (cost of conventional electrical system, \$)

$=11\left(\frac{P_{0}}{3285}\right)^{-0.40} \times P_{0} \times 1000$

Heat Transport System Cost

Cost scales at the thermal power.

$C_{\text {HT }}$ (cost of heat transport system, $\$$ )

$=45 \times P_{0} \times 1000$

I\&C Cost

Cost is held constant. 
$C_{I \& C}$ (cost of I\&C, $\left.\$\right)=12,000,000$ (fusion

related) $+13,000,000$ (PWR related)

$=25,000,000$

\section{Auxiliary and Maintenance Cost}

Cost is held constant.

$C_{A \& M}$ (cost of auxiliary and maintenance, \$)

$=30,000,000$ (fusion related) $+24,000,000$

$($ PWR related $)=54,000,000$

\section{Building Cost}

Cost of the vacuum containment building is held constant. The other buildings scale as the thermal power to the 0.8 power.

$C_{\text {bld }}($ cost of buildings, $\$)=70,000,000+$

$$
30,000,000\left(\frac{P_{0}}{3285}\right)^{0.8}
$$

\section{Reactor Cost}

$C_{R}$ (cost of reactor, $\left.\$\right)=C_{B}+C_{S}+C_{T F}+C_{P F}$

$$
+c_{v}+0.33 c_{\text {beams }}
$$

\section{Electrical Plant Cost}

$C_{E P}($ total capitai cost, $\$)=C_{\text {PFDS }}+0.67 C_{\text {beams }}$

$$
+C_{C E}
$$

\section{Total Plant Coet}

$$
\begin{gathered}
C_{\text {total }} \text { (total capital cost, } \$ \text { ) }=C_{R}+C_{E P}+C_{T} \\
+C_{\text {tur }}+C_{H T}+C_{\text {bld }}+C_{I \& C}+C_{A \& M}
\end{gathered}
$$

Unit Cost

$U C[$ unit cost, $\$ / k W(t)]=\frac{C_{\text {total }}}{1000 P_{0}}$

\section{A.4 DUTY FACTOR MODEL}

The following equations are employed in the duty factor model. Refer to Fig. A.l for geometrical relationships.

\section{Assumptions}

(1) The plasma safety factor, $q$, is constant and equal to the TNS value.

(2) The plasma temperature is constant and equal to the TNS value.

(3) The current density in the TF coil, $\mathrm{J}$, is $18 \times 10^{6} \mathrm{~A} / \mathrm{m}^{2}\left(1800 \mathrm{~A} / \mathrm{cm}^{2}\right)$.

$A_{w}$ (TF coil winding cross-sectional area, $m^{2}$ )

$$
=\frac{5 \times 10^{6} B_{T} R_{0}}{J}
$$

$t_{w}$ (radial thickness of winding, $m$ )

$$
=\left(R_{0}-R_{c}\right)-\sqrt{\left(R_{0}-R_{c}\right)^{2}-\left(A_{w} / \pi\right) 1.27}
$$

stress (hoop stress in TF coil, psi)

$$
=0.25 B_{T} R_{0} J \ln \left(\frac{R_{0}+R_{c}}{R_{0}-R_{c}}\right) 1.45 \times 10^{-4}
$$

$t_{c}$ (radial thickness of case, $m$ )

$$
=t_{w}\left(\frac{\text { stress }}{60,000}\right)
$$

$t_{T F}$ (radial thickness of TF coil, $\left.m\right)=t_{W}+t_{c}$

$R_{O H}$ (radius of $O H$ coil, $m$ ) $=R_{0}-R_{C}-t_{T F}$

$R_{B}$ (radius of bore, $m$ ) $=R_{O H}-0.31$

$\Delta \phi$ (flux swing capability of $\mathrm{OH}$ coil, V-sec)

$$
=60 \frac{\left(R_{U H}^{2}-0.31 R_{U H}+0.032\right)}{2.71}
$$

I (plasma current, A)

$$
=2.75 \times 10^{6}\left[\frac{\frac{B_{T}}{B^{2}} \frac{1+\sigma_{p}^{2}}{4.4} \frac{2}{(A / 4.0)}}{\frac{1.5}{(0)}}\right]
$$

$\mathrm{L}_{\mathrm{p}}$ (plasma inductance, henries)

$$
=1.05 \times 10^{-6} k_{0}[\ln (8 A)-1.75]
$$


$R$ (plasma resistance, $\Omega$ )

$=\left(1.6 \times 10^{-8}\right)\left(\frac{\mathrm{a}}{\mathrm{T} .5}\right)^{2.0} \frac{6}{\mathrm{R}_{0}} \frac{1}{\mathrm{~S}}$

$T_{B}$ (burn time, min) $=\frac{\Delta \phi-0.25 L_{P} I}{R I} \frac{1}{60}$
$D$ (duty factor) $=\frac{T_{B}}{T_{B}+T .0}$

$P_{A}$ (average thermal power, $\left.M W\right)=P_{0} D$

UCA [average unit cost, $\$ / \mathrm{kW}(t)]=\frac{C_{\text {total }}}{P_{A} \times 1000}$ 


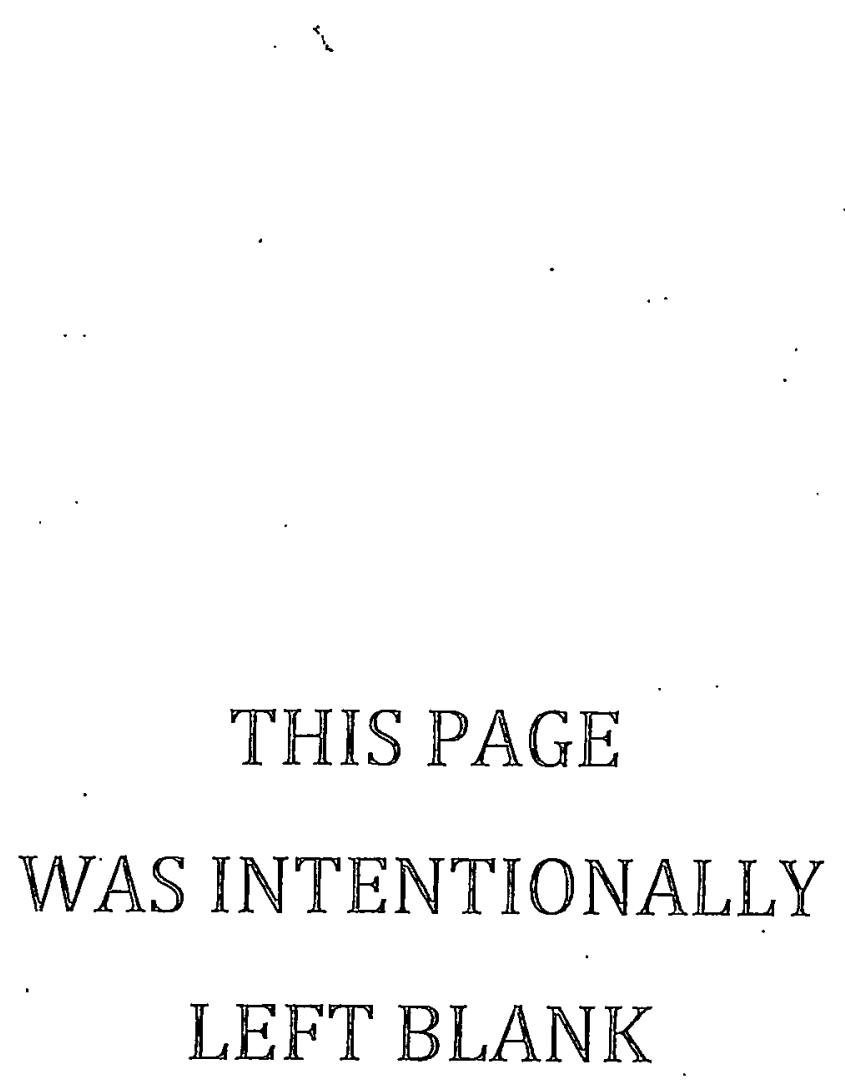


ORNL/TM-5813

INTERNAL DISTRIBUTION

1. R. G. Alsmiller, Jr.

2. B. R. Appleton

3. J. K. Ballou

4. L. A. Berry

E. S. Bettis

. E. H. Bryant

. J. D. Callen

8. D. D. Cannon

9-10. Central Research Library

11-30. J. F. Clarke

31. R. E. Clausing

32. S. D. Clinton

33. R. J. Colchin

34. F. L. Culler

35. R. A. Dand 1

36. S. Datz

37. J. H. DeVan

38. R. A. Dory

39. L. Dresner

40. J. L. Dunlap

41. P. Fisher

42. A. P. Fraas

43-44. Fusion Energy Division Library

45. Fusion Energy Division Reports Office

46. T. A. Gabriel

47. M. L. Grossbeck

48. P. N. Haubenreich

49. J. T. Hogan

50. J. Horak

51. T. J. Huxford

52. G. G. Kelley

53. G. Krist

54. Laboratory Records

55. Laboratory Records - ORNL-RC

56. C. G. Lawson

\author{
57. M. S. Lubell \\ 58. J. W. Lue \\ 59. F. B. Marcus \\ 60. P. J. Masiasz \\ 61. B. F. Maskewitz \\ 62. J. May \\ 63. W. McAfee \\ 64. H. M. McCoy \\ 65. H. C. McCurdy \\ 66. A. T. Mense \\ 67. R. V. Miskell \\ 68. 0. B. Morgan \\ 69. ORNL Patent Office \\ 70. Y-K. M. Peng \\ 71. H. Postma \\ 72. R. L. Reid \\ 73. M. Roberts \\ 74. M. T. Robinson \\ 75. M. W. Rosenthal \\ 76. R. T. Santoro \\ 77. G. Schilling \\ 78. J. L. Scott \\ 79. J. E. Selle \\ 80. T. E. Shannon \\ 81. P. Spampinato \\ 82-116. D. Steiner \\ 117. L. D. Stewart \\ 118. W. C. T. Stoddart \\ 119. N. A. Uckan \\ 120. J. S. Watson \\ 121. H. L. Watts \\ 122. R. Werner \\ 123. F. W. Wiffen \\ 124. H. T. Yeh \\ 125. $Y-12$ Document Reference Section
}

EXTERNAL DISTRIBUTION

126. D. Anthony, General Electric Co., Building 2, Room 447, 1 River Road, Schenectady, NY 12345

127. Peter L. Auer, Laboratory of Plasma Studies, Cornell University, 312 Upson Hall, Ithaca, NY 14853

128. C. C. Baker, General Atomic Co., San Diego, CA 92138

129. J. Baublitz, Division of Magnetic Fusion Energy, Energy Research and Development Administration, Washington, DC 20545

130. J. Beal, Division of Magnetic Fusion Energy, Energy Research and Development Administration, Washington, DC 20545

131. J. W. Bennett, Division of Reactor Development and Demonstration, Energy Research and Development Administration, Washington, DC 20545

132. R. Blanken, Division of Magnetic Fusion Energy, Energy Research and Development Administration, Washington, DC 20545

133. S. L. Bogart, Division of Magnetic Fusion Energy, Energy Research and Development Administration, Washington, DC 20545

134. Keith A. Brueckner, Department of Physics, University of California at San Diego, La Jolla, CA 92037

135. Sol Buchsbaum, Vice President, Network Planning and Customer Services, Bell Laboratories Room 2G 610, Holmdel, NJ 07733

136. R. N. Cherdack, Burns and Roe Inc., 283 Highway 17, Paramus, NJ 07652

137. F. E. Coffman, Division of Magnetic Fusion Energy, Energy Research and Development Administration, Washington, DC 20545

138. M. Cohen, Division of Magnetic Fusion Energy, Energy Research and Development Administration, Washington, DC 20545

139. R. W. Conn, Nuclear Engineering Department, University of Wisconsin, Madison, WF 53706

140. Library, Culham Laboratory, Abingdon, 0xon, OX14 3DB, United Kingdom

141. E. Dalder, Division of Magnetic Fusion Energy, Energy Research and Development Administration, Washington, DC 20545 
142. N. Anne Davies, Division of Magnetic Fusion Energy, Energy Research and Development Administration, Washington, DC 20545

143. S. 0. Dean, Division of Magnetic Fusion Energy, Energy Research and Development Administration, Washington, DC 20545

144. J. F. Decker, Division of Magnetic Fusion Energy, Energy Research and Development Administration, Washington, DC 20545

145. David A Dingee, Manager, Fusion Programs, Battelle-Northwest, Battelle Blvd., Richland, WA 99352

146. T. Edelbaum, Charles Stark Draper Laboratories, 75 Cambridge Pkwy., Cambridge, MA 02]42

147. W. R. Ellis, Division of Magnetic Fusion Energy, Energy Research and Development Administration, Washington, DC 20545

148. A. Favale, Grumman Aerospace Corp., Bethpage, NY 11714

149. C. Finfgeld, Division of Magnetic Fusion Energy, Energy Research and Development Administration, Washington, DC 20545

150. C. A. Flanagan, Westinghouse Electric Corp., Fusion Power Systems, P.0. Box 10864, Pittsburgh, PA 15236

151. H. K. Forsen, Exxon Nuclear Co., Bellevue, WA 98004

152. T. K. Fowler, University of Cal ifornia, Lawrence Radiation Laboratory, P.0. Box 808, Livermore, CA 94551

153. J.W. French, Westinghouse Electric Corp., Fusion Power Systems, P.0. Box 10864, Pittsburgh, PA 15236

154. H. P. Furth, Princeton Plasma Physics Laboratory, Princeton University, P.0. Box 451, Princeton, NJ 08540

155. G. Gibson, Westinghouse Electric Corp., Fusion Power Systems, P.0. Box 10864, Pittsburgh, PA 15236

156. B. Gore, Pacific Northwest Laboratories, Battelle Blvd., P.0. Box 999, Richland, WA 99352

157. M. B. Gottlieb, Princeton Plasma Physics Laboratory, Princeton University, P.0. Box 451, Princeton, $\mathrm{NJ} 08540$

158. W. C. Gough, Electric Power Research Institute, Palo Alto, CA 94304

159. Roy W. Gould, Bldg. 116-81, California Institute of Technology, Pasadena, CA 91109

160. J. Nelson Grace, Division of Magnetic Fusion Energy, Energy Research and Development Administration, Washington, DC 20545

161. Harold Grad, Courant Institute, New York University, 251 Mercer St., New York, NY 10012

162. E. Gregory, AIRCO Inc., Murray Hill, NJ 07974

163. R. Harder, General Atomic Co., San Diego, CA 92138

164. F. M. Heck, Westinghouse Electric Corp., Fusion Power Systems, P.0. Box 10864, Pittsburgh, PA 15236

165. C. Henning, Division of Magnetic Fusion Energy, Energy Research and Development Administration, Washington, UC ZUS4b

166. G. Hess, Division of Magnetic Fusion Energy, Energy Research and Development Administration, Washington, DC 20545

167. G. Hopkins, General Atomic Co., P.0. Box 608, San Diego, California 92138

168. Anthony Hsu, Division of Magnetic Fusion Energy, Energy Research and Development Administration, Washington, DC 20545

169. Henry Hurwitz, General Electric Company, Keseäch ànd Vevelopitient Center, But1ding k-1, Radiation, P.0. Box 8, Schenectady, NY 12301

170. A. J. Imtink, Jr., Carnegie-Mellon University, Pittsburgh, PA 15213

171. Institute for Energy Analysis, P.0. Box 117, Oak Ridge, TN 37830

172. N. E. Johnson, Mechanics Research inc., Oak Ridge, TN 37830

173. C. K. Jones, Westinghouse Electric Corp., Research and Development Laboratory, 1130 Beulah Rd., Pittsburgh, PA 15235

174. E. E. Kintner, Division of Magnetic Fusion Energy, Energy Research and Uevelopment Administration, Washington, DC 20545

175. D. Klein, Westinghouse Electric Corp., Fusion Power Systems, P.0. B̈ox 10864, Pittsburgh, PA 15236

176. R. Kostoff, Division of Magnetic Fusion Energy, Energy Research and Development Administration, Washington, DC 20545

17\%. C. Kulcinski, Nuclear Englneerlng Dept., University of Wisconsin, Mâdisnn, WT 5.3706

178. K. Kumer, Materials and Process, McDonnel1 Douglas, P.0. Box 516, St. Louis, M0 63156

179. L. M. Lidsky, Dept. of Nuclear Engineering. Massachusetts Institute of Technology, Cambridge, MA 02139

180. M. Lotker, Advanced Energy Conversion Research, Northeastern Utilities Service Co., P.0. Box 270, Hartford, CT 06101

181. Bruce J. Mann. Chief, Evaluation Branch, LVF, Environmental Monitoring and Support Lab., P.0. Box 15027, Las Vegas, NV 89114

182. V. A. Maroni, CTR Program, 208 W715, Argonne National Laboratory, 9700 S. Cass Ave., Argonne, IL 60439

183. R. Mason, Division of Magnetic Fusion Energy, Energy Research and Development Administration, Wastinglür, DC 80545 
184. D. G. McAlees, Exxon Nuclear Corporation, Research and Technology Center, Laser Enrichment Department, 2955 George Washington Way, Richland, WA 99352

185. R. Mills, Princeton Plasma Physics Laboratory, Princeton University, P.0. Box 451, Princeton, NJ 08540

186. K. Moses, Division of Magnetic Fusion Energy, Energy Research and Development Administration, Washington, DC 20545

187. M. Murphy, Division of Magnetic Fusion Energy, Energy Research and Development Administration, Washington, DC 20545

188. J. O. Neff, Division of Magnetic Fusion Energy, Energy Research and Development Administration, Washington, DC 20545

189. T. Ohkawa, General Atomic Co., San Diego, CA 92112

190. J. Powel1, Brookhaven National Laboratory, Upton, Long Island, NY 11973

191. Plasma Physics Library, Princeton Plasma Physics Laboratory, Princeton University, P.0. Box 451, Princeton, NJ 08540

192. J. Purcell, General Atomic Co., San Diego, CA 92112

193. Research and Technical Support Division, ERDA-ORO, P.0. Box E, Oak Ridge, TN 37830

194. T. Reuther, Division of Magnetic Fusion Energy, Energy Research and Development Administration, Washington, DC 20545

195. F. L. Ribe, Los Alamos Scientific Laboratory, P.0. Box 1663, Los Alamos, NM 87544

196. D. J. Rose, Department of Nuclear Engineering, Massachusetts Institute of Technology, Cambridge, MA 02139

197. M. N. Rosenbluth, School of Natural Sciences, Princeton University, P.0. Box 451, Princeton, NJ 08540

198. C. Rosner, Intermagnetics General Corp., Charles Industrial Park, New Karner Rd., Guilderland, NY 12084

199. P. Sager, General Atomic Co., San Diego, CA 92112

200. Z. M. Shapiro, Westinghouse Electric Corp., Fusion Power Systems, P.0. Box 10864, Pittsburgh, PA 15236

201. Weston M. Stacey, Jr., ANL-CTR Program, Bldg. 208, Argonne National Laboratory, 9700 S. Cass Ave., Argonne, IL 60439

202. G. Siegel, Tennessee Valley Authority, 1360 Comerce Union Bank Bldg., Chattanooga; T.N 37401

203. J. Stekly, Magnetic Corp. of America, 179 Bear Hill Rd., Waltham, MA 02154

204. C. Taylor, Controlled Thermonuclear Research, Mail Code L-382, Lawrence Livermore Laboratory, P.0. Box 808, Livermore, CA 94550

205. K. Thomassen, CTR Division, Mail Stop 640, P.0. Box 1663, Los Alamos, NM 87544

206. B. Twining, Division of Magnetic Fusion Energy, Energy Researcli and Development Administration, Washington, DC 20545

207. T. C. Varljen, Westinghouse Electric Corp., Fusion Power Systems, P.0. Box 10864, Pittsburgh, PA 09864

208. S. Waddle, ERDA-ORO, P.0. Box E, Oak Ridge, TN 37830

209. S. T. Wang, CTR Program, $208 \mathrm{~W}$ W15, Argonne National Laboratory, $9700 \mathrm{~S}$. Cass Ave., Argonne, IL 60439

210. H. J. Willenberg, Senior Research Scientist, Battelle Pacific Northwest Laboratories, Battelle Boulevard, Richland, WA 99352

211. J. Willis, Division of Magnetic Fusion Energy, Energy Research and Development Administration, Washington, DC 20545

212. W. Wilkes, Mound Laboratories, Miamiburg, $\mathrm{OH}, 45432$

213. J. M. Williams, Division of Magnetic Fusion Energy, Energy Research and Development Administration, Washington, DC 20545

214. Herbert $H$. Woodson, Department of Electrical Engineering, University of Texas, Austin, TX 78712

215. E. Ziurys, Division of Magnetic Fusion Energy, Energy Research and Development Administration, Washington, DC 20545

216. K. Zwilsky, Division of Magnetic Fusion Energy, Energy Research and Development Administration, Washington, DC 20545

217-243. Technical Information Center, P.0. Box 62, Oak Ridge, TN 37830 